\title{
Reactivity, recruitment and remodeling of collateral arteries in diabetes
}

Citation for published version (APA):

Ruiter, M. S. (2012). Reactivity, recruitment and remodeling of collateral arteries in diabetes. [Doctoral Thesis, Maastricht University]. Maastricht University. https://doi.org/10.26481/dis.20120906mr

Document status and date:

Published: 01/01/2012

DOI:

10.26481/dis.20120906mr

Document Version:

Publisher's PDF, also known as Version of record

\section{Please check the document version of this publication:}

- A submitted manuscript is the version of the article upon submission and before peer-review. There can be important differences between the submitted version and the official published version of record.

People interested in the research are advised to contact the author for the final version of the publication, or visit the DOI to the publisher's website.

- The final author version and the galley proof are versions of the publication after peer review.

- The final published version features the final layout of the paper including the volume, issue and page numbers.

Link to publication

\footnotetext{
General rights rights.

- You may freely distribute the URL identifying the publication in the public portal. please follow below link for the End User Agreement:

www.umlib.nl/taverne-license

Take down policy

If you believe that this document breaches copyright please contact us at:

repository@maastrichtuniversity.nl

providing details and we will investigate your claim.
}

Copyright and moral rights for the publications made accessible in the public portal are retained by the authors and/or other copyright owners and it is a condition of accessing publications that users recognise and abide by the legal requirements associated with these

- Users may download and print one copy of any publication from the public portal for the purpose of private study or research.

- You may not further distribute the material or use it for any profit-making activity or commercial gain

If the publication is distributed under the terms of Article $25 \mathrm{fa}$ of the Dutch Copyright Act, indicated by the "Taverne" license above, 
Reactivity, recruitment and remodeling

of collateral arteries in diabetes 
(C) Copyright Matthijs Ruiter, Amsterdam 2012

Printed by: Gildeprint Drukkerijen - www.gildeprint.nl ISBN: 978-94-6190-782-0 


\title{
Reactivity, recruitment and remodeling of collateral arteries in diabetes
}

\author{
PROEFSCHRIFT \\ ter verkrijging van de graad van doctor aan de Universiteit Maastricht, \\ op gezag van de Rector Magnificus, prof. dr. L.L.G. Soete \\ volgens het besluit van het College van Decanen, \\ in het openbaar te verdedigen \\ op donderdag 6 september 2012 om 14.00 uur \\ door \\ Matthijs Steven Ruiter, \\ Geboren op 14 februari 1981 te Leeuwarden
}


Promotores:

Prof. dr. N.C. Schaper

Prof. dr. C.D.A. Stehouwer

\section{Copromotores:}

Dr. M.S.P. Huijberts

Dr. J.M.C.G. van Golde

\section{Beoordelingscommissie:}

Prof. dr. H. Struijker Boudier (voorzitter)

Prof. dr. L.H. Koole

Prof. dr. B.I. Levy, INSERM U689, Parijs

Prof. dr. G.W.H. Schurink

Prof. dr. C.J.M. de Vries, Academisch Medisch Centrum, Amsterdam

Financial support by the Dutch Heart Foundation and Dutch Diabetes Research Foundation for the publication of this thesis is gratefully acknowledged.

The author also gratefully acknowledges CARIM, DSM Biomedical BV, Novo Nordisk and Lilly Nederland for their additional financial support. 


\section{Contents}

$\begin{array}{lll}\text { Chapter } 1 & \text { General introduction } & 7\end{array}$

Chapter 2 Diabetes impairs arteriogenesis in the peripheral circulation:

review of molecular mechanisms 15

Chapter 3 Impaired collateral recruitment and outward remodeling

in experimental diabetes 45

Chapter 4 Experimental diabetes impairs soluble guanylate cyclase

function in hindlimb collateral arteries 63

Chapter 5 The role of methylglyoxal in hyperglycemia-induced

impairments of vasoreactivity in the rat saphenous artery 83

Chapter 6 The effect of local vasodilator therapy on arteriogenesis

in the rabbit ischemic hindlimb 99

$\begin{array}{lll}\text { Chapter } 7 & \text { General discussion } & 117\end{array}$

$\begin{array}{ll}\text { Abbreviations } & 133\end{array}$ 

ChAPTER 1

General introduction 


\section{Peripheral arterial disease}

Peripheral artrial disease (PAD) is a common manifestation of systemic atherosclerosis, affecting $16 \%$ of the population over 55 years of age in Europe and North America. ${ }^{1}$ PAD is generally characterized by occlusive arterial disease of the lower extremities, leading to considerable loss of quality of life and is associated with substantial medical costs. ${ }^{2,3}$ Half of the PAD patients older than 55 years are asymptomatic. Of the symptomatic patients, approximately $40 \%$ experience intermittent claudication. ${ }^{4}$ Untreated PAD can progress to critical $\operatorname{limb}$ ischemia (CLI), and is associated with decreased mobility, foot ulceration and lower extremity amputation. ${ }^{5,6}$ Furthermore, PAD is associated with increased 5- to 10 -year mortality. ${ }^{7}$ Patient care can benefit from early diagnosis and improved risk factor management. ${ }^{8}$ A well-known risk factor in the development of PAD is diabetes mellitus (DM).

\section{The role of diabetes mellitus}

$D M$ increases the prevalence of PAD, independently of other cardiovascular risk factors. $^{9-12}$ In DM, PAD has a more diffuse and distal manifestation, occurs especially in tibial arteries, and can present long occlusions. ${ }^{13-15}$ Typically, PAD patients with DM are younger, have a higher body mass index (BMI) and more neuropathy, and exhibit a greater number of cardiovascular comorbidities compared with PAD patients without DM. ${ }^{16,17}$ Moreover, DM increases hospitalization, comorbidities and mortality in PAD patients. ${ }^{16,18}$ A common complication is the diabetic foot. The global annual incidence of developing a diabetic foot ulcer ranges from $1.0 \%$ to $4.1 \%$ and the prevalence ranges from $4 \%$ to $10 \% .{ }^{19}$ Together with infection, PAD is a major predictor for the clinical outcome of diabetic foot ulcers. ${ }^{6}$ Ulceration may lead to amputation, which has dramatic consequences for mobility and quality of life. ${ }^{17,20} \mathrm{DM}$ is known to increase the risk of minor and major amputation in the lower extremity. ${ }^{20,21}$ The vascular complications induced by DM call for careful monitoring and treatment of patients.

\section{Restoration of perfusion}

In case of an obstruction in the main conducting artery to the lower extremity, surgical procedures like bypass surgery, or less invasive procedures like balloon angioplasty and stent implantation may be considered. Although these interventions can restore blood flow, the long-term prognosis is negatively affected by $\mathrm{DM}^{22} \mathrm{DM}$ patients have a higher incidence of restenosis, a less favourable 
prognosis after leg bypass surgery, and a lower amputation-free survival. ${ }^{18,23,24}$ In addition, DM is associated with surgical complications. ${ }^{18,23}$ Pharmacological enhancement of the natural vascular adaptation may form an alternative for complex surgical intervention. Two processes of vascular adaptation can be distinguished after embryogenesis. A well-known adaptation to tissue ischemia is angiogenesis, the sprouting of new capillaries. The newly formed vessels provide nutrients and oxygen to nearby tissue. However, these capillary networks are not sufficient to conduct large amounts of blood to the distal lower extremities. ${ }^{25}$ In case of an occlusion of a large conducting artery, perfusion may be restored by outward remodeling of existing vasculature, a process called arteriogenesis.

\section{Arteriogenesis}

In arteriogenesis, pre-existing anastomoses grow from an average $40 \mu \mathrm{m}$ in diameter to almost a 20 -fold. ${ }^{26,27}$ After 3 to 4 weeks, the remodeled collateral artery is hardly distinguishable from an original arteriole, except for their typical tortuous geometry and a slightly higher collagen content between the layers of smooth muscle cells (SMCs). ${ }^{26,28,29}$ This dramatic remodeling does not restore conductance to the initial level. Without intervention, the conductance of the collateral circulation reaches up to $50 \%$ of the unobstructed artery. ${ }^{30}$

The progress of arteriogenesis is well described. ${ }^{26,31,32}$ When an arterial occlusion becomes manifest, a pressure gradient develops. The low distal pressure forces the blood through pre-existing anastomoses. ${ }^{32,33}$ This recruitment induces shear stress on the vessel wall of these arterioles. If the situation persists, the prolonged shear stress will induce endothelial activation, attracting monocytes to the vessel wall. Monocytes invade the vessel wall, followed by production of several growth factors (GFs). This leads to proliferation and migration of endothelial cells (ECs) and SMCs, as well as degradation of the extracellular matrix, in order to make room for the expanding vessel. The late phase of arteriogenesis is maturation of the vessels, when cells are once again orderly arranged and extra synthesis of collagen and elastin takes place. The final phase of arteriogenesis consists of pruning of vessels that are eliminated in competition for flow. ${ }^{31}$ Unfortunately, arteriogenesis is affected by DM. It was demonstrated that in the presence of DM, arteriogenesis in the coronary circulation is impaired. ${ }^{34,35}$ This also seems true for the peripheral circulation. ${ }^{36}$ 


\section{Arteriogenesis therapy}

The process of outward remodeling consists of a complex interplay of GFs and other molecules. In experimental models, the roles of numerous factors have been investigated, in order to improve or accelerate the process. Administration of a number of factors improved arteriogenesis in animal models, but the effects were not clinically relevant. ${ }^{37}$ For example, the potential of vascular endothelial growth factor (VEGF) in angiogenesis and arteriogenesis has been studied extensively, and has demonstrated promising results in animal models. ${ }^{38,39}$ However, in clinical studies VEGF failed to live up to its promise. ${ }^{40,41}$ Another example is monocyte chemotactic protein-1 (MCP-1), which clearly showed improvements in arteriogenesis in experimental work. ${ }^{30}$ Clinical therapy based on this factor however, is undesirable due to its atherogenic effects.

In general, the biological effects needed to improve structural remodeling locally, are potentially hazardous systemically. GF administration may lead to proliferative retinopathy, edema, plaque instabilization and tumor growth. ${ }^{42-44}$ High systemic levels with these therapeutic agents should therefore be avoided. Alternative strategies, acting on other parts of the remodeling process, may be considered to evade the deleterious side effects. A safe alternative was demonstrated in rabbits, in which oral administration of a vasodilator improved flow restoration in the ischemic hindlimb. ${ }^{45}$

\section{Thesis objectives and outline}

The aim of the present thesis is to determine to which extent DM affects arteriogenesis, on the level of reactivity, recruitment and remodeling of collateral arteries. In chapter 2, a review of the present literature is provided, outlining the mechanisms by which DM affects arteriogenesis from a molecular point of view. This review provides a starting point for the chapters with experimental research. Chapter 3 describes to which extent DM impairs recruitment and remodeling of collateral arteries in an experimental model of hindlimb ischemia. The effect of DM on reactivity of collateral arteries in vitro is described in chapter 4 . In chapter 5, part of the pathway by which DM affects reactivity is investigated. Subsequently, chapter 6 returns to the ischemic hindlimb model, in which the recruitment and remodeling of collateral arteries are stimulated by local vasodilator administration. Finally, in chapter 7, the experimental results are discussed and placed in perspective of the present literature. The thesis is concluded by recommendations for future research, and considerations for clinical therapy. 


\section{References}

1. Belch JJ, Topol EJ, Agnelli G, Bertrand M, Califf RM, Clement DL, Creager MA, Easton JD, Gavin JR, 3rd, Greenland P, Hankey G, Hanrath P, Hirsch AT, Meyer J, Smith SC, Sullivan $F$, Weber MA: Critical issues in peripheral arterial disease detection and management: a call to action. Arch Intern Med 2003;163:884-892.

2. Holler D, Claes C, von der Schulenburg JM: Treatment costs and quality of life of patients with peripheral arterial occlusive disease--the German perspective. Vasa 2004;33:145-153.

3. Prompers L, Huijberts $M$, Schaper $N$, Apelqvist J, Bakker K, Edmonds $M$, Holstein $P$, Jude E, Jirkovska A, Mauricio D, Piaggesi A, Reike H, Spraul M, Van Acker K, Van Baal S, Van Merode F, Uccioli L, Urbancic V, Ragnarson Tennvall G: Resource utilisation and costs associated with the treatment of diabetic foot ulcers. Prospective data from the Eurodiale Study. Diabetologia 2008;51:1826-1834.

4. Schainfeld RM: Management of peripheral arterial disease and intermittent claudication. J Am Board Fam Pract 2001;14:443-450.

5. Dolan NC, Liu K, Criqui MH, Greenland P, Guralnik JM, Chan C, Schneider JR, Mandapat AL, Martin G, McDermott MM: Peripheral artery disease, diabetes, and reduced lower extremity functioning. Diabetes Care 2002;25:113-120.

6. Prompers L, Schaper N, Apelqvist J, Edmonds M, Jude E, Mauricio D, Uccioli L, Urbancic V, Bakker K, Holstein P, Jirkovska A, Piaggesi A, Ragnarson-Tennvall G, Reike H, Spraul M, Van Acker K, Van Baal J, Van Merode F, Ferreira I, Huijberts M: Prediction of outcome in individuals with diabetic foot ulcers: focus on the differences between individuals with and without peripheral arterial disease. The EURODIALE Study. Diabetologia 2008;51:747-755.

7. Eberhardt RT, Coffman JD: Cardiovascular morbidity and mortality in peripheral arterial disease. Curr Drug Targets Cardiovasc Haematol Disord 2004;4:209-217.

8. Stehouwer CD, Clement D, Davidson C, Diehm C, Elte JW, Lambert M, Sereni D: Peripheral arterial disease: a growing problem for the internist. Eur J Intern Med 2009;20:132-138.

9. Donahue RP, Orchard TJ: Diabetes mellitus and macrovascular complications. An epidemiological perspective. Diabetes Care 1992;15:1141-1155.

10. Lange S, Diehm C, Darius H, Haberl R, Allenberg JR, Pittrow D, Schuster A, von Stritzky $B$, Tepohl G, Trampisch HJ: High prevalence of peripheral arterial disease and low treatment rates in elderly primary care patients with diabetes. Exp Clin Endocrinol Diabetes 2004;112:566-573.

11. Marso SP, Hiatt WR: Peripheral arterial disease in patients with diabetes. J Am Coll Cardiol 2006;47:921-929.

12. Pyorala K, Laakso M, Uusitupa M: Diabetes and atherosclerosis: an epidemiologic view. Diabetes Metab Rev 1987;3:463-524.

13. Graziani L, Silvestro A, Bertone V, Manara E, Andreini R, Sigala A, Mingardi R, De Giglio $R$ : Vascular involvement in diabetic subjects with ischemic foot ulcer: a new morphologic categorization of disease severity. Eur J Vasc Endovasc Surg 2007;33:453460. 
14. Beckman JA, Creager MA, Libby P: Diabetes and atherosclerosis: epidemiology, pathophysiology, and management. Jama 2002;287:2570-2581.

15. Lanzer P: Topographic distribution of peripheral arteriopathy in non-diabetics and type 2 diabetics. Z Kardiol 2001;90:99-103.

16. Kamalesh M, Shen J: Diabetes and peripheral arterial disease in men: trends in prevalence, mortality, and effect of concomitant coronary disease. Clin Cardiol 2009;32:442-446.

17. Larsson J, Agardh CD, Apelqvist J, Stenstrom A: Long-term prognosis after healed amputation in patients with diabetes. Clin Orthop Relat Res 1998:149-158.

18. Faglia E, Clerici G, Clerissi J, Gabrielli L, Losa S, Mantero M, Caminiti M, Curci V, Quarantiello A, Lupattelli T, Morabito A: Long-term prognosis of diabetic patients with critical limb ischemia: a population-based cohort study. Diabetes Care 2009;32:822827.

19. Setacci C, de Donato G, Setacci F, Chisci E: Diabetic patients: epidemiology and global impact. J Cardiovasc Surg (Torino) 2009;50:263-273.

20. Sheahan MG, Hamdan AD, Veraldi JR, McArthur CS, Skillman JJ, Campbell DR, Scovell SD, Logerfo FW, Pomposelli FB, Jr.: Lower extremity minor amputations: the roles of diabetes mellitus and timing of revascularization. J Vasc Surg 2005;42:476-480.

21. Humphrey LL, Palumbo PJ, Butters MA, Hallett JW, Jr., Chu CP, O'Fallon WM, Ballard $D J:$ The contribution of non-insulin-dependent diabetes to lower-extremity amputation in the community. Arch Intern Med 1994;154:885-892.

22. Patel PJ, Hieb RA, Bhat AP: Percutaneous revascularization of chronic total occlusions. Tech Vasc Interv Radiol 2010;13:23-36.

23. Currie CJ, Morgan CL, Peters JR: The epidemiology and cost of inpatient care for peripheral vascular disease, infection, neuropathy, and ulceration in diabetes. Diabetes Care 1998;21:42-48.

24. Malmstedt J, Leander K, Wahlberg E, Karlstrom L, Alfredsson L, Swedenborg J: Outcome after leg bypass surgery for critical limb ischemia is poor in patients with diabetes: a population-based cohort study. Diabetes Care 2008;31:887-892.

25. Scholz D, Ziegelhoeffer T, Helisch A, Wagner S, Friedrich C, Podzuweit T, Schaper W: Contribution of arteriogenesis and angiogenesis to postocclusive hindlimb perfusion in mice. J Mol Cell Cardiol 2002;34:775-787.

26. Wahlberg E: Angiogenesis and arteriogenesis in limb ischemia. J Vasc Surg 2003;38:198-203.

27. Wolf C, Cai WJ, Vosschulte R, Koltai S, Mousavipour D, Scholz D, Afsah-Hedjri A, Schaper W, Schaper J: Vascular remodeling and altered protein expression during growth of coronary collateral arteries. J Mol Cell Cardiol 1998;30:2291-2305.

28. Buschmann I, Schaper W: The pathophysiology of the collateral circulation (arteriogenesis). J Pathol 2000;190:338-342.

29. Scholz D, Ito W, Fleming I, Deindl E, Sauer A, Wiesnet M, Busse R, Schaper J, Schaper W: Ultrastructure and molecular histology of rabbit hind-limb collateral artery growth (arteriogenesis). Virchows Arch 2000;436:257-270.

30. Hoefer IE, van Royen N, Buschmann IR, Piek JJ, Schaper W: Time course of arteriogenesis following femoral artery occlusion in the rabbit. Cardiovasc Res 2001;49:609-617. 
31. Schaper W: Collateral circulation: past and present. Basic Res Cardiol 2009;104:5-21.

32. van Royen N, Piek JJ, Buschmann I, Hoefer I, Voskuil M, Schaper W: Stimulation of arteriogenesis; a new concept for the treatment of arterial occlusive disease. Cardiovasc Res 2001;49:543-553.

33. Heil M, Schaper W: Pathophysiology of collateral development. Coron Artery Dis 2004;15:373-378.

34. Abaci A, Oguzhan A, Kahraman S, Eryol NK, Unal S, Arinc H, Ergin A: Effect of diabetes mellitus on formation of coronary collateral vessels. Circulation 1999;99:2239-2242.

35. Waltenberger J: Impaired collateral vessel development in diabetes: potential cellular mechanisms and therapeutic implications. Cardiovasc Res 2001;49:554-560.

36. Rivard A, Silver M, Chen D, Kearney M, Magner M, Annex B, Peters K, Isner JM: Rescue of diabetes-related impairment of angiogenesis by intramuscular gene therapy with adeno-VEGF. Am J Pathol 1999;154:355-363.

37. Simons M, Ware JA: Therapeutic angiogenesis in cardiovascular disease. Nat Rev Drug Discov 2003;2:863-871.

38. Chang DS, Su H, Tang GL, Brevetti LS, Sarkar R, Wang R, Kan YW, Messina LM: Adeno-associated viral vector-mediated gene transfer of VEGF normalizes skeletal muscle oxygen tension and induces arteriogenesis in ischemic rat hindlimb. Mol Ther 2003;7:44-51.

39. Hopkins SP, Bulgrin JP, Sims RL, Bowman B, Donovan DL, Schmidt SP: Controlled delivery of vascular endothelial growth factor promotes neovascularization and maintains limb function in a rabbit model of ischemia. J Vasc Surg 1998;27:886-894; discussion 895.

40. Epstein SE, Fuchs S, Zhou YF, Baffour R, Kornowski R: Therapeutic interventions for enhancing collateral development by administration of growth factors: basic principles, early results and potential hazards. Cardiovasc Res 2001;49:532-542.

41. Rissanen TT, Vajanto I, Yla-Herttuala S: Gene therapy for therapeutic angiogenesis in critically ischaemic lower limb - on the way to the clinic. Eur J Clin Invest 2001;31:651666.

42. Hayden MR, Tyagi SC: Vasa vasorum in plaque angiogenesis, metabolic syndrome, type 2 diabetes mellitus, and atheroscleropathy: a malignant transformation. Cardiovasc Diabetol 2004;3:1.

43. Shyu KG, Chang H, Wang BW, Kuan P: Intramuscular vascular endothelial growth factor gene therapy in patients with chronic critical leg ischemia. Am J Med 2003;114:85-92.

44. Duh E, Aiello LP: Vascular endothelial growth factor and diabetes: the agonist versus antagonist paradox. Diabetes 1999;48:1899-1906.

45. Senthilkumar A, Smith RD, Khitha J, Arora N, Veerareddy S, Langston W, Chidlow JH, Jr., Barlow SC, Teng X, Patel RP, Lefer DJ, Kevil CG: Sildenafil promotes ischemiainduced angiogenesis through a PKG-dependent pathway. Arterioscler Thromb Vasc Biol 2007;27:1947-1954. 
CHAPTER 1 


\section{CHAPTER 2}

\section{Diabetes impairs arteriogenesis}

in the peripheral circulation: review of molecular mechanisms

Matthijs S. Ruiter Jolanda M. van Golde Nicolaas C. Schaper Coen D. Stehouwer Maya S. Huijberts

Clin Sci (Lond) 2010;119(6):225-38 


\section{Summary}

Patients suffering from both DM and PAD are at risk for developing critical limb ischemia, ulceration, and amputation. In addition, DM complicates surgical treatment of PAD and impairs arteriogenesis.

Arteriogenesis is defined as the remodeling of preexisting arterioles into conductance vessels to restore the perfusion distal to the occluded artery. Several strategies to promote arteriogenesis in the peripheral circulation have been devised, but the mechanisms through which DM impairs arteriogenesis are hardly understood. This review provides an overview of the present literature on the deteriorating effects of DM on the key players in the arteriogenesis process. DM affects arteriogenesis at a number of levels. It elevates vasomotor tone and attenuates sensing of shear stress and the response to vasodilatory stimuli, reducing the recruitment and dilatation of collateral arteries. Second, DM impairs the downstream signaling of monocytes, without decreasing monocyte attraction. In addition, endothelial progenitor cell function is attenuated in DM. There is ample evidence that GF signaling is impaired in diabetic arteriogenesis. Although these defects could be restored in animal experiments, clinical results were disappointing. Furthermore, the DM-induced impairment of endothelial nitric oxide synthase strongly affects outward remodeling, as nitric oxide (NO) signaling plays a key role in several remodeling processes. Finally, in the structural phase of arteriogenesis, DM impairs matrix turnover, SMC proliferation and fibroblast migration. This review concludes with suggestions for new and more sophisticated therapeutic approaches for the diabetic population. 


\section{Peripheral arterial disease in diabetes mellitus}

DM is recognized as a major cardiovascular risk factor. PAD is a common vascular complication in the diabetic population, as DM increases the risk of developing PAD at least twofold. ${ }^{1-3}$ Patients suffering from both DM and PAD exhibit poor lower extremity function and are at risk for developing critical limb ischemia, ulceration, and amputation. ${ }^{4,5}$ In type 2 DM, PAD has a more distal and generalized manifestation. ${ }^{6,7}$ PAD patients with DM are typically younger, with higher BMI and more neuropathy, and exhibit a greater number of cardiovascular comorbidities compared with patients without DM. PAD impairs survival with a 2- to 3-fold increased risk of 5- to 10-year mortality. ${ }^{8}$ Mortality for PAD patients is even higher in the presence of DM. ${ }^{9-11}$ DM is also known to complicate treatment of PAD. DM patients have a less favorable outcome after leg bypass surgery, a higher incidence of restenosis, more surgical complications, longer hospitalization and a lower amputation-free survival. ${ }^{9,10,12,13}$

A natural adaptive response to obstructed blood flow in a conducting artery is outward remodeling of pre-existing anastomoses. In this process termed arteriogenesis, blood flow to the tissue distal to an occlusion can largely be restored. The sprouting of capillaries in response to tissue ischemia, a process called angiogenesis, also occurs, but is not sufficient to restore flow the distal part of the lower extremities. ${ }^{14}$ And although angiogenesis is involved in PAD and impaired wound healing in $D M$, it is beyond the scope of the present review. In arteriogenesis, the presence of DM limits the amount of collateral development and the adaptive response to blood flow obstruction. ${ }^{15}$ Type 2 DM attenuates recruitment and functional outward remodeling of pre-existing collateral arterioles, demonstrated clinically in the coronary circulation ${ }^{16,17}$ and experimentally in the lower extremities. ${ }^{18-20}$ The impairment of arteriogenesis by type $1 \mathrm{DM}$ appears to be less severe. ${ }^{18}$

Currently, several strategies to promote arteriogenesis in the peripheral circulation have been devised. And although some studies have targeted the diabetic collateral circulation, the mechanisms through which DM impairs arteriogenesis are hardly understood. This review provides an overview of the present literature on the deteriorating effects of DM on the collateral circulation and on the different phases of arteriogenesis. 


\section{Vascular dysfunction in diabetes}

Type 1 and 2 DM are two distinct conditions, but in respect to vascular function they share several mechanisms, which are addressed in a number of reviews. ${ }^{21-24}$ The most important shared factors seem to be hyperglycemia, oxidative stress, formation of advanced glycation endproducts (AGEs), and protein kinase C (PKC) production. In addition, in type $2 \mathrm{DM}$, the constant state of low-grade inflammation of the endothelium affects vascular function, and may play an important part in the etiology of the disease. ${ }^{25,26}$ Furthermore, type $2 \mathrm{DM}$ is associated with several imbalances, including dyslipidemia and hypertension, which also affect vascular structure and function. ${ }^{24,27,28}$ The diabetic artery displays a change in phenotype and function of endothelium and smooth muscle, and altered structure and composition of the extra-cellular matrix compared to the non-diabetic artery. As a result, the diabetic artery in general has a decreased wall/lumen ratio, and a stiffer vessel wall compared to the non-diabetic artery. ${ }^{21,23,24,27}$ Evidently, the effect of DM on vessels varies with size, region and function. ${ }^{24,29}$

\section{Arteriogenesis in the peripheral circulation}

The functional outward remodeling of pre-existing anastomoses starts after blood flow obstruction in an artery. In experimental models, the process takes 4 weeks, after which a number of pre-existing collateral arterioles are remodeled into conducting arteries. ${ }^{30}$ When an arterial occlusion becomes manifest, blood takes the path of lowest resistance, through the pre-existing collateral anastomoses, increasing local blood flow in these vessels up to 200 -fold. ${ }^{31}$ The process is extensively described in a number of reviews. ${ }^{30,32-34}$ After remodeling, the collateral artery is hardly distinguishable from a normal artery, except for slightly higher collagen content between the SMC layers. ${ }^{31,35,36}$ Collateral vessels grow from 30-50 $\mu \mathrm{m}$ in diameter to almost a 20 -fold, and typically present a tortuous geometry. ${ }^{34,36}$ Notably, this dramatic remodeling does not restore conductance to the initial level. Without intervention, the conductance of the collateral circulation reaches up to $50 \%$ of the unobstructed artery. ${ }^{33,37}$

\section{Effects of diabetes on arteriogenesis}

Impairment of arteriogenesis in the lower extremity by DM has been established by several studies, both in type $1^{18}$ and type $2 \mathrm{DM},{ }^{15,18-20,38}$ but the exact mechanisms have not yet been clarified. In the following sections the effect of DM on the subsequent processes of recruitment and outward remodeling are addressed. A schematic overview of these findings is presented in figure 2.1. 


\section{Acute phase}

Several studies have investigated the acute phase of arteriogenesis, comprising sensing of shear stress, endothelial activation and subsequent vasodilatation.

\section{Sensing of shear stress}

The increase in flow through the collateral circulation following arterial obstruction induces hydrostatic pressure, cyclic strain, and turbulent wall shear forces in the collateral vessels. ${ }^{31}$ Shear stress on the endothelium has been identified as the main trigger for arteriogenesis. ${ }^{35,39,40}$ And although sensing of fluid shear stress seems to be impaired in $\mathrm{DM}^{41,42}$ research in this area is hampered by the incomplete understanding of the underlying mechanism. Several mechanisms have been proposed by which the vessel wall senses shear stress. Integrins, adhesion molecules, receptor tyrosine kinases, caveolae and ion channels link the internal cytoskeleton to the extracellular matrix and may serve as mechanoreceptors. ${ }^{43}$ Common promoter elements responding to shear stress were identified in several genes, including intercellular adhesion molecule-1, transforming growth factor $\beta$ (TGF- $\beta$ ), and endothelial nitric oxide synthase (eNOS). ${ }^{40,43,44}$

Many proinflammatory stimuli inhibit Krüppel-like factor-2 (KLF-2), which plays a central role in the downstream signalling of shear stress. ${ }^{45}$ As diabetic vessels are in a constant state of inflammation, KLF-2 inhibition may account at least in part for decreased shear sensing in DM. This state of inflammation also decreases eNOS steady state mRNA, ${ }^{46}$ which is not only involved in shear signalling, but also in other stages in remodeling. ${ }^{47}$ In addition, Woo et al demonstrated that AGEs and reactive oxygen species (ROS) can lead to posttranslational modification of ERK (extracellular signal-regulated kinase) 5, resulting in reduced flow-induced activation of KLF-2. ${ }^{41}$ This may play a role in DM.

Another possible sensor for shear stress is the glycocalyx. This luminal lining of the endothelium, consisting of membranous glycoproteins, proteoglycans, and associated plasma proteins, was proposed to serve as a mechanosensing entity. ${ }^{42,48}$ Hyperglycemia reduced the glycocalyx content, and decreased shearinduced dilatation, without affecting ACh-induced dilatation. ${ }^{42,48}$ It is uncertain whether this also plays a role in peripheral collaterals.

Additionally, primary cilia on the endothelium, containing polycystin-1 for function and polaris for structure, function as antennas of the EC, sensing changes in shear stress and regulating vascular tone via $\mathrm{NO}$ production and $\mathrm{Ca}^{2+}$ signalling. ${ }^{49}$ The effect of DM on primary cilia is not yet clear, and the presence of cilia has to be confirmed in collateral arteries. ${ }^{32}$ 
In addition to shear forces on the ECs, changes in blood flow may exert cyclic stretch on the SMCs, which induces vascular remodeling via several mechanisms involving eNOS, PKC, and nuclear factor kappa B (NFKB). ${ }^{50}$ As these factors are known to be affected by $\mathrm{DM}^{23,47}$ this may alter the response to cyclic stretch on the vessel wall.

\section{Endothelial activation}

Prolonged exposure to shear stress leads to vasodilatation and activation of the endothelium. ${ }^{40,51}$ Endothelial activation starts with the opening of chloride channels, increasing EC volume and permeability. In addition, eNOS expression and activation increase, mediating several processes in outward remodeling. ${ }^{52,53}$ Within 12 hours after ligation, expression of adhesion molecules (intracellular and vascular cell adhesion molecules ICAM and VCAM) and MCP-1 is upregulated. Importantly, the diabetic vasculature is already in a state of inflammation, leading to elevated expression of ICAM, VCAM, and E-selectin. Additionally, PKC, tumor nectrosis factor- $\alpha(\mathrm{TNF}-\alpha)$, and NFKB are present in higher concentrations as compared to the non-diabetic situation. ${ }^{21,54,55}$ It is likely that this activated and inflammatory state affects the response to shear stress, but the extent to which this occurs is presently unclear. Although the activation of the endothelium and the onset of inflammation have not specifically been studied in diabetic arteriogenesis, production of MCP-1 has been investigated.

An important step in the activation of the collateral endothelium is the attraction of monocytes by MCP-1. Administration of MCP-1 increased post-ischemic collateral conductance in healthy, ${ }^{35}$ and hyperlipidemic rabbits, ${ }^{56}$ but this has not yet been shown in diabetic animals. However, MCP-1 also plays a key role in the development of atherosclerosis. ${ }^{57}$ Plasma MCP-1 levels are associated with traditional risk factors for atherosclerosis and with cardiovascular disease mortality ${ }^{58,59}$ In type 2 DM patients, circulating MCP-1 levels are increased. ${ }^{60}$ The MCP-1 levels correlate with blood glucose, $\mathrm{HbA}_{1 \mathrm{c}}$, triglycerides, $\mathrm{BMI}$, and C-reactive protein. ${ }^{54}$ In cultured EC, high glucose induces MCP-1 expression, a process mediated by ROS, NFKB and plasminogen activator inhibitor-1 (PAI-1)..$^{54}$ In accordance, experimental type $1 \mathrm{DM}$ elevates MCP-1 production from mast cells both under normoxic and hypoxic conditions. ${ }^{61}$ In addition to the increased MCP-1 levels, the expression of MCP-1 receptor CCR2 on monocytes is elevated in patients with $\mathrm{DM}^{57}$ It is therefore not likely that the attraction of monocytes is impaired in DM. Monocyte migration and receptor signal transduction are discussed later on. 


\section{Vasoreactivity}

The influence of DM on endothelial function has been the topic of many studies, both clinical and experimental. However, the term endothelial function does not distinguish between acetylcholine (ACh)-mediated and flow-mediated dilatation. Although many clinical studies agree that ACh-induced dilatation is reduced in type $2 \mathrm{DM}^{22,24,62}$ flow-mediated dilatation (FMD) appears to be either impaired ${ }^{63}$ or unchanged. $24,27,29,64$ The endothelial function in type 2 DM patients is correlated with plasma CRP and TNF- $\alpha{ }^{64,65}$ In addition, determination of the effect of DM itself in clinical studies of type 2 DM is hampered, as endothelial function is affected by concomitant obesity, dyslipidemia and hypertension. ${ }^{24,28}$ In clinical research studying type $1 \mathrm{DM}$, symptoms are less pronounced. The results vary from unchanged to decreased ACh-mediated dilatation. Furthermore, the majority of studies suggest unchanged flow-mediated dilatation, ${ }^{24,27,66,67}$ although impaired FMD has also been observed. ${ }^{68}$ Similar to the effects of DM on the endothelium, NO sensitivity in the SMC was reported decreased $62,69,70$ or unchanged in DM. ${ }^{24,27,66,67,69}$

In animal models of DM, a decrease in endothelium-dependent vasodilatation is well established. The majority of these models represent type $1 \mathrm{DM}$, in which insulin production is diminished by streptozotocin (STZ) or alloxan injection. In mesenteric arteries, abdominal aorta and thoracic aorta, chronic hyperglycemia consistently reduced ACh-mediated vasorelaxation. ${ }^{24,71-73}$ In femoral and mesenteric arteries, experimental DM impaired the NO-cGMP pathway of relaxation, but not the endothelium-deriver hyperpolarizing factor (EDHF) pathway. ${ }^{74}$ Wigg et al however, demonstrated that STZ-induced DM reduced the EDHF-dependent relaxation of mesenteric arteries, but not the NO-dependent relaxation of femoral arteries in rats. ${ }^{75}$ Overall, in these models of type $1 \mathrm{DM}$, NO sensitivity remains unaffected, indicating the impairment is localized in the endothelium rather than the SMC in these vascular beds. ${ }^{24}$ It should be noted however, that disease duration affects the outcome, as demonstrated by a study of Pieper et al., in which sensitivity to ACh increased shortly after chemical induction of DM, but decreased after several weeks. ${ }^{76}$ Similar to ACh-induced relaxation, flow-induced vasorelaxation in mesenteric resistance arteries was attenuated in diabetic rats compared to non-diabetic littermates. ${ }^{77}$ Vasodilatation in DM animal models was improved by L-Arginine supplementation, ${ }^{78}$ eNOS gene transfer ${ }^{79}$, and supplementation of eNOS co-factor tetrahydrobiopterin $\left(\mathrm{BH}_{4}\right){ }^{80}$ Furthermore, in accordance with clinical studies, vasomotor function was related to $\mathrm{HbA}_{1 \mathrm{c}}{ }^{81,82} \mathrm{TNF}$ $\alpha$, upregulated in inflammation and DM, inhibits vasorelaxation both ex vivo ${ }^{83}$ and in vivo. ${ }^{84}$ 
In leptin receptor deficient Lepr(db/db) mice, an experimental model for type 2 DM, ACh-induced vasorelaxation was decreased compared to wild-type (WT) or normoglycemic $\operatorname{Lepr}(\mathrm{Db} / \mathrm{db})$ control mice. This difference was established consistently in aorta rings, mesenteric arteries and coronary arterioles. ${ }^{85-90}$ Administration of superoxide dismutase, TNF- $\alpha$ antibodies or $\mathrm{PKC}_{\beta}$ inhibitors partially restored the impaired relaxation. ${ }^{85,86,88-90}$ These results indicate roles for ROS, inflammation and PKC, respectively. In addition, DM reduced flow-mediated dilatation in coronary arterioles. ${ }^{86,88}$ However, DM did not alter eNOS expression in aorta and mesenteric arteries. ${ }^{87,90}$ eNOS enzymatic activity requires several cofactors, including $\mathrm{BH}_{4}$, which is impaired in experimental insulin resistance. ${ }^{91}$ In Lepr(db/db) mice, decreased $\mathrm{BH}_{4}$ availability resulted in uncoupling of eNOS, an impairment which could be restored by exogenous $\mathrm{BH}_{4}$ administration. ${ }^{89}$ Uncoupling of eNOS results in production of superoxide rather than NO by NOS. ${ }^{92}$ In clinical type $2 \mathrm{DM}, \mathrm{BH}_{4}$ administration had the additional advantage of increasing insulin sensitivity. ${ }^{93}$ The endothelium-independent vasorelaxation, in response to an NO-donor, was unaltered ${ }^{89}$ or decreased ${ }^{87,88,90}$ in $\operatorname{Lepr}(\mathrm{db} / \mathrm{db})$ mice compared to control mice.

In addition to vasorelaxation, DM affects vasoconstriction. The production of vasoconstrictor prostanoids by the endothelium, causing the SMC to contract, is enhanced by hyperglycemia and by oxygen-derived free radicals in the endothelium. ${ }^{94,95}$ In addition, increased levels of endothelin-1, a potent endothelium-borne vasoconstrictor, are found in DM, and even at the pre-diabetic insulin-resistant vasculature. ${ }^{96,97}$ The increased tone was confirmed in several animal studies. In experimental type $1 \mathrm{DM}, \alpha$-adrenergic tone of the iliac artery was increased compared to nondiabetic controls. ${ }^{98}$ Besides, noradrenalin-induced contraction was elevated by DM in skeletal muscle arterioles. ${ }^{72}$ In addition, pressure-sensitive myogenic tone was enhanced in rat mesenteric and gracilis muscle by DM..$^{72,99}$ This may be due to increased activation of voltage-dependent $\mathrm{Ca}^{2+}$ channels and/or PKC in SMC. In Lepr $(\mathrm{db} / \mathrm{db})$ mice, vasomotor tone and sensitivity to constrictory stimuli were slightly increased. ${ }^{89,90}$

The effects of DM on vasoreactivity in the lower extremity have been less extensively studied. In lower extremities of DM patients, ACh-induced and SNPinduced vasodilatation was reduced compared to control subjects, a difference most pronounced in the presence of neuropathy. ${ }^{62}$ In experimental DM, an impaired response to ACh was demonstrated in skeletal muscle arterioles of the STZ rat hindlimb. ${ }^{82,100}$ In addition, these arterioles demonstrated decreased NO sensitivity. ${ }^{82}$ In iliac arteries, STZ-induced DM reduced NO sensitivity. ${ }^{98}$ To summarize, although current literature is not conclusive about the exact 
mechanisms of impaired vasoreactivity in the diabetic vasculature, DM seems to increase constriction and decrease dilatation, reducing the recruitment and dilatation of collateral arteries. The locations and mechanisms of impairment are dependent on the type of DM, presence of comorbidities, experimental model and vascular bed.

After activation and dilatation of the collateral arteries, the outward remodeling is further directed by circulating cells, GFs and NO signaling.

\section{Circulating cells}

Attraction and invasion of monocytes into the vessel wall is the next important step in arteriogenesis. ${ }^{35,101}$ In addition to monocytes, endothelial progenitor cells (EPCS) and other bone marrow-derived cells have been investigated.

\section{Monocytes}

In a rabbit hindlimb ligation model, monocytes from alloxan-induced diabetic animals showed reduced migratory response to both VEGF-A and MCP-1, compared to monocytes from normoglycemic animals. ${ }^{19}$ In a coronary arteriogenesis study, monocyte chemotaxis by VEGF was shown to be reduced in type 2 DM patients. As the VEGF receptor-1 (FIt-1) activity seemed unchanged, the authors suggest the defect is downstream in the VEGF signaling. ${ }^{102}$ Monocyte chemotaxis in response to Flt-1 activation involves phosphatidylinositol 3-kinases (PI3K) and Akt, or mitogen-activated kinases p38 and ERK1/2. In monocytes of DM patients, phosphorylation of ERK1, Akt and p38 is higher than in controls. ${ }^{103}$ In addition, monocytes from DM subjects express more receptor for AGEs (RAGE) protein, potentially making them more sensitive to AGEs. ${ }^{103}$ These changes result in impaired, but not absent receptor signaling in DM monocytes, which contributes to impaired remodeling. ${ }^{104}$

\section{Endothelial progenitor cells}

Similar to monocytes, endothelial progenitor cells are found in the remodeling vessel wall. EPCs, which are primarily involved in vasculogenesis and angiogenesis, are also believed to play a role in arteriogenesis, by invading the remodeling wall and differentiating into ECs. Recently however, the relevance of these cells in the remodeling vessel wall, and the extent to which they are able to assume endothelial characteristics in vivo, were disputed. ${ }^{105}$ But although the role of EPCs in arteriogenesis seems small, it may still provide therapeutic opportunities. ${ }^{51}$ Both type 1 and 2 DM are associated with decreased EPC number and function. ${ }^{106}$ In a clinical study, a higher number of circulating EPCs was associated with more coronary collateral development. ${ }^{107}$ In experimental research, the number of EPC 
correlates with the severity of ischemia and capillary density in the hindlimb. ${ }^{108} \mathrm{DM}$ patients with PAD display a reduction of EPCs compared to DM patients without PAD. EPCs from diabetic PAD patients have a $35 \%$ reduced capacity to adhere to mature ECs than EPCs from DM patients without PAD. ${ }^{109}$ Moreover, CD34 ${ }^{+}$ circulating cells produce fewer EC in type 1 DM patients. ${ }^{110}$ In accordance with these clinical data, DM mice exhibited suppressed EPC mobilization following hindlimb ischemia. ${ }^{18,106,111-113}$ More specifically, there is an inverse relation between DM duration and number of EPCS in ischemic tissue. ${ }^{108}$ Furthermore, diabetic EPCs have a reduced angiogenic capacity, decreased eNOS expression, are more proinflammatory, and show impaired integration. ${ }^{18,106,113,114}$ In spite of these results, the mechanisms by which DM impairs EPC function remain largely unknown. In vitro, high glucose and TNF- $\alpha$ reduced the number of EPCs dose-dependently. ${ }^{115}$ In cultures of $\mathrm{CD}_{3} 4^{+}$cells, more ECs were derived from non-diabetic subjects compared to type $1 \mathrm{DM}$ patients. ${ }^{110}$ In vivo, reduced EPC performance can partially be explained oxidative stress ${ }^{116}$ and by eNOS uncoupling, which was shown to affect EPC function and mobilization. ${ }^{106,112}$ To counter the impaired EPC response, non-diabetic EPC were administered in DM hindlimb ischemia, accelerating blood flow restoration. ${ }^{110}$ Besides, administration of either High glucose and TNF- $\alpha$ vitamin B1 analogue benfotiamine or statins prevented the DM-induced decrease in circulating EPCs, in mice subjected to limb ischemia. ${ }^{113,117}$ Similarly, insulin and granulocyte colony stimulating factor partially restored defective EPC mobilisation in DM rats after ischemia-reperfusion injury. ${ }^{118}$

Other bone marrow-derived cells

Complementary to EPC and monocyte research, several studies have aimed at bone marrow-derived cells. Bone marrow cell (BMC) implantation in experimental research improves post-ischemic perfusion recovery, deambulatory impairment and ischemic damage in both diabetic and control animals, ${ }_{1}^{119}$ unless the BMCs originate from DM patients. These diabetic BMCs increase arteriolar density and angiographic score to a lesser extent than non-diabetic BMCs. ${ }^{108}$ In addition, BMCs from obese, diabetic Zucker rats show less VEGF production, EC differentiation and EC colony-forming potential than BMC from lean rats. ${ }^{120}$ In contrast, VEGF production from BMCs was not affected by STZ-induced DM in rats. ${ }^{119}$ Finally, DM decreased adhesion of BMCs to EC, and BMC-induced SMC recruitment in mice. ${ }^{108}$ In summary, although the attraction of monocytes is not decreased in DM, downstream signaling seems to be impaired in monocytes from diabetic patients. A number of studies demonstrated that both EPC and BMC function is attenuated by DM, but presently the extent to which these impairments affect arteriogenesis remains unclear. 


\section{Growth factors}

After transformation to macrophages, monocytes produce GFs. In addition, platelets adhere and produce interleukin-4, increasing adhesion molecule expression. ${ }^{51}$ Numerous GFs are involved in arteriogenesis, including MCP-1, VEGF, fibroblast growth factor, hypoxia-inducible factor, granulocyte-macrophage colony stimulating factor, hepatocyte growth factor, tumor necrosis factor- $\alpha$, transforming growth factor- $\beta$, and platelet derived growth factor. ${ }^{34,51}$ Administration of some of these GFs was effective in improving arteriogenesis in a non-diabetic model. ${ }^{51,121}$

In arteriogenesis, VEGF upregulates adhesion molecules on the endothelium, produces MCP-1, and induces proliferation of EC and SMC. ${ }^{16}$ As argued before, DM impairs VEGF-A signalling in monocytes. The VEGF-A serum levels in the patients from this study were increased. ${ }^{102}$ This increase was confirmed in another study, ${ }^{122}$ but unchanged ${ }^{123,124}$ or decreased ${ }^{125}$ VEGF levels in DM have also been reported. In experimental DM, levels of Akt, eNOS and CGMP, downstream effectors of VEGF, were lower in the hindlimb of type $2 \mathrm{DM}$ animals. ${ }^{126}$ In addition, $\operatorname{Lepr}(\mathrm{db} / \mathrm{db})$ blunts the upregulation of VEGF after femoral artery ligation. ${ }^{38}$ In accordance, STZinduced DM reduced VEGF production in the mouse ischemic hindlimb. ${ }^{111,127}$ Promotion of VEGF transcription restored this impaired post-ischemic flow restoration, by restoring Akt and eNOS levels, and by increasing EC proliferation and survival. ${ }^{127}$ In the hindlimb, type 2 DM reduces VEGF receptor Flt-1. Following hindlimb ischemia, DM animals exhibit higher Flt-1 expression than non-diabetic mice. ${ }^{126}$ However, this does not lead to improved VEGF-induced arteriogenesis. ${ }^{126,128}$ Notably, although DM reduces VEGF-induced arteriogenesis, it promotes VEGF-mediated angiogenesis in capillary beds, as seen in retinopathy and plaque destabilization. ${ }^{128,129}$ Waltenberger provides an explanation for this paradox, stating that short-time stimulation of outward remodeling is decreased by a state of VEGF resistance, the unspecific pre-activation of intracellular pathways. Long-time exposure to the angiogenic factor enhances neovascularization, despite the poor response. ${ }^{104}$

The function of fibroblast growth factor-2 (FGF-2), which stimulates EC and SMC proliferation, is impaired by STZ-induced DM in the remodeling hindlimb artery. ${ }^{130,131}$ In vitro, hyperglycemia decreased mitogenic and chemotactic activity of FGF-2 in a time- and dose-dependent matter. ${ }^{132}$ Glycation of FGF-2 decreased receptor binding, ERK phosphorylation and angiogenic activity. In vivo, this impairment of FGF-2 was demonstrated in diabetic mice. ${ }^{132}$ Administration of FGF-2 in the murine DM ischemic hindlimb increased perfusion, capillary density and mature vessel density. ${ }^{130,131}$ Combination therapy of FGF-2 with a vasodilator 
magnified the improvement. This was demonstrated with both prostaglandin E1 and the $5 \mathrm{HT}_{2 \mathrm{~A}}$ receptor blocker sarpogrelate. ${ }^{130,131}$

Hypoxia-inducible factor- $1 \alpha$ (HIF-1 $\alpha$ ) is an important factor in capillary sprouting in response to tissue ischemia, but also plays a role in outward remodeling of arterioles. Levels of HIF- $1 \alpha$ are decreased in type 2 DM patients. ${ }^{133}$ HIF- $1 \alpha$ upregulation in response to ischemia-reperfusion injury was attenuated by experimental DM. ${ }^{118}$ In agreement, remodeling induced by HIF- $1 \alpha$ was shown to be impaired in experimental diabetic arteriogenesis. ${ }^{110}$ Adenoviral HIF- $1 \alpha$ administration restored impaired eNOS and Akt expression in Lepr(db/db) mice. ${ }^{134}$ It was demonstrated that DM-induced methylglyoxal reduced HIF- $1 \alpha$ activity, leading to decreased eNOS, VEGF, and stromal cell-derived factor-1 (SDF-1) gene expression following ischemia. This defect could be restored by anti-oxidant superoxide dismutase. ${ }^{135}$

Hepatocyte growth factor (HGF) stimulates EC growth without affecting the SMC, restoring perfusion and angiographic score in experimental hindlimb ischemia. ${ }^{136}$ In vitro, incubation with high glucose reduced HGF mRNA and protein. In accordance, HGF levels were lower in the ischemic hindlimb of DM animals compared to normoglycemic animals. The reduced perfusion restoration and angiographic score in type 1 DM animals could be normalized by HGF gene transfer. ${ }^{136}$

\section{FIGURE 2.1}

Schematic representation of the effects of DM on arteriogenesis. Events in remodeling are introduced from left to right, resulting in the remodeled collateral artery shown on the right side. AGE: advanced glycation endproduct; BMC: bone marrow-derived cell; cGMP: cyclic guanosine monophosphate; EC: endothelial cell; eNOS: endothelial nitric oxide synthase; EPC: endothelial progenitor cell; ERK: extracellular signal-regulated kinase; Flt-1: vascular endothelial growth factor receptor-1; FGF-2: fibroblast growth factor-2; GMCSF: granulocyte macrophage colony-stimulating factor; HGF: hepatocyte growth factor; HIF-1 $\alpha$ : hypoxia-inducible factor-1 $\alpha$; ICAM: intercellular adhesion molecule; Il-4: interleukin-4; KLF-2: Krüppel-like factor-2; MCP-1: monocyte chemotactic protein-1; MMP: matrix metalloproteinase; NO: nitric oxide; PAI-1: plasminogen activator inhibitor-1; PDGF: platelet-derived growth factor; PKC: protein kinase C; ROS: reactive oxygen species; SDF-1: stromal cell-derived factor-1; SMC: smooth muscle cell; TIMP: tissue inhibitor of metalloproteinases; TNF- $\alpha$ : tumor necrosis factor- $\alpha$; VCAM: vascular cell adhesion molecule; VEGF: vascular endothelial growth factor. 


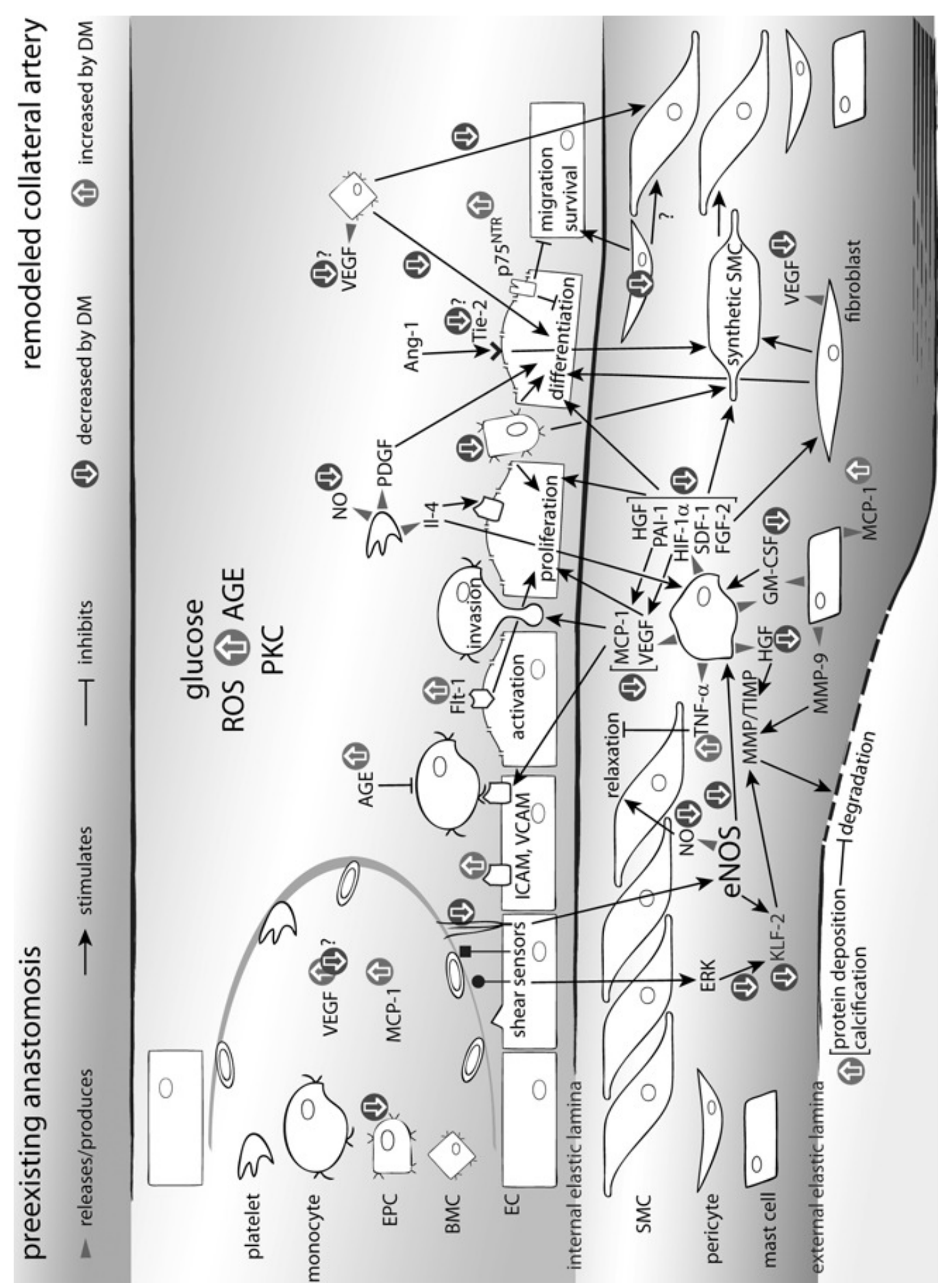


The upregulation of granulocyte-macrophage colony stimulating factor (GM-CSF) mobilizes monocytes and their progenitors from bone marrow into the blood, and provides a stable inflammatory environment for the monocytes to adhere, invade, and produce more factors. Locally, GM-CSF clearly increases collateral conductance, by reducing monocyte apoptosis and extending the life cycle of monocytes and macrophages. ${ }^{51}$ In type 1 and type 2 DM patients, intravenous injection of recombinant GM-CSF combined with local injections of peripheral blood mononuclear cells decreased lower limb pain, and ulceration. Blood perfusion, angiographic score and ankle-brachial pressure increased compared to non-treated DM patients. Notably, heparin was administered during tratment to reduce the risk of embolism. ${ }^{137}$

Overall, DM impairs release and signaling of several GFs involved in arteriogenesis. Both clinically and experimentally, this resulted in attenuated restoration of lower limb perfusion.

\section{Nitric oxide signaling}

A protein that is activated early in the process of outward remodeling and continues to play a role during most of the processes is eNOS. Expression of eNOS is 6-fold increased in developing collateral arteries. ${ }^{138}$ eNOS is essential in blood flow restoration and collateral outward remodeling ${ }^{139}$ but not in formation of capillaries. ${ }^{140}$ This is confirmed by a study in eNOS knockout mice, in which impaired arteriogenesis was restored by adenoviral eNOS administration. ${ }^{47}$ In addition, inhibition of eNOS with L-NAME 3 days after onset of hindlimb ischemia, resulted in decreased blood flow recovery and smaller collateral artery diameter. ${ }^{139}$ DM is known to affect eNOS. In experimental models, eNOS-mediated NO release was decreased in STZ-induced diabetic mice ${ }^{18}$ and rats, but not until 12 weeks of hyperglycemia. ${ }^{119}$ Similarly, $\operatorname{Lepr}(\mathrm{db} / \mathrm{db})$ mice presented diminished eNOS expression ${ }^{18}$ and phophorylation. ${ }^{141}$ In addition, upregulation of eNOS and Akt in response to myocardial infarction was blunted by $\operatorname{Lepr}(\mathrm{db} / \mathrm{db}) .{ }^{142}$ It seems that hindlimb ischemia further reduced eNOS expression in experimental type 2 DM, but not in experimental type $1 \mathrm{DM} .{ }^{18}$ Clinically, it has been shown that DM patients with neuropathy exhibited decreased eNOS expression in the lower extremity compared to healthy subjects, regardless of the absence or presence of macrovascular disease. ${ }^{62}$ Recently, another eNOS-related mechanism in the diabetic ischemic hindlimb was presented. The p75 receptor of neurotrophins p $75^{\mathrm{NTR}}$, which is scarcely present in healthy ECs, becomes strongly expressed by capillary ECs after induction of peripheral ischemia in STZ-induced diabetic mice. Expression of $p 75^{\mathrm{NTR}}$ impairs the survival, proliferation, migration, and adhesion 
capacities of cultured EC and endothelial progenitor cells in vitro, and impairs blood flow recovery in vivo, via the Akt-eNOS pathway. ${ }^{143}$ Antagonism of $p 75^{\mathrm{NTR}}$ in the ischemic muscle inhibited EC apoptosis, normalized EC proliferation, and restored blood flow recovery in DM mice. As the receptor antagonism had no effect on normoglycemic ischemic muscle, this appears to be a mechanism specific for the diabetic hindlimb. ${ }^{143}$ In summary, DM impairs eNOS function, which affects the process of arteriogenesis on numerous levels.

\section{Structural phase}

One week after the onset of outward remodeling, the structural phase of arteriogenesis commences. After degradation of the extracellular matrix, the proliferation and migration of EC and SMC ultimately lead to maturation of the collateral artery.

\section{Matrix turnover}

Matrix metalloproteinases (MMPs) and their inhibitors (TIMPs) regulate turnover and remodeling of the extracellular matrix. In arteriogenesis, the external elastic lamina and elastin are broken down by MMPs and plasmin, creating room for the expanding vessel. ${ }^{51}$ In addition, MMPs promote SMC migration. During remodeling, MMP-2, MMP-9, and TIMP-1 are upregulated in the intima. PAI-1 protects from excess proteolysis. ${ }^{144}$ The balance between MMP and TIMP is essential in both maintenance and remodeling of the vessel wall. Experimental DM impairs this balance during arteriogenesis. ${ }^{110}$ In cell culture, hyperglycemia inhibits expression and activity of MMP-1, MMP-2 and MMP-9 in ECs and SMCs. ${ }^{145}$ In rats, STZ-induced DM amplifies the hindlimb ischemia-induced upregulation of MMP-2 and MMP-9, and suppresses the increase in TIMP- $1 .{ }^{111}$ Contrastingly, Lepr $(\mathrm{db} / \mathrm{db})$ blunted ischemia-induced upregulation of MMP-2, MMP-12 and MMP-16 in the murine hindlimb. ${ }^{38}$ In another study, hyperglycemia reduced activation of MMP-1, MMP-2, MMP-3, and MMP-13, by promoting HGF and AGE accumulation. This process hampers remodeling of the vessel wall. ${ }^{144}$ For clinical practice, it is important to realise that MMP trancription is strongly affected by glucose levels and oxidative stress. In well-controlled type 2 DM patients, macrophage derived MMP and TIMP levels were not affected. ${ }^{144}$

\section{Proliferation, migration and maturation}

During the late phase of arteriogenesis, EC and smooth SMC proliferate and migrate. ${ }^{35}$ SMC account for a large part of the production of new tissue, changing their phenotype from a contractile to a synthetic and proliferative one. ${ }^{32}$ Not much is known about this process in lower extremity circulation, contrary to the field of 
myocard infarction (MI). In remodeling coronary arteries, SMC change not only to the synthetic phenotype, but exhibit an embryonal protein expression pattern. ${ }^{36}$ In experimental MI, Lepr(db/db) DM blunted upregulation of Tie-2, the receptor for Ang-1 which promotes SMC recruitment and was shown to be pivotal in vessel maturation. Decreased capillary but not arteriolar density could be restored by adenoviral Ang-1 administration. ${ }^{142}$ Additionally, DM enhanced Ang-2, identified as a vessel destabilizing agent controlling vessel regression, in MI. ${ }^{142}$ Besides, Lepr(db/db) mice showed decreased SMC coverage in infarcted myocard area compared to wild-type mice, a difference which could be normalized by HIF- $1 \alpha$ administration. ${ }^{134}$ It is probable that these factors also play a role in peripheral arteriogenesis.

In the microcirculation, pericytes regulate EC survival, proliferation and migration by cell-cell and paracrine signalling. Although the relevance of pericytes in arteriogenesis has not yet been established, their presence in collateral arteries was already confirmed. ${ }^{51}$ It was suggested that pericytes may give rise to SMC, but this is not entirely clear. ${ }^{51}$ Pericytes can also originate from bone marrow. ${ }^{146}$ Hyperglycemia, ROS and AGEs promote pericyte apoptosis. ${ }^{106}$ Therefore, if they play a role in lower extremity arteriogenesis, DM may impair pericyte function.

During the maturation phase, EC and SMC are orderly arranged and cell-cell contact is established. Elastin and collagen synthesis takes place, adding extra layers to the vessel. ${ }^{32,34}$ FGF-2 stimulates fibroblast maturation. ${ }^{35}$ Migration of fibroblasts is markedly impaired in Lepr(db/db). ${ }^{147}$ Cultured diabetic fibroblasts display elevated levels of pro-MMP-9 and MMP-9, but not of MMP-2 compared to wild-type fibroblasts. In both normoxic and hypoxic conditions, fibroblasts of Lepr(db/db) mice show decreased VEGF production compared to wild-type fibroblasts. ${ }^{147}$ The final phase of arteriogenesis consists of pruning of vessels that are eliminated in competition for flow. ${ }^{32}$

Although DM seems to affect matrix turnover, fibroblast function, and proliferation and migration of EC and SMC in collateral arteries, it is questionable whether the factors involved in the late phases of arteriogenesis play a decisive role in the impairment by DM.

\section{Therapeutic considerations}

Arteriogenesis is a tightly orchestrated process. While numerous studies started unraveling the many pathways involved, it has become clear that stimulation or inhibition of a single factor may not be sufficient to influence the outcome. This was demonstrated in a number of studies concerning GF therapy. Levels of VEGF, FGF, HIF- $1 \alpha$, and HGF are decreased by DM in the ischemic hindlimb, and 
administration of these factors improved arteriogenesis in experimental models. ${ }^{110,126,130,131,136}$ In clinical practice however, results of GF administration have been disappointing. ${ }^{148,149} \mathrm{~A}$ possible explanation is the narrow therapeutic timeframe and limited duration of the effect. ${ }^{150}$ Additionally, in translating experimental research to clinical therapy, it should be considered that most experimental models are based on acute induction of ischemia, whereas the progress in patients follows a more gradual course. Importantly, the molecules responsible for structural outward remodeling are involved in multiple processes throughout the body. GF treatment can therefore lead to detrimental side effects, such as proliferative retinopathy, edema, plaque instabilization and tumor growth. ${ }^{129,151,152}$

In addition to GF signaling, DM affects monocytes. The impairment of monocyte function in DM appears to be in the downstream signalling rather than in the production and mobility. This may however not easily be corrected in a clinical setting. Other factors discussed in the present paper include EPCs and other bone marrow derived cells. Although many studies have investigated these factors, their role in arteriogenesis or the effect of DM has not yet been established to the extent that they can be translated to therapy. The same holds true for MMPs, fibroblasts and pericytes. Moreover, the latter factors and cells play a role in the structural phase of arteriogenesis. It is not likely that an intervention in the later stage greatly enhances outward remodeling.

Earlier in the remodeling process, eNOS may provide an interesting target for therapy. Both in sensing of shear stress and in vasoreactivity, eNOS plays an important role. Impairments in eNOS levels or function by DM were demonstrated. ${ }^{62,119,142}$ The increase of eNOS potentiates arteriogenesis on a number of levels, but as its function is not limited to arteriogenesis, this may affect other processes. Another interesting therapy may be provided by vasodilator therapy. Administration of a vasodilator may stimulate recruitment of collateral arteries, thereby enhancing shear stress on the vessel wall. Moreover, vasodilator therapy is not associated with the side effects found in GF therapy. In non-diabetic models, the potential of vasodilator therapy in revascularization has already been demonstrated. ${ }^{153} \mathrm{~A}$ multi-level approach may be even more beneficial. Recent studies demonstrate that combination therapy of FGF-2 with a vasodilator restored the impaired arteriogenesis in diabetic mice. ${ }^{130,131}$

\section{Future prospects}

In the development of therapy aimed at promoting arteriogenesis, the first challenge is to find a combination of factors that stimulate outward remodeling, 
without deteriorating arteriogenesis. Based on present results, the combination of a vasodilator with one or possibly more GFs may be effective. The appropriate method of administration may depend on the mechanism and possible side effects of the factor. Local administration, targeted delivery or gene transfer may prevent systemic adverse events. However, surgical interventions should be kept to a minimum, as DM is associated with surgical complications and longer hospitalization.

\section{Conclusions}

- DM increases the risk of developing PAD, complicates treatment and impairs arteriogenesis.

- DM elevates vasomotor tone and attenuates sensing of shear stress and the response to vasodilatory stimuli, reducing the recruitment and dilatation of collateral arteries.

- DM impairs the downstream signaling of monocytes, without decreasing attraction. This could be detrimental in peripheral arteriogenesis.

- EPC and BMC function is attenuated in DM, but the extent to which this is relevant to arteriogenesis is presently unclear.

- In diabetic arteriogenesis, GF signaling is impaired. Although these defects could be (partially) restored in animal experiments, clinical results were disappointing.

- NO signaling plays a key role throughout the remodeling process. The DMinduced eNOS impairment may therefore explain a large part of the attenuated outward remodeling in DM, making it an interesting therapeutic target.

- In the structural phase of arteriogenesis, DM impairs matrix turnover, SMC proliferation and fibroblast migration, but the extent to which these changes in the later phases of remodeling affect arteriogenesis remains uncertain.

- Therapy for improvement of arteriogenesis in DM should have a multi-level effect and aim at the early phase of remodeling. 


\section{References}

1. Gregg EW, Sorlie P, Paulose-Ram R, Gu Q, Eberhardt MS, Wolz M, Burt V, Curtin L, Engelgau M, Geiss L: Prevalence of lower-extremity disease in the US adult population $>=40$ years of age with and without diabetes: 1999-2000 national health and nutrition examination survey. Diabetes Care 2004;27:1591-1597.

2. Kannel WB, McGee DL: Diabetes and cardiovascular disease. The Framingham study. Jama 1979;241:2035-2038.

3. Tapp RJ, Zimmet PZ, Harper CA, de Courten MP, Balkau B, McCarty DJ, Taylor HR, Welborn TA, Shaw JE: Diabetes care in an Australian population: frequency of screening examinations for eye and foot complications of diabetes. Diabetes Care 2004;27:688-693.

4. Dolan NC, Liu K, Criqui MH, Greenland P, Guralnik JM, Chan C, Schneider JR, Mandapat $\mathrm{AL}$, Martin G, McDermott MM: Peripheral artery disease, diabetes, and reduced lower extremity functioning. Diabetes Care 2002;25:113-120.

5. Prompers L, Schaper N, Apelqvist J, Edmonds M, Jude E, Mauricio D, Uccioli L, Urbancic V, Bakker K, Holstein P, Jirkovska A, Piaggesi A, Ragnarson-Tennvall G, Reike $H$, Spraul M, Van Acker K, Van Baal J, Van Merode F, Ferreira I, Huijberts M: Prediction of outcome in individuals with diabetic foot ulcers: focus on the differences between individuals with and without peripheral arterial disease. The EURODIALE Study. Diabetologia 2008;51:747-755.

6. Beckman JA, Creager MA, Libby P: Diabetes and atherosclerosis: epidemiology, pathophysiology, and management. Jama 2002;287:2570-2581.

7. Lanzer P: Topographic distribution of peripheral arteriopathy in non-diabetics and type 2 diabetics. Z Kardiol 2001;90:99-103.

8. Eberhardt RT, Coffman JD: Cardiovascular morbidity and mortality in peripheral arterial disease. Curr Drug Targets Cardiovasc Haematol Disord 2004;4:209-217.

9. Faglia E, Clerici G, Clerissi J, Gabrielli L, Losa S, Mantero M, Caminiti M, Curci V, Quarantiello A, Lupattelli T, Morabito A: Long-term prognosis of diabetic patients with critical limb ischemia: a population-based cohort study. Diabetes Care 2009;32:822827.

10. Kamalesh M, Shen J: Diabetes and peripheral arterial disease in men: trends in prevalence, mortality, and effect of concomitant coronary disease. Clin Cardiol 2009;32:442-446.

11. Larsson J, Agardh CD, Apelqvist J, Stenstrom A: Long-term prognosis after healed amputation in patients with diabetes. Clin Orthop Relat Res 1998:149-158.

12. Malmstedt J, Leander K, Wahlberg E, Karlstrom L, Alfredsson L, Swedenborg J: Outcome after leg bypass surgery for critical limb ischemia is poor in patients with diabetes: a population-based cohort study. Diabetes Care 2008;31:887-892.

13. Currie CJ, Morgan CL, Peters JR: The epidemiology and cost of inpatient care for peripheral vascular disease, infection, neuropathy, and ulceration in diabetes. Diabetes Care $1998 ; 21: 42-48$. 
14. Scholz D, Ziegelhoeffer T, Helisch A, Wagner S, Friedrich C, Podzuweit T, Schaper W: Contribution of arteriogenesis and angiogenesis to postocclusive hindlimb perfusion in mice. J Mol Cell Cardiol 2002;34:775-787.

15. De Vivo S, Palmer-Kazen U, Kalin B, Wahlberg E: Risk factors for poor collateral development in claudication. Vasc Endovascular Surg 2005;39:519-524.

16. Waltenberger J: Impaired collateral vessel development in diabetes: potential cellular mechanisms and therapeutic implications. Cardiovasc Res 2001;49:554-560.

17. Abaci A, Oguzhan A, Kahraman S, Eryol NK, Unal S, Arinc H, Ergin A: Effect of diabetes mellitus on formation of coronary collateral vessels. Circulation 1999;99:2239-2242.

18. Yan J, Tie G, Park B, Yan Y, Nowicki PT, Messina LM: Recovery from hind limb ischemia is less effective in type 2 than in type 1 diabetic mice: roles of endothelial nitric oxide synthase and endothelial progenitor cells. J Vasc Surg 2009;50:1412-1422.

19. van Golde JM, Ruiter MS, Schaper NC, Voo S, Waltenberger J, Backes WH, Post MJ, Huijberts MS: Impaired collateral recruitment and outward remodeling in experimental diabetes. Diabetes 2008;57:2818-2823.

20. Rivard A, Silver M, Chen D, Kearney M, Magner M, Annex B, Peters K, Isner JM: Rescue of diabetes-related impairment of angiogenesis by intramuscular gene therapy with adeno-VEGF. Am J Pathol 1999;154:355-363.

21. Das Evcimen N, King GL: The role of protein kinase $\mathrm{C}$ activation and the vascular complications of diabetes. Pharmacol Res 2007;55:498-510.

22. Schalkwijk CG, Stehouwer CD: Vascular complications in diabetes mellitus: the role of endothelial dysfunction. Clin Sci (Lond) 2005;109:143-159.

23. Brownlee M: Biochemistry and molecular cell biology of diabetic complications. Nature 2001;414:813-820.

24. De Vriese AS, Verbeuren TJ, Van de Voorde J, Lameire NH, Vanhoutte PM: Endothelial dysfunction in diabetes. Br J Pharmacol 2000;130:963-974.

25. Sjoholm A, Nystrom T: Endothelial inflammation in insulin resistance. Lancet 2005;365:610-612.

26. Sjoholm A, Nystrom T: Inflammation and the etiology of type 2 diabetes. Diabetes Metab Res Rev 2006;22:4-10.

27. Schofield I, Malik R, Izzard A, Austin C, Heagerty A: Vascular structural and functional changes in type 2 diabetes mellitus: evidence for the roles of abnormal myogenic responsiveness and dyslipidemia. Circulation 2002;106:3037-3043.

28. Makimattila S, Liu ML, Vakkilainen J, Schlenzka A, Lahdenpera S, Syvanne M, Mantysaari M, Summanen P, Bergholm R, Taskinen MR, Yki-Jarvinen H: Impaired endothelium-dependent vasodilation in type 2 diabetes. Relation to LDL size, oxidized LDL, and antioxidants. Diabetes Care 1999;22:973-981.

29. Meyer MF, Lieps D, Schatz H, Pfohl M: Impaired flow-mediated vasodilation in type 2 diabetes: lack of relation to microvascular dysfunction. Microvasc Res 2008;76:61-65.

30. van Royen N, Piek JJ, Buschmann I, Hoefer I, Voskuil M, Schaper W: Stimulation of arteriogenesis; a new concept for the treatment of arterial occlusive disease. Cardiovasc Res 2001;49:543-553.

31. Buschmann I, Schaper W: The pathophysiology of the collateral circulation (arteriogenesis). J Pathol 2000;190:338-342.

32. Schaper W: Collateral circulation: past and present. Basic Res Cardiol 2009;104:5-21. 
33. Heil M, Schaper W: Pathophysiology of collateral development. Coron Artery Dis 2004;15:373-378.

34. Wahlberg E: Angiogenesis and arteriogenesis in limb ischemia. J Vasc Surg 2003;38:198-203.

35. Scholz D, Ito W, Fleming I, Deindl E, Sauer A, Wiesnet M, Busse R, Schaper J, Schaper $\mathrm{W}$ : Ultrastructure and molecular histology of rabbit hind-limb collateral artery growth (arteriogenesis). Virchows Arch 2000;436:257-270.

36. Wolf C, Cai WJ, Vosschulte R, Koltai S, Mousavipour D, Scholz D, Afsah-Hedjri A, Schaper W, Schaper J: Vascular remodeling and altered protein expression during growth of coronary collateral arteries. J Mol Cell Cardiol 1998;30:2291-2305.

37. Hoefer IE, van Royen N, Buschmann IR, Piek JJ, Schaper W: Time course of arteriogenesis following femoral artery occlusion in the rabbit. Cardiovasc Res 2001;49:609-617.

38. Schiekofer S, Galasso G, Sato K, Kraus BJ, Walsh K: Impaired revascularization in a mouse model of type 2 diabetes is associated with dysregulation of a complex angiogenic-regulatory network. Arterioscler Thromb Vasc Biol 2005;25:1603-1609.

39. Pipp F, Boehm S, Cai WJ, Adili F, Ziegler B, Karanovic G, Ritter R, Balzer J, Scheler C, Schaper W, Schmitz-Rixen T: Elevated fluid shear stress enhances postocclusive collateral artery growth and gene expression in the pig hind limb. Arterioscler Thromb Vasc Biol 2004;24:1664-1668.

40. Heil M, Schaper W: Influence of mechanical, cellular, and molecular factors on collateral artery growth (arteriogenesis). Circ Res 2004;95:449-458.

41. Woo CH, Shishido T, McClain C, Lim JH, Li JD, Yang J, Yan C, Abe J: Extracellular signal-regulated kinase 5 SUMOylation antagonizes shear stress-induced antiinflammatory response and endothelial nitric oxide synthase expression in endothelial cells. Circ Res 2008;102:538-545.

42. Kelly R, Ruane-O'Hora T, Noble MI, Drake-Holland AJ, Snow HM: Differential inhibition by hyperglycaemia of shear stress- but not acetylcholine-mediated dilatation in the iliac artery of the anaesthetized pig. J Physiol 2006;573:133-145.

43. Li YS, Haga JH, Chien S: Molecular basis of the effects of shear stress on vascular endothelial cells. J Biomech 2005;38:1949-1971.

44. Buschmann IR, Lehmann K, Le Noble F: Physics meets molecules: is modulation of shear stress the link to vascular prevention? Circ Res 2008;102:510-512.

45. Atkins GB, Jain MK: Role of Kruppel-like transcription factors in endothelial biology. Circ Res 2007;100:1686-1695.

46. Tai SC, Robb GB, Marsden PA: Endothelial nitric oxide synthase: a new paradigm for gene regulation in the injured blood vessel. Arterioscler Thromb Vasc Biol 2004;24:405412.

47. Yu J, deMuinck ED, Zhuang Z, Drinane M, Kauser K, Rubanyi GM, Qian HS, Murata T, Escalante B, Sessa WC: Endothelial nitric oxide synthase is critical for ischemic remodeling, mural cell recruitment, and blood flow reserve. Proc Natl Acad Sci U S A 2005;102:10999-11004.

48. Gouverneur M, Berg B, Nieuwdorp M, Stroes E, Vink H: Vasculoprotective properties of the endothelial glycocalyx: effects of fluid shear stress. J Intern Med 2006;259:393400. 
49. Nauli SM, Kawanabe Y, Kaminski J], Pearce WJ, Ingber DE, Zhou J: Endothelial cilia are fluid shear sensors that regulate calcium signaling and nitric oxide production through polycystin-1. Circulation 2008;117:1161-1171.

50. Haga JH, Li YS, Chien S: Molecular basis of the effects of mechanical stretch on vascular smooth muscle cells. J Biomech 2007;40:947-960.

51. Schaper W, Schaper J: Arteriogenesis. Boston, Kluwer Academic Publishers, 2004.

52. Luque Contreras D, Vargas Robles H, Romo E, Rios A, Escalante B: The role of nitric oxide in the post-ischemic revascularization process. Pharmacol Ther 2006;112:553563.

53. Lloyd PG, Yang HT, Terjung RL: Arteriogenesis and angiogenesis in rat ischemic hindlimb: role of nitric oxide. Am J Physiol Heart Circ Physiol 2001;281:H2528-2538.

54. Dragomir E, Simionescu M: Monocyte chemoattractant protein-1--a major contributor to the inflammatory process associated with diabetes. Arch Physiol Biochem 2006;112:239-244.

55. Sheetz MJ, King GL: Molecular understanding of hyperglycemia's adverse effects for diabetic complications. Jama 2002;288:2579-2588.

56. van Royen N, Hoefer I, Buschmann I, Kostin S, Voskuil M, Bode C, Schaper W, Piek JJ: Effects of local MCP-1 protein therapy on the development of the collateral circulation and atherosclerosis in Watanabe hyperlipidemic rabbits. Cardiovasc Res 2003;57:178185.

57. Niu J, Kolattukudy PE: Role of MCP-1 in cardiovascular disease: molecular mechanisms and clinical implications. Clin Sci (Lond) 2009;117:95-109.

58. Deo R, Khera A, McGuire DK, Murphy SA, Meo Neto Jde P, Morrow DA, de Lemos JA: Association among plasma levels of monocyte chemoattractant protein-1, traditional cardiovascular risk factors, and subclinical atherosclerosis. J Am Coll Cardiol 2004;44:1812-1818.

59. Piemonti L, Calori G, Lattuada G, Mercalli A, Ragogna F, Garancini MP, Ruotolo G, Luzi $\mathrm{L}$, Perseghin G: Association between plasma monocyte chemoattractant protein-1 concentration and cardiovascular disease mortality in middle-aged diabetic and nondiabetic individuals. Diabetes Care 2009;32:2105-2110.

60. Simeoni E, Winkelmann BR, Hoffmann MM, Fleury S, Ruiz J, Kappenberger L, Marz W, Vassalli G: Association of RANTES G-403A gene polymorphism with increased risk of coronary arteriosclerosis. Eur Heart J 2004;25:1438-1446.

61. Marisa C, Lucci I, Di Giulio C, Bianchi G, Grilli A, Patruno A, Reale M: MCP-1 and MIP-2 expression and production in $\mathrm{BB}$ diabetic rat: effect of chronic hypoxia. Mol Cell Biochem 2005;276:105-111.

62. Veves A, Akbari CM, Primavera J, Donaghue VM, Zacharoulis D, Chrzan JS, DeGirolami U, LoGerfo FW, Freeman R: Endothelial dysfunction and the expression of endothelial nitric oxide synthetase in diabetic neuropathy, vascular disease, and foot ulceration. Diabetes 1998;47:457-463.

63. Henry RM, Ferreira I, Kostense PJ, Dekker JM, Nijpels G, Heine RJ, Kamp O, Bouter LM, Stehouwer CD: Type 2 diabetes is associated with impaired endothelium-dependent, flow-mediated dilation, but impaired glucose metabolism is not; The Hoorn Study. Atherosclerosis 2004;174:49-56. 
64. Nystrom T, Nygren A, Sjoholm A: Persistent endothelial dysfunction is related to elevated C-reactive protein (CRP) levels in Type II diabetic patients after acute myocardial infarction. Clin Sci (Lond) 2005;108:121-128.

65. Nystrom T, Nygren A, Sjoholm A: Increased levels of tumour necrosis factor-alpha (TNF-alpha) in patients with Type II diabetes mellitus after myocardial infarction are related to endothelial dysfunction. Clin Sci (Lond) 2006;110:673-681.

66. Huvers FC, De Leeuw PW, Houben AJ, De Haan CH, Hamulyak K, Schouten H, Wolffenbuttel BH, Schaper NC: Endothelium-dependent vasodilatation, plasma markers of endothelial function, and adrenergic vasoconstrictor responses in type 1 diabetes under near-normoglycemic conditions. Diabetes 1999;48:1300-1307.

67. Smits P, Kapma JA, Jacobs MC, Lutterman J, Thien T: Endothelium-dependent vascular relaxation in patients with type I diabetes. Diabetes 1993;42:148-153.

68. Dogra G, Rich L, Stanton K, Watts GF: Endothelium-dependent and independent vasodilation studies at normoglycaemia in type I diabetes mellitus with and without microalbuminuria. Diabetologia 2001;44:593-601.

69. Chan NN, Vallance $P$, Colhoun HM: Nitric oxide and vascular responses in Type I diabetes. Diabetologia 2000;43:137-147.

70. McVeigh GE, Brennan GM, Johnston GD, McDermott BJ, McGrath LT, Henry WR, Andrews JW, Hayes JR: Impaired endothelium-dependent and independent vasodilation in patients with type 2 (non-insulin-dependent) diabetes mellitus. Diabetologia 1992;35:771-776.

71. Miranda FJ, Alabadi JA, Llorens S, Ruiz de Apodaca RF, Centeno JM, Alborch E: Influence of experimental diabetes on regulatory mechanisms of vascular response of rabbit carotid artery to acetylcholine. Life Sci 2000;66:2071-2080.

72. Ungvari Z, Pacher P, Kecskemeti V, Papp G, Szollar L, Koller A: Increased myogenic tone in skeletal muscle arterioles of diabetic rats. Possible role of increased activity of smooth muscle Ca2+ channels and protein kinase C. Cardiovasc Res 1999;43:10181028.

73. Sobrevia L, Mann GE: Dysfunction of the endothelial nitric oxide signalling pathway in diabetes and hyperglycaemia. Exp Physiol 1997;82:423-452.

74. Shi Y, Ku DD, Man RY, Vanhoutte PM: Augmented endothelium-derived hyperpolarizing factor-mediated relaxations attenuate endothelial dysfunction in femoral and mesenteric, but not in carotid arteries from type I diabetic rats. J Pharmacol Exp Ther 2006;318:276-281.

75. Wigg SJ, Tare M, Tonta MA, O'Brien RC, Meredith IT, Parkington HC: Comparison of effects of diabetes mellitus on an EDHF-dependent and an EDHF-independent artery. Am J Physiol Heart Circ Physiol 2001;281:H232-240.

76. Pieper GM: Enhanced, unaltered and impaired nitric oxide-mediated endotheliumdependent relaxation in experimental diabetes mellitus: importance of disease duration. Diabetologia 1999;42:204-213.

77. Tribe RM, Thomas CR, Poston L: Flow-induced dilatation in isolated resistance arteries from control and streptozotocin-diabetic rats. Diabetologia 1998;41:34-39.

78. Pieper GM, Dondlinger LA: Plasma and vascular tissue arginine are decreased in diabetes: acute arginine supplementation restores endothelium-dependent relaxation by augmenting cGMP production. J Pharmacol Exp Ther 1997;283:684-691. 
79. Zanetti M, Sato J, Katusic ZS, O'Brien T: Gene transfer of endothelial nitric oxide synthase alters endothelium-dependent relaxations in aortas from diabetic rabbits. Diabetologia 2000;43:340-347.

80. Heitzer T, Krohn K, Albers S, Meinertz T: Tetrahydrobiopterin improves endotheliumdependent vasodilation by increasing nitric oxide activity in patients with Type II diabetes mellitus. Diabetologia 2000;43:1435-1438.

81. Rodriguez-Manas L, Angulo J, Peiro C, Llergo JL, Sanchez-Ferrer A, Lopez-Doriga P, Sanchez-Ferrer CF: Endothelial dysfunction and metabolic control in streptozotocininduced diabetic rats. Br J Pharmacol 1998;123:1495-1502.

82. Angulo J, Rodriguez-Manas L, Peiro C, Neira M, Marin J, Sanchez-Ferrer CF: Impairment of nitric oxide-mediated relaxations in anaesthetized autoperfused streptozotocin-induced diabetic rats. Naunyn Schmiedebergs Arch Pharmacol 1998;358:529-537.

83. Aoki N, Siegfried M, Lefer AM: Anti-EDRF effect of tumor necrosis factor in isolated, perfused cat carotid arteries. Am J Physiol 1989;256:H1509-1512.

84. Wang $\mathrm{P}, \mathrm{Ba} \mathrm{ZF}$, Chaudry IH: Administration of tumor necrosis factor-alpha in vivo depresses endothelium-dependent relaxation. Am J Physiol 1994;266:H2535-2541.

85. Khazaei M, Moien-Afshari F, Elmi S, Mirdamadi A, Laher I: The effects of diethyldithiocarbamate, a SOD inhibitor, on endothelial function in sedentary and exercised db/db mice. Pathophysiology 2009;16:15-18.

86. Zhang C, Park Y, Picchi A, Potter BJ: Maturation-induces endothelial dysfunction via vascular inflammation in diabetic mice. Basic Res Cardiol 2008;103:407-416.

87. Lam TY, Seto SW, Lau YM, Au LS, Kwan YW, Ngai SM, Tsui KW: Impairment of the vascular relaxation and differential expression of caveolin-1 of the aorta of diabetic +db/+db mice. Eur J Pharmacol 2006;546:134-141.

88. Bagi Z, Koller A, Kaley G: Superoxide-NO interaction decreases flow- and agonistinduced dilations of coronary arterioles in Type 2 diabetes mellitus. Am J Physiol Heart Circ Physiol 2003;285:H1404-1410.

89. Pannirselvam M, Verma S, Anderson TJ, Triggle CR: Cellular basis of endothelial dysfunction in small mesenteric arteries from spontaneously diabetic ( $\mathrm{db} / \mathrm{db}-/-)$ mice: role of decreased tetrahydrobiopterin bioavailability. Br J Pharmacol 2002;136:255-263.

90. Lagaud GJ, Masih-Khan E, Kai S, van Breemen C, Dube GP: Influence of type II diabetes on arterial tone and endothelial function in murine mesenteric resistance arteries. J Vasc Res 2001;38:578-589.

91. Shinozaki K, Kashiwagi A, Nishio Y, Okamura T, Yoshida Y, Masada M, Toda N, Kikkawa $\mathrm{R}$ : Abnormal biopterin metabolism is a major cause of impaired endothelium-dependent relaxation through nitric oxide/O2- imbalance in insulin-resistant rat aorta. Diabetes 1999;48:2437-2445.

92. Vasquez-Vivar J, Hogg N, Martasek P, Karoui H, Pritchard KA, Jr., Kalyanaraman B: Tetrahydrobiopterin-dependent inhibition of superoxide generation from neuronal nitric oxide synthase. J Biol Chem 1999;274:26736-26742.

93. Nystrom T, Nygren A, Sjoholm A: Tetrahydrobiopterin increases insulin sensitivity in patients with type 2 diabetes and coronary heart disease. Am J Physiol Endocrinol Metab 2004;287:E919-925. 
94. Vanhoutte PM, Tang EH: Endothelium-dependent contractions: when a good guy turns bad! J Physiol 2008;586:5295-5304.

95. Shi Y, So KF, Man RY, Vanhoutte PM: Oxygen-derived free radicals mediate endothelium-dependent contractions in femoral arteries of rats with streptozotocininduced diabetes. Br J Pharmacol 2007;152:1033-1041.

96. Mather KJ, Mirzamohammadi B, Lteif A, Steinberg HO, Baron AD: Endothelin contributes to basal vascular tone and endothelial dysfunction in human obesity and type 2 diabetes. Diabetes 2002;51:3517-3523.

97. Wiernsperger NF: In defense of microvascular constriction in diabetes. Clin Hemorheol Microcirc 2001;25:55-62.

98. Martinez-Nieves B, Dunbar JC: Vascular dilatatory responses to sodium nitroprusside (SNP) and alpha-adrenergic antagonism in female and male normal and diabetic rats. Proc Soc Exp Biol Med 1999;222:90-98.

99. Crijns FR, Wolffenbuttel BH, De Mey JG, Struijker Boudier HA: Mechanical properties of mesenteric arteries in diabetic rats: consequences of outward remodeling. Am J Physiol 1999;276:H1672-1677.

100. Crijns FR, Struijker Boudier HA, Wolffenbuttel BH: Arteriolar reactivity in conscious diabetic rats: influence of aminoguanidine treatment. Diabetes 1998;47:918-923.

101. Voskuil M, van Royen N, Hoefer IE, Seidler R, Guth BD, Bode C, Schaper W, Piek JJ, Buschmann IR: Modulation of collateral artery growth in a porcine hindlimb ligation model using MCP-1. Am J Physiol Heart Circ Physiol 2003;284:H1422-1428.

102. Waltenberger J, Lange J, Kranz A: Vascular endothelial growth factor-A-induced chemotaxis of monocytes is attenuated in patients with diabetes mellitus: A potential predictor for the individual capacity to develop collaterals. Circulation 2000;102:185190.

103. Tchaikovski V, Olieslagers S, Bohmer FD, Waltenberger J: Diabetes mellitus activates signal transduction pathways resulting in vascular endothelial growth factor resistance of human monocytes. Circulation 2009;120:150-159.

104. Waltenberger J: VEGF resistance as a molecular basis to explain the angiogenesis paradox in diabetes mellitus. Biochem Soc Trans 2009;37:1167-1170.

105. Ingram DA, Caplice NM, Yoder MC: Unresolved questions, changing definitions, and novel paradigms for defining endothelial progenitor cells. Blood 2005;106:1525-1531.

106. Spinetti G, Kraenkel N, Emanueli C, Madeddu P: Diabetes and vessel wall remodelling: from mechanistic insights to regenerative therapies. Cardiovasc Res 2008;78:265-273.

107. Lambiase PD, Edwards RJ, Anthopoulos P, Rahman S, Meng YG, Bucknall CA, Redwood SR, Pearson JD, Marber MS: Circulating humoral factors and endothelial progenitor cells in patients with differing coronary collateral support. Circulation 2004;109:2986-2992.

108. Zhou B, Bi YY, Han ZB, Ren H, Fang ZH, Yu XF, Poon MC, Han ZC: G-CSF-mobilized peripheral blood mononuclear cells from diabetic patients augment neovascularization in ischemic limbs but with impaired capability. J Thromb Haemost 2006;4:993-1002.

109. Fadini GP, Sartore S, Albiero M, Baesso I, Murphy E, Menegolo M, Grego F, Vigili de Kreutzenberg S, Tiengo A, Agostini C, Avogaro A: Number and function of endothelial progenitor cells as a marker of severity for diabetic vasculopathy. Arterioscler Thromb Vasc Biol 2006;26:2140-2146. 
110. Schatteman GC, Hanlon HD, Jiao C, Dodds SG, Christy BA: Blood-derived angioblasts accelerate blood-flow restoration in diabetic mice. J Clin Invest 2000;106:571-578.

111. Kang LN, Chen Q, Wang L, Gao L, Meng K, Chen JH, Ferro A, Xu B: Decreased Mobilization of Endothelial Progenitor Cells Contributes to Impaired Neovascularization in Diabetes. Clin Exp Pharmacol Physiol 2009.

112. Avogaro A, Fadini GP, Gallo A, Pagnin E, de Kreutzenberg S: Endothelial dysfunction in type 2 diabetes mellitus. Nutr Metab Cardiovasc Dis 2006;16 Suppl 1:S39-45.

113. Gadau S, Emanueli C, Van Linthout S, Graiani G, Todaro M, Meloni M, Campesi I, Invernici G, Spillmann F, Ward K, Madeddu P: Benfotiamine accelerates the healing of ischaemic diabetic limbs in mice through protein kinase B/Akt-mediated potentiation of angiogenesis and inhibition of apoptosis. Diabetologia 2006;49:405-420.

114. Loomans CJ, van Haperen R, Duijs JM, Verseyden C, de Crom R, Leenen PJ, Drexhage HA, de Boer HC, de Koning EJ, Rabelink TJ, Staal FJ, van Zonneveld AJ: Differentiation of bone marrow-derived endothelial progenitor cells is shifted into a proinflammatory phenotype by hyperglycemia. Mol Med 2009;15:152-159.

115. Seeger FH, Haendeler J, Walter DH, Rochwalsky U, Reinhold J, Urbich C, Rossig L, Corbaz A, Chvatchko Y, Zeiher AM, Dimmeler S: p38 mitogen-activated protein kinase downregulates endothelial progenitor cells. Circulation 2005;111:1184-1191.

116. Case J, Ingram DA, Haneline LS: Oxidative stress impairs endothelial progenitor cell function. Antioxid Redox Signal 2008;10:1895-1907.

117. Emanueli C, Monopoli A, Kraenkel N, Meloni M, Gadau S, Campesi I, Ongini E, Madeddu $P$ : Nitropravastatin stimulates reparative neovascularisation and improves recovery from limb Ischaemia in type-1 diabetic mice. Br J Pharmacol 2007;150:873-882.

118. Fadini GP, Sartore S, Schiavon M, Albiero M, Baesso I, Cabrelle A, Agostini C, Avogaro A: Diabetes impairs progenitor cell mobilisation after hindlimb ischaemia-reperfusion injury in rats. Diabetologia 2006;49:3075-3084.

119. Hirata K, Li TS, Nishida M, Ito H, Matsuzaki M, Kasaoka S, Hamano K: Autologous bone marrow cell implantation as therapeutic angiogenesis for ischemic hindlimb in diabetic rat model. Am J Physiol Heart Circ Physiol 2003;284:H66-70.

120. Li TS, Furutani A, Takahashi M, Ohshima M, Qin SL, Kobayashi T, Ito H, Hamano K: Impaired potency of bone marrow mononuclear cells for inducing therapeutic angiogenesis in obese diabetic rats. Am J Physiol Heart Circ Physiol 2006;290:H13621369.

121. Schierling W, Troidl K, Troidl C, Schmitz-Rixen T, Schaper W, Eitenmuller IK: The Role of Angiogenic Growth Factors in Arteriogenesis. J Vasc Res 2009;46:365-374.

122. Lim HS, Blann AD, Chong AY, Freestone B, Lip GY: Plasma vascular endothelial growth factor, angiopoietin-1, and angiopoietin-2 in diabetes: implications for cardiovascular risk and effects of multifactorial intervention. Diabetes Care 2004;27:2918-2924.

123. Shimada K, Baba T, Neugebauer S, Onozaki A, Yamada D, Midorikawa S, Sato W, Watanabe T: Plasma vascular endothelial growth factor in Japanese Type 2 diabetic patients with and without nephropathy. J Diabetes Complications 2002;16:386-390.

124. Dullaart RP, Oomen PH, Sluiter WJ: Circulating vascular endothelial growth factor is unaffected by acute hyperglycemia and hyperinsulinemia in type 1 diabetes mellitus. Eur J Intern Med 2007;18:193-195. 
125. Chung AW, Hsiang YN, Matzke LA, McManus BM, van Breemen C, Okon EB: Reduced expression of vascular endothelial growth factor paralleled with the increased angiostatin expression resulting from the upregulated activities of matrix metalloproteinase- 2 and -9 in human type 2 diabetic arterial vasculature. Circ Res 2006;99:140-148.

126. Hazarika S, Dokun AO, Li Y, Popel AS, Kontos CD, Annex BH: Impaired angiogenesis after hindlimb ischemia in type 2 diabetes mellitus: differential regulation of vascular endothelial growth factor receptor 1 and soluble vascular endothelial growth factor receptor 1. Circ Res 2007;101:948-956.

127. Li Y, Hazarika S, Xie D, Pippen AM, Kontos CD, Annex BH: In mice with type 2 diabetes, a vascular endothelial growth factor (VEGF)-activating transcription factor modulates VEGF signaling and induces therapeutic angiogenesis after hindlimb ischemia. Diabetes 2007; 56:656-665.

128. Simons M: Angiogenesis, arteriogenesis, and diabetes: paradigm reassessed? J Am Coll Cardiol 2005;46:835-837.

129. Duh E, Aiello LP: Vascular endothelial growth factor and diabetes: the agonist versus antagonist paradox. Diabetes 1999;48:1899-1906.

130. Bir SC, Fujita M, Marui A, Hirose K, Arai Y, Sakaguchi H, Huang Y, Esaki J, Ikeda T, Tabata $Y$, Komeda M: New therapeutic approach for impaired arteriogenesis in diabetic mouse hindlimb ischemia. Circ J 2008;72:633-640.

131. Huang $Y$, Marui A, Sakaguchi $H$, Esaki J, Arai $Y$, Hirose K, Bir SC, Horiuchi $H$, Maruyama T, Ikeda T, Tabata Y, Komeda M: Sustained release of prostaglandin E1 potentiates the impaired therapeutic angiogenesis by basic fibroblast growth factor in diabetic murine hindlimb ischemia. Circ J 2008;72:1693-1699.

132. Facchiano F, D'Arcangelo D, Russo K, Fogliano V, Mennella C, Ragone R, Zambruno G, Carbone V, Ribatti D, Peschle C, Capogrossi MC, Facchiano A: Glycated fibroblast growth factor-2 is quickly produced in vitro upon low-millimolar glucose treatment and detected in vivo in diabetic mice. Mol Endocrinol 2006;20:2806-2818.

133. Marfella R, Esposito K, Nappo F, Siniscalchi M, Sasso FC, Portoghese M, Di Marino MP, Baldi A, Cuzzocrea S, Di Filippo C, Barboso G, Baldi F, Rossi F, D'Amico M, Giugliano D: Expression of angiogenic factors during acute coronary syndromes in human type 2 diabetes. Diabetes 2004;53:2383-2391.

134. Chen JX, Stinnett A: Ang-1 gene therapy inhibits hypoxia-inducible factor-1alpha (HIF1alpha)-prolyl-4-hydroxylase-2, stabilizes HIF-1alpha expression, and normalizes immature vasculature in db/db mice. Diabetes 2008;57:3335-3343.

135. Ceradini DJ, Yao D, Grogan RH, Callaghan MJ, Edelstein D, Brownlee M, Gurtner GC: Decreasing intracellular superoxide corrects defective ischemia-induced new vessel formation in diabetic mice. J Biol Chem 2008;283:10930-10938.

136. Taniyama Y, Morishita R, Hiraoka K, Aoki M, Nakagami H, Yamasaki K, Matsumoto K, Nakamura T, Kaneda $Y$, Ogihara T: Therapeutic angiogenesis induced by human hepatocyte growth factor gene in rat diabetic hind limb ischemia model: molecular mechanisms of delayed angiogenesis in diabetes. Circulation 2001;104:2344-2350.

137. Huang P, Li S, Han M, Xiao Z, Yang R, Han ZC: Autologous transplantation of granulocyte colony-stimulating factor-mobilized peripheral blood mononuclear cells improves critical limb ischemia in diabetes. Diabetes Care 2005;28:2155-2160. 
138. Cai WJ, Kocsis E, Luo X, Schaper W, Schaper J: Expression of endothelial nitric oxide synthase in the vascular wall during arteriogenesis. Mol Cell Biochem 2004;264:193200.

139. Park B, Hoffman A, Yang Y, Yan J, Tie G, Bagshahi H, Nowicki PT, Messina LM: Endothelial nitric oxide synthase affects both early and late collateral arterial adaptation and blood flow recovery after induction of hind limb ischemia in mice. J Vasc Surg 2009.

140. Brevetti LS, Chang DS, Tang GL, Sarkar R, Messina LM: Overexpression of endothelial nitric oxide synthase increases skeletal muscle blood flow and oxygenation in severe rat hind limb ischemia. J Vasc Surg 2003;38:820-826.

141. Kobayashi T, Taguchi K, Yasuhiro T, Matsumoto T, Kamata K: Impairment of PI3-K/Akt pathway underlies attenuated endothelial function in aorta of type 2 diabetic mouse model. Hypertension 2004;44:956-962.

142. Chen JX, Stinnett A: Disruption of Ang-1/Tie-2 signaling contributes to the impaired myocardial vascular maturation and angiogenesis in type II diabetic mice. Arterioscler Thromb Vasc Biol 2008;28:1606-1613.

143. Caporali A, Pani E, Horrevoets AJ, Kraenkel N, Oikawa A, Sala-Newby GB, Meloni M, Cristofaro B, Graiani G, Leroyer AS, Boulanger CM, Spinetti G, Yoon SO, Madeddu P, Emanueli C: Neurotrophin p75 receptor (p75NTR) promotes endothelial cell apoptosis and inhibits angiogenesis: implications for diabetes-induced impaired neovascularization in ischemic limb muscles. Circ Res 2008;103:e15-26.

144. Kadoglou NP, Daskalopoulou SS, Perrea D, Liapis CD: Matrix metalloproteinases and diabetic vascular complications. Angiology 2005;56:173-189.

145. Tayebjee MH, Lip GY, MacFadyen RJ: What role do extracellular matrix changes contribute to the cardiovascular disease burden of diabetes mellitus? Diabet Med 2005;22:1628-1635.

146. Cai X, Lin Y, Friedrich CC, Neville C, Pomerantseva I, Sundback CA, Zhang Z, Vacanti JP, Hauschka PV, Grottkau BE: Bone marrow derived pluripotent cells are pericytes which contribute to vascularization. Stem Cell Rev 2009;5:437-445.

147. Lerman OZ, Galiano RD, Armour M, Levine JP, Gurtner GC: Cellular dysfunction in the diabetic fibroblast: impairment in migration, vascular endothelial growth factor production, and response to hypoxia. Am J Pathol 2003;162:303-312.

148. van Royen N, Schirmer SH, Atasever B, Behrens CY, Ubbink D, Buschmann EE, Voskuil M, Bot P, Hoefer I, Schlingemann RO, Biemond BJ, Tijssen JG, Bode C, Schaper W, Oskam J, Legemate DA, Piek JJ, Buschmann I: START Trial: a pilot study on STimulation of ARTeriogenesis using subcutaneous application of granulocytemacrophage colony-stimulating factor as a new treatment for peripheral vascular disease. Circulation 2005;112:1040-1046.

149. Rajagopalan S, Mohler E, 3rd, Lederman RJ, Saucedo J, Mendelsohn FO, Olin J, Blebea J, Goldman C, Trachtenberg JD, Pressler M, Rasmussen H, Annex BH, Hirsch AT: Regional Angiogenesis with Vascular Endothelial Growth Factor (VEGF) in peripheral arterial disease: Design of the RAVE trial. Am Heart J 2003;145:1114-1118.

150. Gounis MJ, Spiga MG, Graham RM, Wilson A, Haliko S, Lieber BB, Wakhloo AK, Webster $\mathrm{KA}$ : Angiogenesis is confined to the transient period of VEGF expression that follows adenoviral gene delivery to ischemic muscle. Gene Ther 2005;12:762-771. 
151. Hayden MR, Tyagi SC: Vasa vasorum in plaque angiogenesis, metabolic syndrome, type 2 diabetes mellitus, and atheroscleropathy: a malignant transformation. Cardiovasc Diabetol 2004;3:1.

152. Shyu KG, Chang $H$, Wang BW, Kuan P: Intramuscular vascular endothelial growth factor gene therapy in patients with chronic critical leg ischemia. Am J Med 2003;114:85-92.

153. Senthilkumar A, Smith RD, Khitha J, Arora N, Veerareddy S, Langston W, Chidlow JH, Jr., Barlow SC, Teng X, Patel RP, Lefer DJ, Kevil CG: Sildenafil promotes ischemiainduced angiogenesis through a PKG-dependent pathway. Arterioscler Thromb Vasc Biol 2007;27:1947-1954. 
CHAPTER 2 


\section{ChAPTER 3}

\section{Impaired collateral recruitment}

and outward remodeling in experimental diabetes

Jolanda M. van Golde

Matthijs S. Ruiter

Nicolaas C. Schaper

Stefan Vöö

Johannes Waltenberger

Walter H. Backes

Mark J. Post

Maya S. Huijberts

Diabetes 2008;57(10):2818-23 


\section{Summary}

Objective - In this study, the effect of chronic hyperglycemia on acute ligation-induced collateral vasodilation, on monocyte chemotaxis, and on structural outward remodeling of collaterals was investigated.

Methods - Femoral artery ligation was performed 8 weeks after alloxan or saline treatment in New Zealand White rabbits. Angiography was performed directly, 1 and 3 weeks after ligation. These angiographic recordings were used to quantify number of collaterals, lumen, and blood volume index. Reactive hyperemia response was tested by intramuscular laser Doppler measurements. Subsequently, blood was sampled from the aorta for monocyte chemotaxis.

Results - Ligation resulted in markedly lower acute collateral vasodilation in diabetic compared with control rabbits. Also, hyperemic vasodilatory response to local ischemia was impaired in diabetic rabbits. This difference persisted at 1 and 3 weeks after ligation, with a lower number of visible collaterals. In addition, the collateral lumen was markedly lower in diabetic rabbits after the maturation phase. Likewise, a reduced blood volume index in the region of growing collaterals was observed in diabetic animals. The monocyte migration toward VEGF-A and monocyte chemotactic protein-1 was strongly reduced in diabetic rabbits.

Conclusions - This study demonstrates that chronic hyperglycemia negatively affects the different phases of arteriogenesis: 1) impaired shear induced vasodilatation; 2) impaired outward collateral growth, reflected in the number of collaterals and blood volume index; and 3) inhibition of monocyte chemotaxis. Impairments were most evident in the acute phase of arteriogenesis. Therapies aimed at restoring acute collateral recruitment, such as vasodilators, may be of interest to improve collateral function in DM. 


\section{Introduction}

Individuals with DM have a substantially increased risk (two- to fourfold) of developing ischemic cardiovascular events, with a poor prognosis after these events, ${ }^{1}$ as illustrated by an increased incidence of critical limb ischemia and lowerextremity amputation in diabetic individuals. ${ }^{2,3}$ This poor clinical

outcome may be caused by impaired compensatory responses in the setting of acute or chronic ischemia in DM, such as reduced vasodilation and delayed collateral remodeling. Cardiovascular disease places a high burden on economic reserves, medical capacities, and the quality of life in diabetic patients, stressing the importance of unraveling the underlying pathophysiological mechanisms to improve current therapies. ${ }^{4}$ Arteriogenesis, i.e., the acute recruitment (acute phase) and subsequent outward remodeling (remodeling phase) of collateral arteries, plays an important role in the adaptation to flow obstruction and tissue ischemia. ${ }^{5,6}$ During the occlusion of a conduit artery, often caused as a complication of atherosclerosis, blood flow is redirected through adjacent preexisting collaterals. In contrast to angiogenesis, which is initiated by ischemia, arteriogenesis occurs in regions of high-fluid shear stress. Prolonged elevated shear stress results in outward remodeling of a pre-existing collateral. ${ }^{7}$ Several studies have demonstrated the importance of increased levels of eNOS mRNA and protein in regions of increased shear stress. ${ }^{8,9}$ The increased NO release in regions of increased shear stress leads to the acute vasodilatory response of pre-existing collaterals and is critical for arteriogenesis. ${ }^{10}$ In diabetic subjects, this response may be impaired because of endothelial dysfunction reflected by impaired NO release and/or vasodilatory responses. ${ }^{11-13}$ Because vasodilation is the initial step of outward remodeling, impairments in this phase might be fundamental for impaired outward remodeling. Under conditions of prolonged increased shear stress, structural outward remodeling occurs and involves attraction and adherence of monocytes and the degradation of the extracellular matrix. ${ }^{14}$ In both diabetic animals and diabetic patients, impaired attraction of circulating cells ${ }^{15,16}$ and impaired collagenolysis have been described previously. ${ }^{17,18}$ In healthy animal models, therapeutic arteriogenesis by means of GFs has been demonstrated to stimulate outward remodeling of collateral vessels. ${ }^{19-22}$ However, therapeutic application of these GFs showed limited success in clinical phase II studies, which can in part be attributed to comorbidities in the patient population, such as DM. ${ }^{23}$ Although previous studies have demonstrated that outward remodeling may be impaired by hyperglycemia, ${ }^{18,24-26}$ little is known about disturbances in the acute vasodilation phase of the arteriogenesis process. We hypothesize that the diabetic 
state may induce significant disturbances in collateral development by impairment of both the acute and structural remodeling phase of arteriogenesis. The rabbit ischemic hind limb model has been used extensively in arteriogenesis research. In recent years, we have adapted this model to study collateral artery growth longitudinally in the same animal. ${ }^{27}$ The aim of the present study was to investigate the effect of experimental DM on both the acute and remodeling phases of collateral development in the ischemia hind limb model and the role of monocyte chemotaxis.

\section{Methods}

The present study was performed with the approval of the Animal Experimental Committee of our institution. Thirty-one New Zealand White rabbits were included and randomly assigned to receive either alloxan or saline injection (same volume as alloxan). Alloxan $(110 \mathrm{mg} / \mathrm{kg}$ ) was injected into the lateral ear vein to induce type 1-like DM in the rabbit. To prevent initial hypoglycemia, $10 \mathrm{ml} 5 \%$ glucose i.v. was injected after alloxan administration, and drinking water with $10 \%$ glucose was supplemented for the first $24 \mathrm{~h}$. Weight and blood glucose levels were determined on a weekly basis. Rabbits with blood glucose levels $<10 \mathrm{mmol} / \mathrm{l}(\mathrm{n}=$ 9) were excluded for further investigation. In a subset of these alloxan-treated rabbits $(n=4)$, blood glucose levels did not change and served as controls for alloxan side effects. Eight weeks after saline or alloxan injection, unilateral femoral artery ligation was performed in both diabetic $(n=10)$ and control rabbits $(n=$ $12)$. During the procedure, the rabbits were ventilated with isoflurane (2-3\%). The left femoral artery was ligated (day 0 ) under sterile conditions by placing two ligations ( $\sim 2 \mathrm{~cm}$ apart) distal to the branches of the circumflex artery and the deep femoral artery. The occlusion of a conductance artery causes blood flow redistribution through interconnecting (pre-existing) arterioles, which causes functional changes in the endothelium through activation of the shear stressresponsive element. ${ }^{28}$ Buprenorphine was given intramuscularly as postoperative analgesia and was continued twice a day for 2 days. During the 3-week follow-up period, no pressure sores or signs of gangrene were observed in the ligated limbs of either control or diabetic rabbits. Animals were killed by lethal bleeding.

\section{X-ray angiography}

Angiograms were performed in the same animal immediately (within $30 \mathrm{~min}$ ), 1 week, and 3 weeks after femoral artery ligation to monitor the remodeling of collaterals over time. Coronal X-ray angiography (XRA) series (12 frames per second) were obtained using a portable X-ray system (BV Pulsera; Philips Medical 
Systems, Best, the Netherlands) (in-plane resolution $300 \times 300 \mu \mathrm{m}$; field of view $220 \times 220 \mathrm{~mm}$; operated at tube voltage $72 \mathrm{kV}$ ). Bolus injections of a nonionic iodine contrast agent (Omnipaque; Amersham Health, Eindhoven, the Netherlands) ( $5 \mathrm{ml} / \mathrm{s} ; 240 \mathrm{mg}$ iodine $/ \mathrm{ml} ; 1.6 \mathrm{ml} / \mathrm{kg}$ body wt) were given through a catheter (4F) inserted via the carotid artery and placed $2-3 \mathrm{~cm}$ proximal to the abdominal aorta bifurcation. XRA films were digitally stored for offline analysis. The number of collaterals was counted by two independent observers as defined by Longland, ${ }^{29}$ which requires identification of the stem, midzone, and reentry zone. Angiographically visible collaterals were derived from three main vessels: the circumflex artery, the deep femoral artery, and the internal iliac artery. For the 3week time point, collaterals were categorized as smaller or larger than $600 \mu \mathrm{m}$ (pixel size $300 \mu \mathrm{m}$ ) in diameter.

\section{Quantitative subtraction angiography}

To address the importance of the luminal volume of collateral arteries, we developed and applied quantitative subtraction angiography. This method enables automated and observerindependent collateral artery growth quantification. To this end, computational software was developed in MATLAB (The Math Works, Natick, MA). Early precontrast frames of the angiographic time series, frame numbers 3-12 before contrast injection, were averaged to provide a noise-suppressed precontrast mask image ( $\mathrm{I}_{\text {pre }}$ ) on which all anatomic structures were depicted except the blood vessels. The frame with maximal contrast intensity of the collateral arteries was defined. Five frames above and below this maximal intensity frame were averaged to provide a noise-suppressed maximal contrast image $\left(I_{\max }\right)$. For signal analysis, the quantitative description by Bushberg et al. $^{30}$ was used. On the pertaining logarithmic subtraction images $\left(\mathrm{I}_{\mathrm{sub}}\right)$, the region of interest was manually drawn based on predefined landmarks in the adductor magnus muscle of the ligated limb in the direct surrounding of the occlusion. This is the site of collateral anastomoses derived from the deep femoral artery and the internal iliac artery, as depicted in figure 3.1. In this region of interest, the number of enhanced pixels (above noise level) due to collateral filling were quantified directly, 1 and 3 weeks after ligation. In addition, the signal intensities of the pixels in the subtraction angiogram were normalized to the maximal absolute signal intensity in the aorta to provide a measure of the blood volume as function of signal intensity relative to the aorta enhancement. The blood volume index is then defined as the sum of pixel intensities ( $\mathrm{I}_{\text {sub }}$ above noise level), normalized to the maximal aortic signal intensity in the subtraction images in the region of collateral growth. Reactive hyperemia response was tested 3 weeks after ligation in a subset of healthy $(n=5)$ and 
diabetic $(n=5)$ rabbits with intramuscular laser Doppler in the gastrocnemius muscle. An intramuscular laser Doppler needle probe was positioned in $\mathrm{m}$. gastrocnemius of the right limb, as described previously. ${ }^{31}$ Temperature and blood pressure were kept constant during the measurement period. Baseline laser Doppler measurements were started after a 20-min stabilization period. Subsequently, a vascular clamp was placed on the iliac artery and the iliac vein. After $10 \mathrm{~min}$, the clamp was released, and the reactive hyperemia response in terms of peak perfusion and time to peak could be assessed.

Monocyte chemotaxis analysis was performed ex vivo as previously described ${ }^{16} 3$ weeks after ligation. Briefly, blood-derived monocytes were isolated from $\sim 65 \mathrm{ml}$ whole blood obtained in heparinized tubes by arterial puncture just above the bifurcation of the iliac artery. Blood was layered onto Histopaque-1077 (Sigma), and the mononuclear interface was collected. Subsequently, monocytes were isolated from mononuclear cell fraction using a further gradient centrifugation. The collected monocytes were washed in PBS and resuspended in Dulbecco's modified Eagle's medium (Biochrom). The number of isolated monocytes was counted by light microscopy using a Neubauer chamber. The vitality of the isolated monocytes was assessed by trypan blue exclusion; routinely, this was $>72 \%$. Monocyte chemotaxis was quantified using a modified 48-well Boyden chamber (Nuclepore). The chemoattractants VEGF-A (1 ng/ml) (Reliatech), MCP-1 (30 ng/ml) (Reliatech), or formylMetLeuPhe (fMLP) $\left(10^{-8} \mathrm{~mol} / \mathrm{l}\right)$ (Sigma) were added to the lower chamber. The monocyte suspension ( $5 \times 10^{5}$ cells $/ \mathrm{ml}$ ) was added to the upper chamber, which was separated from the lower chamber by a $5-\mu \mathrm{m}$-pore size polycarbonate membrane (Nuclepore). After incubation for $1.5 \mathrm{~h}$ at $37^{\circ} \mathrm{C}$ in a $5 \% \mathrm{CO}_{2}$ atmosphere, adherent cells on the filter membrane were fixed in $99 \%$ ethanol for $10 \mathrm{~min}$ and stained using Giemsa dye. The upper side of the polycarbonate membrane was scraped to remove the nonmigrated cells. The migrated cells adhering to the lower side of the membrane were counted in five high-power fields and in three different wells using light microscopy.

\section{Capillary-to-fiber ratio}

Immediately after the lethal bleeding, 3 weeks after ligation, the tibialis and soleus muscle were dissected from the lower limb, from both the ligated and the contralateral side. Cryosections $(10 \mu \mathrm{m})$, cut perpendicular to the muscle fiber direction, were stained using nitroblue tetrazolium/5 bromo-4-chloro-3indolylphosphate-p-toluidine salt (Gibco, Grand Island, NY) of alkaline phosphatase in ECs. The ratio of capillary to fiber was scored in three randomly selected optic fields in each muscle section. 


\section{Statistical analysis}

All results are expressed as median and interquartile range, except data from subtraction angiography and the capillary-to-fiber ratio, which are expressed as mean and SE. Differences in the glucose levels, total number of collaterals, collateral lumen, blood volume index, and monocyte migration function of control and diabetic rabbits were compared by the Mann-Whitney two-tailed test. The level of statistical significance was set at $P<0.05$.
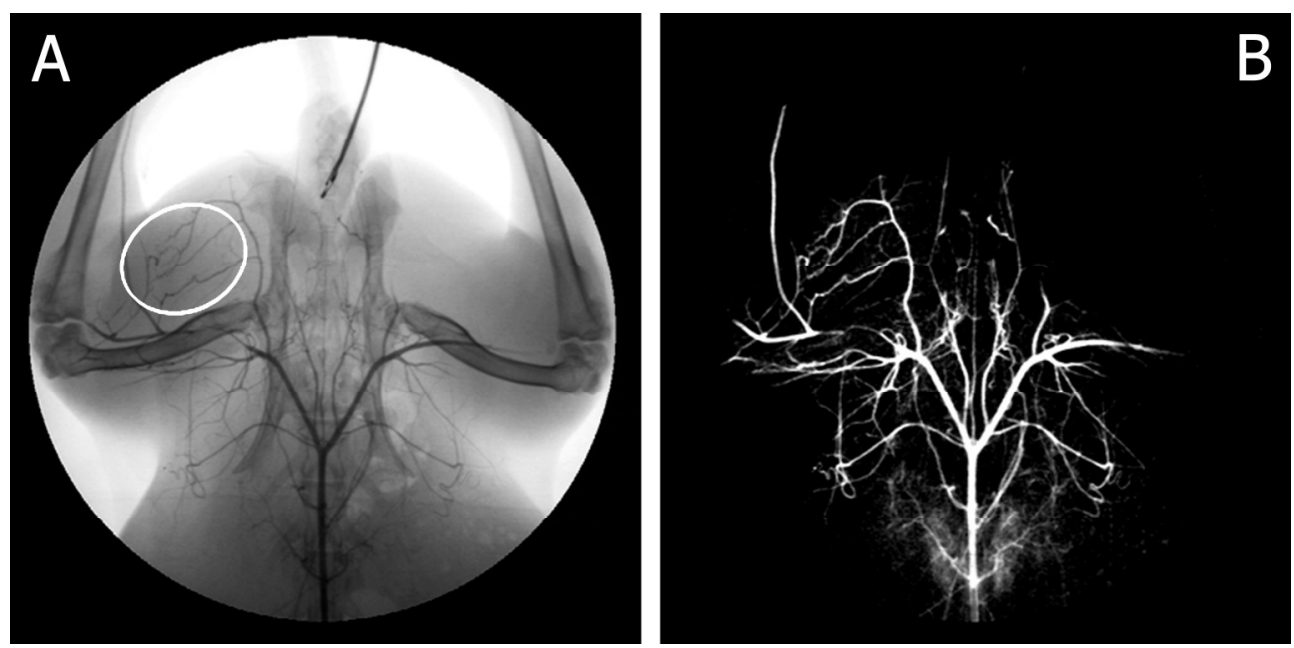

FIGURE 3.1

Representative X-ray angiogram 3 weeks after ligation (A) and corresponding postsubtraction angiogram (B). The circle indicates the region of interest in the ligated limb.

\section{Results}

\section{Animal model}

Glucose levels in rabbits that received alloxan increased after 2 days, reached a steady state within 1 week, and remained elevated until the rabbits were killed. Glucose levels were significantly increased in the diabetic rabbits compared with the controls: 23.2 (17.7-30.3) and 6.55 (6.2-7.6) $\mathrm{mmol} / \mathrm{l}$, respectively. Body weight at the end of the study was not different between the diabetic and control animals: $3.2(3-3.5)$ and $3.1(3.0-3.2) \mathrm{kg}$, respectively. Rabbits treated with alloxan without any effects on glucose levels showed responses similar to the untreated rabbits (data not shown). 


\section{$\mathrm{X}$-ray angiography}

\section{Number of collaterals}

Immediately after ligation ( 0 weeks), no collateral recruitment in diabetic rabbits was observed (figure 3.2), whereas in healthy animals, $6.5(5-7.75 ; P=0.0001$ ) collaterals were counted. One week after ligation, the number of collaterals was $30 \%$ lower in diabetic than control rabbits: 10 (8.5-11.5) versus 13 (10.25-14.0; P $=0.058)$ collaterals, respectively. Three weeks after ligation, a significantly lower number of collaterals was observed in diabetic rabbits, 10 (9.5-12.0), compared with controls, $13.5(11.25-14 ; \mathrm{P}=0.026)$.

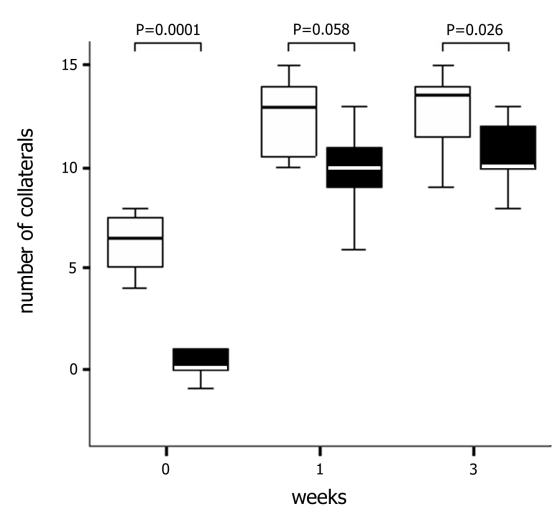

\section{FIGURE 3.2}

Number of collaterals in the left limb immediately, 1 week and 3 weeks after ligation. The $\mathrm{p}$-values between diabetic rabbits (black boxes) and controls (white boxes) are presented at different time points. Values are represented as median (bolded line), 25-75 percentiles (box) and 5-95 percentiles (whiskers).

\section{Size of collaterals}

In diabetic animals, the size of the collaterals was smaller than in controls (figure 3.3; data are expressed as percentage of total number of collaterals). Three weeks after ligation, only $12.5 \%(0-26)$ of collaterals in diabetic animals was $>600 \mu \mathrm{m}$. In the control group, this percentage was markedly higher, $43 \%(30-50)(P=$ $0.002)$.

\section{Quantitative subtraction angiography}

Subtraction angiography in the region of remodeling collaterals showed less enhanced pixels in the tissues of diabetic rabbits than controls, suggesting a reduction in blood volume (figure 3.4). In the control group, the number of enhanced pixels increased significantly within 1 week, in contrast to the diabetic rabbits, which showed a significant increase only at 3 weeks after ligation. Diabetic rabbits had a markedly lower blood volume index than controls; values were $57 \%$ lower directly after ligation $(P=0.030), 61 \%$ after 1 week $(P=0.004)$, and $45 \%$ after 3 weeks $(P=0.045)$. 


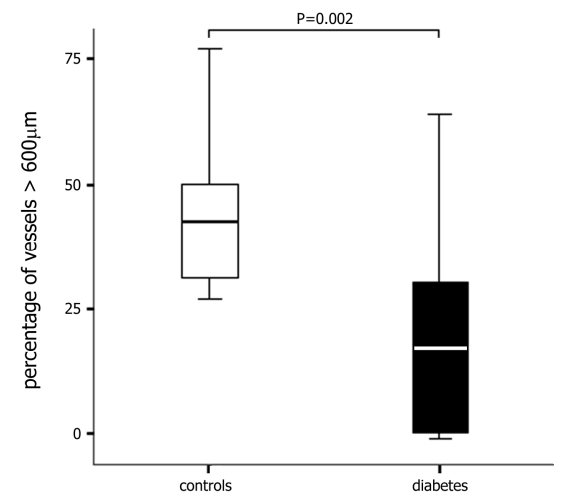

\section{FIGURE 3.3}

Percentage of collaterals with a lumen larger than $600 \mu \mathrm{m}$ in the ligated $\operatorname{limb} 3$ weeks after ligation. The diabetic rabbits (black boxes) had a significantly lower percentage of collaterals larger than 600 $\mu \mathrm{m}$ than the control rabbits (white boxes). Values are represented as median (bolded line), 25-75 percentiles (box) and 5-95 percentiles (whiskers).

\section{Reactive hyperemia}

Impaired vasodilatory response in diabetic rabbits was confirmed by reactive hyperemia experiments, performed in a subset of rabbits (four controls and four diabetic rabbits). The peak perfusion, based on microvascular vasodilation capacity, ${ }^{31}$ occurred within $2 \mathrm{~s}$ in control animals and was completely absent in diabetic rabbits.

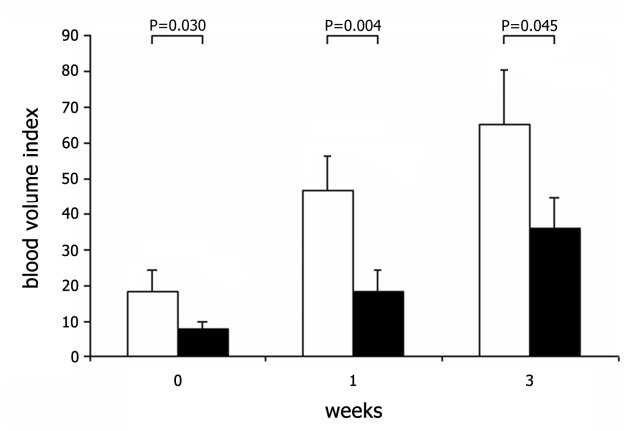

\section{Monocyte chemotaxis}

In figure 3.5, the migratory response of monocytes toward two different growth factors (VEGF-A and MCP-1) and the chemoattractant peptide FMLP as a positive control are shown (data are expressed as a percentage of unstimulated monocytes). In control animals, VEGF-A and MCP-1 induced a strong chemotactic response in monocytes. VEGF-A-induced migration of monocytes was twofold lower in diabetic rabbits compared with controls $(P=0.019)$. The same was observed for MCP-1 stimulation ( $P=0.028$ ). No difference between controls and diabetic rabbits was observed in the $\mathrm{fMLP}$-induced migratory response. Capillary- 
to-fiber ratio. In the contralateral limb, capillary-to-fiber ratios were higher in the soleus muscle than in the anterior tibialis muscle: $2.57 \pm 0.14$ and $1.98 \pm 0.13$ (mean ratio $\pm \mathrm{SE}$ ), respectively. Hyperglycemia did not affect the capillary-to-fiber ratios in the tibialis and soleus muscle in the contralateral limb. Three weeks after ligation, the ratios were similar to baseline levels, indicating that neither ligation nor hyperglycemia had an effect on capillary-to-fiber ratio.

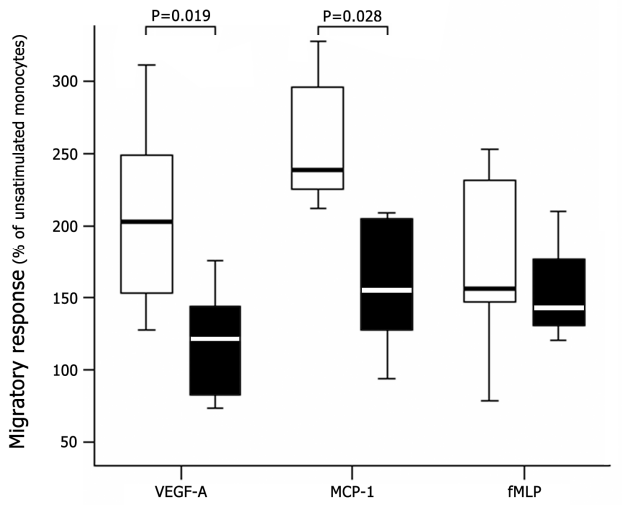

\section{FigURE 3.5}

Chemotactic response of monocytes towards VEGF-A (10 ng/ml), MCP-1 (10 $\mathrm{ng} / \mathrm{ml})$ and $\mathrm{fMLP}(10-8 \mathrm{M})$ gradient. Monocytes were isolated from either diabetic (black boxes) or control rabbits (white boxes). Data are presented as median (bolded line), 25-75 percentiles (box) and 5-95 percentiles (whiskers).

\section{Discussion}

Pre-existing collaterals provide an alternative way of blood supply to a region distal to an arterial occlusion. ${ }^{32}$ Progressive occlusion of a conductance artery due to atherosclerosis results in sustained blood flow redistribution through these collaterals, thereby triggering these vessels to increase their lumen (acute vasodilation) and express adhesion molecules and attracting factors that ultimately lead to structural outward remodeling of the pre-existing collateral artery. ${ }^{19,33}$ This study demonstrates that chronic hyperglycemia negatively affects the acute phase of the arteriogenic process. Both shear-induced vasodilatation and monocyte migration were impaired in diabetic rabbits. In addition, we observed impaired outward collateral growth in diabetic rabbits, as reflected by the number of collaterals and the blood volume index in the region of remodeling collaterals compared with nondiabetic animals.

The most prominent differences between healthy and diabetic rabbits were observed in the acute phase of the arteriogenic process. Angiography showed a rapid recruitment of pre-existing collateral arteries directly after ligation in healthy rabbits in contrast to the diabetic rabbits. In addition, the postocclusive reactive hyperemic vasodilatory response was impaired in our diabetic animals. In the contralateral limb, pre-existing collaterals were not visible in either the diabetic or 
the nondiabetic animals. These data concur with earlier studies that showed that impaired flow mediated vasodilation or postocclusive reactive hyperemic vasodilatory response in DM. ${ }^{34,35}$ The defect in collateral recruitment could also have been caused by an impaired runoff secondary to a decrease in capillary-tofiber ratio. However, we did not observe an effect of chronic hyperglycemia on baseline capillary-tofiber ratio nor were there any differences in this ratio 3 weeks after ligation. The current study is, to our knowledge, one of the first to show an impaired immediate recruitment of pre-existing collaterals in DM. Both shearmediated vasodilation and reactive hyperemia (in part) are mediated by NO. Because shear stress-induced vasodilation is postulated to be the initiation step of arteriogenesis, loss of this vasodilatory response might contribute to the poorer outcome after occlusion of a conduit artery in the case of DM. Our assumption that impaired recruitment has detrimental effects on collateral growth is confirmed by the work of $\mathrm{Yu}$ et al. $^{36}$ who demonstrated impaired contraction-stimulated hyperemia and impaired arteriogenesis in an eNOS knockout mouse model. One of the main pathways responsible for vasodilation after high-fluid shear stress is the Akt-eNOS pathway. ${ }^{37,38}$ An explanation for the impaired vasodilation response in pre-existing collaterals to increased shear stress in diabetic rabbits, as observed in this study, might be the impaired eNOS activation and NO generation ${ }^{39}$ by mechanisms such as inhibition of phosphorylation of PI3K and Akt and peroxynitrite generation by hyperglycemia. ${ }^{40}$ Besides the adverse effects of DM on vasomotor tone regulation, mechanotransduction and expression of vasoactive proteins might also be affected by hyperglycemia. Further studies are necessary to elucidate the exact role and underlying defect in the impaired shear stress sensing in pre-existing collaterals that results in impaired outward remodeling. Sustained shear stress leads to activation of the collateral ECs. Subsequently, monocyte recruitment and adhesion to activated endothelium occur. The migrated monocytes mature into macrophages and release different GFs important in outward remodeling of the collateral. In this study, the impaired migratory response of monocytes toward VEGF-A and MCP-1 gradient in diabetic rabbits confirms the results described previously in clinical studies. ${ }^{16}$ The inhibitory effects of hyperglycemia on monocyte function might also be explained by an impaired signaling downstream the VEGF receptor. ${ }^{41}$ Also for the migration toward VEGF, impaired eNOS signaling has been shown in endothelial progenitor cells derived from diabetic patients. ${ }^{15}$

Previous studies on arteriogenesis focused on postmortem angiograms and/or hemodynamic measurements. We introduced the technique of serially obtained in vivo angiograms. ${ }^{27}$ Both number and lumen of collaterals were increased directly 
after ligation up to 21 days after ligation in control rabbits, but this process was significantly impaired in diabetic rabbits. These findings agree with a previous report showing a significantly lower angiographic score in the diabetic ischemic mice model. ${ }^{18,26}$ The quantification of the collateral lumen and grading of collateral filling based on the commonly used Rentrop classification is subjective. We have applied subtraction angiography to quantify the blood volume index in the region of collateral growth. Advantages of our quantitative subtraction angiography are the operator-independent analyses and the quantitative values. The disadvantage of this method is that no absolute blood volume or flow values are derived. For several reasons we preferred this method above other blood flow analyses. First, blood volume index is a measure of collateral-dependent full-thickness limb perfusion, and unlike laser Doppler imaging, it is not limited to superficial tissues. It is assumed that superficial and deep perfusion are correlated and recovery of skin perfusion in diabetic ischemic mice is significantly impaired. ${ }^{18,26}$ However, this correlation has never been tested. Second, the angiographic method allows longitudinal follow-up, which is a major advantage over the accurate but destructive methods required for microspheres or collateral conductance measurements. On our subtraction angiograms, the blood volume index was derived from the first pass of the contrast medium, which is directly related to the blood flow. The subtraction analysis showed a significant difference in blood volume index between diabetic and control rabbits directly after ligation (acute phase) and during the remodeling phase of arteriogenesis. In summary, we conclude that the number of collaterals and the blood volume index are important contributing factors to the blood perfusion recovery distal to the occlusion and are valuable measures to quantify the level of collateral growth.

The current study results emphasize the importance of shear-induced vasodilation of pre-existing collaterals in arteriogenesis. If we seek to restore the impaired collateral remodeling in diabetic subjects, we hypothesize that improvement of shear-induced collateral recruitment by suitable vasodilators might show benefit. The importance of $\mathrm{NO}$ in the arteriogenic process has already been described by Yang et al. ${ }^{10}$ In addition, it has been described that NO is critical for effective therapeutic arteriogenesis achieved by delivery of exogenous GFs (e.g., VEGF and fibroblast growth factor-2). ${ }^{42}$ Future studies should give us a better understanding of the impairment in the PKA/Akt-eNOS pathway in diabetic subjects. Selection of a vasodilator candidate that bypasses the impaired signaling level might open new methods of therapeutic arteriogenesis in diabetic patients by restoring the impaired recruitment of collaterals but also monocyte chemotaxis and GF signaling. 


\section{Acknowledgments}

This study was supported in part by the Cardiovascular Research Institute Maastricht. We thank Eline van den Burg for technical assistance. 


\section{References}

1. Miettinen H, Lehto S, Salomaa V, Mahonen M, Niemela M, Haffner SM, Pyorala K, Tuomilehto J, The FINMONICA Myocardial Infarction Register Study Group: Impact of diabetes on mortality after the first myocardial infarction. Diabetes Care 1998;21:6975.

2. Prompers $L$, Huijberts $M$, Apelqvist J, Jude E, Piaggesi A, Bakker K, Edmonds $M$, Holstein $P$, Jirkovska A, Mauricio D, Tennvall GR, Reike H, Spraul M, Uccioli L, Urbancic V, Van Acker K, Van Baal J, Van Merode F, Schaper N: Optimal organization of health care in diabetic foot disease: introduction to the Eurodiale study. Int J Low Extrem Wounds 2007;6:11-17.

3. Schaper NC, Nabuurs-Franssen MH, Huijberts MS: Peripheral vascular disease and type 2 diabetes mellitus. Diabete Metab Res Rev 2000;16(Suppl. 1):S11-S15.

4. Ragnarson Tennvall G, Apelqvist J: Health-economic consequences of diabetic foot lesions. Clin Infect Dis 2004;39(Suppl. 2):S132-S139.

5. Hoefer IE, van Royen N, Buschmann IR, Piek JJ, Schaper W: Time course of arteriogenesis following femoral artery occlusion in the rabbit. Cardiovasc Res 2001;49:609-617.

6. Van Royen N, Piek JJ, Schaper W, Bode C, Buschmann I: Arteriogenesis: mechanisms and modulation of collateral artery development. J Nucl Cardiol 2001;8:687- 693.

7. Buschmann I, Schaper W: Arteriogenesis versus angiogenesis: two mechanisms of vessel growth. News Physiol Sci 1999;14:121-125.

8. Poppa V, Miyashiro JK, Corson MA, Berk BC: Endothelial NO synthase is increased in regenerating endothelium after denuding injury of the rat aorta. Arterioscler Thromb Vasc Biol 1998;8:1312-1321.

9. Sessa WC: The nitric oxide synthase family of proteins. J Vasc Res 1994;31:131-143

10. Yang HT, Ren J, Laughlin MH, Terjung RL: Prior exercise training produces NOdependent increases in collateral blood flow after acute arterial occlusion. Am J Physiol Heart Circ Physiol 2002;282:H301-H310.

11. Endemann DH, Schiffrin EL: Endothelial dysfunction. J Am Soc Nephrol 2004;15:19831992.

12. Schalkwijk CG, Stehouwer CD: Vascular complications in diabetes mellitus: the role of endothelial dysfunction. Clin Sci (Lond) 2005;109:143-159.

13. Schaper NC: Early atherogenesis in diabetes mellitus. Diabet Med 1996;13(Suppl. 1):S23-S25.

14. Scholz D, Ito W, Fleming I, Deindl E, Sauer A, Wiesnet M, Busse R, Schaper J, Schaper $\mathrm{W}$ : Ultrastructure and molecular histology of rabbit hind-limb collateral artery growth (arteriogenesis). Virchows Arch 2000;436:257-270.

15. Segal MS, Shah R, Afzal A, Perrault CM, Chang K, Schuler A, Beem E, Shaw LC, Li Calzi $\mathrm{S}$, Harrison JK, Tran-Son-Tay R, Grant MB: Nitric oxide cytoskeletal-induced alterations reverse the endothelial progenitor cell migratory defect associated with diabetes. Diabetes 2006;55:102-109.

16. Waltenberger J, Lange J, Kranz A: Vascular endothelial growth factor-Ainduced chemotaxis of monocytes is attenuated in patients with diabetes mellitus: a potential 
predictor for the individual capacity to develop collaterals. Circulation 2000;102:185190.

17. McLennan SV, Kelly DJ, Schache M, Waltham M, Dy V, Langham RG, Yue DK, Gilbert RE: Advanced glycation end products decrease mesangial cell MMP-7: a role in matrix accumulation in diabetic nephropathy? Kidney Int 2007;72:481-488.

18. Tamarat R, Silvestre JS, Huijberts M, Benessiano J, Ebrahimian TG, Duriez M, Wautier MP, Wautier JL, Levy BI: Blockade of advanced glycation end-product formation restores ischemia-induced angiogenesis in diabetic mice. Proc Natl Acad Sci U S A 2003;100:8555-8560.

19. Heil M, Ziegelhoeffer T, Wagner S, Fernandez B, Helisch A, Martin S, Tribulova S, Kuziel WA, Bachmann G, Schaper W: Collateral artery growth (arteriogenesis) after experimental arterial occlusion is impaired in mice lacking CC-chemokine receptor-2. Circ Res 2004;94:671-677.

20. Ito WD, Arras M, Winkler B, Scholz D, Schaper J, Schaper W: Monocyte chemotactic protein-1 increases collateral and peripheral conductance after femoral artery occlusion. Circ Res 1997;80:829-837.

21. Pipp F, Heil M, Issbrucker K, Ziegelhoeffer $T$, Martin $S$, van den Heuvel J, Weich $H$, Fernandez B, Golomb G, Carmeliet P, Schaper W, Clauss M: VEGFR-1-selective VEGF homologue PIGF is arteriogenic: evidence for a monocyte-mediated mechanism. Circ Res 2003;92:378-385.

22. van Royen N, Hoefer I, Buschmann I, Heil M, Kostin S, Deindl E, Vogel S, Korff T, Augustin $\mathrm{H}$, Bode $\mathrm{C}$, Piek JJ, Schaper W: Exogenous application of transforming growth factor beta 1 stimulates arteriogenesis in the peripheral circulation. FASEB J 2002;16:432-434.

23. Epstein SE, Kornowski R, Fuchs S, Dvorak HF: Angiogenesis therapy: amidst the hype, the neglected potential for serious side effects. Circulation 2001;104:115-119.

24. Abaci A, Oguzhan A, Kahraman S, Eryol NK, Unal S, Arinc H, Ergin A: Effect of diabetes mellitus on formation of coronary collateral vessels. Circulation 1999;99:2239-2242.

25. De Vivo S, Palmer-Kazen U, Kalin B, Wahlberg E: Risk factors for poor collateral development in claudication. Vasc Endovascular Surg 2005;39:519-524.

26. Rivard A, Silver M, Chen D, Kearney M, Magner M, Annex B, Peters K, Isner JM: Rescue of diabetes-related impairment of angiogenesis by intramuscular gene therapy with adeno-VEGF. Am J Pathol 1999;154:355-363.

27. de Lussanet QG, van Golde JC, Beets-Tan RG, de Haan MW, Zaar DV, Post MJ, Huijberts MS, Schaper NC, van Engelshoven JM, Backes WH: Magnetic resonance angiography of collateral vessel growth in a rabbit femoral artery ligation model. NMR Biomed 2006;19:77-83.

28. Ito WD, Arras M, Scholz D, Winkler B, Htun P, Schaper W: Angiogenesis but not collateral growth is associated with ischemia after femoral artery occlusion. Am J Physiol 1997;273:H1255-H1265.

29. Longland CJ: Collateral circulation in the limb. Postgrad Med J 1953;29:456-458.

30. Bushberg JT, Seibert JA, Leidholdt EM Jr, Boone JM: Adjuncts to radiology. In The Essential Physics of Medical Imaging. 2nd ed. Philadelphia, PA, Lippincott Williams \& Wilkins 2001, 321-323. 
31. Leahy MJ, de Mul FF, Nilsson GE, Maniewski R: Principles and practice of the laserDoppler perfusion technique. Technol Health Care 1999;7:143-162.

32. Levin DC: Pathways and functional significance of the coronary collateral circulation. Circulation 1974;50:831-837.

33. Schaper W, Scholz D: Factors regulating arteriogenesis. Arterioscler Thromb Vasc Biol 2003;23:1143-1151.

34. Sorensen VR, Mathiesen ER, Clausen P, Flyvbjerg A, Feldt-Rasmussen B: Impaired vascular function during short-term poor glycaemic control in type 1 diabetic patients. Diabet Med 2005;22:871-876.

35. Poredos P, Kek Ljubec A, Poredos P, Visnovic Poredos A: Endothelial dysfunction predictor of structural changes of arterial wall in type I diabetes. Int Angiol $2006 ; 25: 280-286$.

36. Yu J, deMuinck ED, Zhuang Z, Drinane M, Kauser K, Rubanyi GM, Qian HS, Murata T, Escalante B, Sessa WC: Endothelial nitric oxide synthase is critical for ischemic remodeling, mural cell recruitment, and blood flow reserve. Proc Natl Acad Sci U S A 2005;102:10999-11004

37. Eitenmuller I, Volger O, Kluge A, Troidl K, Barancik M, Cai WJ, Heil M, Pipp F, Fischer S, Horrevoets AJ, Schmitz-Rixen T, Schaper W: The range of adaptation by collateral vessels after femoral artery occlusion. Circ Res 2006;99:656-662.

38. Pipp F, Boehm S, Cai WJ, Adili F, Ziegler B, Karanovic G, Ritter R, Balzer J, Scheler C, Schaper W, Schmitz-Rixen T: Elevated fluid shear stress enhances postocclusive collateral artery growth and gene expression in the pig hind limb. Arterioscler Thromb Vasc Biol 2004;24:1664-1668.

39. Brownlee M: Biochemistry and molecular cell biology of diabetic complications. Nature 2001;414:813-820.

40. Varma S, Lal BK, Zheng R, Breslin JW, Saito S, Pappas PJ, Hobson RW II, Duran WN: Hyperglycemia alters PI3k and Akt signaling and leads to endothelial cell proliferative dysfunction. Am J Physiol Heart Circ Physiol 2005;289:H1744-H1751.

41. Waltenberger J: Growth factor signal transduction defects in the cardiovascular system. Cardiovasc Res 2005;65:574-580.

42. Matsunaga T, Warltier DC, Weihrauch DW, Moniz M, Tessmer J, Chilian WM: Ischemiainduced coronary collateral growth is dependent on vascular endothelial growth factor and nitric oxide. Circulation 2000;102:3098-3103. 


\section{CHAPTER 3}




\section{CHAPTER 4}

\section{Experimental diabetes impairs}

soluble guanylate cyclase function

in hindlimb collateral arteries

Matthijs S. Ruiter

Maya S. Huijberts

Nicolaas C. Schaper

Pieter Lemkens

Jo G. De Mey

Jolanda M. van Golde

Submitted 


\section{Summary}

Objective - Collateral artery function is an important determinant of PAD outcome in diabetes. DM impairs recruitment and remodeling of collateral arteries. The present study aims to determine the effect of DM on hindlimb collateral artery vasodilatation.

Methods - Hindlimb collaterals were isolated from the adductor magnus muscle of 10 control and 14 diabetic NZW rabbits. In a myograph, segments were contracted with either phenylephrine or $\mathrm{K}^{+}$. In absence and presence of indomethacin, L-NAME and ODQ vessels were relaxed with acetylcholine, SNP, Bay41-2272 or sildenafil. cGMP content was determined in homogenized tissue.

Expression of SGC and PKG was determined by Western blot.

Results - In absence $(P=0.03)$ and presence $(P=0.03)$ of L-NAME, DM attenuated sensitivity to SNP compared with controls. Similarly, sensitivity to Bay41-2272 was decreased in diabetic arteries both in absence $(P=0.01)$ and presence of $L-N A M E(P=0.02)$. Sensitivity to sildenafil was not affected by DM. No significant differences in acetylcholine-induced relaxation were observed. cGMP production was $16 \%$ lower in diabetic vessels, and expression of $\mathrm{sGC} \alpha 1(\mathrm{P}=0.04)$ and $\mathrm{PKG} 1 \beta$ $(P=0.01)$ was decreased.

Conclusions - Experimental DM impairs SMC function in rabbit hindlimb collateral arteries, suggesting that therapeutic intervention in diabetic arteriogenesis should aim at vascular smooth muscle cells, particularly the sGC/PKG system. 


\section{Introduction}

DM is recognized as a major cardiovascular risk factor. In the DM population, PAD is a common vascular complication, and DM increases the risk of developing PAD at least twofold. ${ }^{1-3}$ Patients suffering from both DM and PAD exhibit poor lower extremity function and are at risk for developing critical limb ischemia, foot ulceration, and amputation. ${ }^{1,4}$

In addition to the enhanced risk of developing PAD and the unfavorable prognosis, adaptive responses to blood flow obstruction are limited. DM attenuates both the acute recruitment and the functional outward remodeling of pre-existing collateral arterioles. This has been demonstrated in in the coronary circulation ${ }^{4,5}$ as well as in the lower extremities. ${ }^{6,7}$ The mechanisms for this impaired acute response are not well understood. Several conditions associated with DM can affect vascular function, including inflammation, endothelial activation, oxidative stress and increased formation of AGEs. ${ }^{8,9}$ In experimental models, endothelial function was shown to be affected by DM. The effect of DM on the endothelium differs between animal models, and is dependent on disease duration. ${ }^{10,11}$ High glucose levels seem to acutely increase endothelium-dependent vasodilatation, whereas chronic exposure to high glucose leads to impaired endothelium-dependent dilatation. ${ }^{11,12}$ An important factor in endothelial function is nitric oxide (NO), which is decreased by DM. ${ }^{10} \mathrm{NO}$ is a potent vasodilator, and responsible for endothelium-dependent vasodilatation together with endothelium-derived EDHF and prostacyclin $\left(\mathrm{PGl}_{2}\right)$. The relative importance of these pathways varies with vessel size, vascular bed, and gender. ${ }^{13-15}$

It is presently unclear how vasodilatation is regulated in hindlimb collateral arteries. A better understanding of vasoreactivity of peripheral collateral arteries in both health and disease is needed to develop more effective therapies for PAD. The aim of the present study is to determine the effect of experimental DM on hindlimb collateral vasoreactivity. We hypothesize that DM impairs NO-dependent vasodilatation in hindlimb collateral arteries.

\section{Materials and methods}

\section{Animal model}

Animal experiments were conducted after approval of the ethical committee of the Maastricht University Medical Centre. Hindlimb collateral vessels from 14 DM and 10 healthy New Zealand White rabbits $(2.5-3.5 \mathrm{~kg})$ were used. DM was induced 
by injection of $105 \mathrm{mg} / \mathrm{kg}$ alloxan monohydrate, and blood glucose was subsequently monitored for 8 weeks, as described before. ${ }^{7}$ Alloxan-treated animals with mean blood glucose levels below $10 \mathrm{mM}$ were excluded from the study. After 8 weeks of chronic hyperglycemia, animals were euthanized by cerebral dislocation under anasthesia induced with ketamine $(50 \mathrm{mg} / \mathrm{kg}$ ) and xylazine $(5 \mathrm{mg} / \mathrm{kg})$. Collateral arteries, defined as the tertiary branches of the arteria femoralis profunda, with a diameter between 200 and $250 \mu \mathrm{m}$, were rapidly isolated from the adductor magnus muscle. Venous blood samples were collected prior to sacrifice.

\section{Isometric tension recording}

Vessel segments freed of surrounding tissue were mounted on two stainless steel wires (40 $\mu \mathrm{m}$ diameter, Danish Myo Technology, Aarhus, Denmark) in a myograph organ chamber (Danish Myo Technology) between an isometric force transducer and a micropositioner. Chambers were filled with Krebs-Ringer bicarbonate solution (KRB: $118.5 \mathrm{mM} \mathrm{NaCl}, 4.7 \mathrm{mM} \mathrm{KCl}, 2.5 \mathrm{mM} \mathrm{CaCl}_{2}, 1.2 \mathrm{mM} \mathrm{MgSO}_{4}, 1.2 \mathrm{mM} \mathrm{KH}_{2} \mathrm{PO}_{4}$, $25.0 \mathrm{mM} \mathrm{NaHCO}$, and $5.5 \mathrm{mM}$ glucose), heated to $37^{\circ} \mathrm{C}$ and aerated $\left(95 \% \mathrm{O}_{2}, 5 \%\right.$ $\mathrm{CO}_{2}$ ). High $\mathrm{K}^{+}$solution (125 mM K-KRB) to induce contraction, was composed of $\mathrm{KRB}$ in which $\mathrm{NaCl}$ was replaced by $\mathrm{KCl}$. High glucose solution to determine the acute effects of glucose, consisted of KRB with $20 \mathrm{mM}$ glucose. After calibration, vessels were stretched to $90 \%$ of the internal circumference corresponding to a transmural pressure of $100 \mathrm{mmHg}$ using the procedure of Halpern and Mulvany. ${ }^{16}$ Viability of the endothelium was confirmed with ACh during contraction induced with phenylephrine (PHE). Vessel segments displaying less than $50 \%$ relaxation were replaced.

\section{Endothelium-dependent vasoreactivity}

To determine the role of the endothelium, ACh-induced relaxation $\left(10^{-8}\right.$ to $\left.10^{-4} \mathrm{M}\right)$ was determined during contraction induced by $10^{-4} \mathrm{M}$ PHE or by $32.5 \mathrm{mM} \mathrm{K}$, prepared by mixing appropriate volumes of KRB and K-KRB. To determine the role of $\mathrm{NO}$ in vasodilatation, the $\mathrm{ACh}$ concentration-response relationship was established during PHE-induced contraction in absence and presence of the NO synthase inhibitor L-NAME $\left(10^{-4} \mathrm{M}\right.$, incubation 30 minutes). By inducing contraction with $\mathrm{K}^{+}$, the EDHF pathway was inhibited. The $\mathrm{PGl}_{2}$ pathway was blocked with the cyclo-oxygenase inhibitor indomethacin (INDO, $10^{-5} \mathrm{M}$, incubation 20 minutes). 


\section{Endothelium-independent vasoreactivity}

Sensitivity to NO was investigated with the NO donor SNP $\left(10^{-8}\right.$ to $\left.10^{-5} \mathrm{M}\right)$ during $\mathrm{K}^{+}$-induced contraction in the presence of INDO, both in absence and presence of L-NAME. Soluble guanylate cyclase (sGC) function was determined with the sGC stimulator Bay41-2272 $\left(10^{-9}\right.$ to $\left.10^{-6} \mathrm{M}\right)$ during depolarization-induced contraction in the presence of INDO, in absence and presence of L-NAME and in absence and presence of the selective $\mathrm{SGC}$ blocker ODQ $\left(10^{-5} \mathrm{M}\right.$, incubation 30 minutes). Finally, the role of phosphodiesterase type 5 (PDE5) was investigated with the PDE5 inhibitor sildenafil $\left(10^{-8}\right.$ to $\left.10^{-5} \mathrm{M}\right)$ during $\mathrm{K}^{+}$-induced contraction in the presence of INDO, in absence and presence of L-NAME and ODQ. In addition, to determine the acute effects of hyperglycemia, experiments in both DM and control vessels were conducted during high glucose incubation $(20 \mathrm{mM}) \mathrm{KRB}$ for 30 minutes. All chemicals were obtained from Sigma-Aldrich (Schnelldorf, Germany) except sildenafil, which was a gift from Pfizer.

\section{Biochemical analysis}

For determination of cGMP levels, segments from the hindlimb collateral arteries as well as the mesenteric arteries were harvested ( $n=4$ for all conditions), isolated and allowed to equilibrate in KRB buffer for 30 minutes. Segments were subsequently incubated for 30 minutes in warm KRB containing $10^{-4} \mathrm{M}$ IBMX, a non-selective phosphodiesterase inhibitor, snap frozen in liquid nitrogen and stored at $-20^{\circ} \mathrm{C}$ until analysis. The cGMP content was determined in homogenates of the arteries with a commercially available competitive enzyme immunoassay kit (GE Healthcare, Buckinghamshire, UK). In addition, cGMP levels in plasma of DM and control animals were determined.

\section{Immunoblot analysis}

From a number of DM and control animals, saphenous artery segments were harvested postmortem to determine expression of SGC and PKG. Isolated segments were snap frozen in liquid nitrogen and stored at $-80^{\circ} \mathrm{C}$. The segments were then pulverized and subsequently lysed in RIPA buffer containing a cocktail of protease and phosphatase inhibitors (Santa Cruz, Heidelberg, Germany). Protein concentration was determined according to Lowry, ${ }^{17}$ and protein samples of $10 \mu \mathrm{g}$ were loaded on $4-12 \%$ precast SDS-PAGE gels (Bio-Rad, Veenendaal, The Netherlands) that were run at $200 \mathrm{~V}$ for 105 minutes. Proteins were electrophoretically transferred to nitrocellulose membranes at $100 \mathrm{~V}$ for 75 minutes. The membranes were blocked with blocking buffer (LI-COR Biosciences, Cambridge, UK) in PBS (1:1) for 30 minutes and incubated overnight at $4{ }^{\circ} \mathrm{C}$ with 
anti-GAPDH and either anti-sGC $\alpha 1$ or anti-PKG1 $\beta$ antibodies (BD Biosciences, Lexington $\mathrm{KY}$ ) in blocking buffer (dilutions 1:200000, 1:50000 and 1:500, respectively). Subsequently, the membrane was washed three times for $10 \mathrm{~min}$ in PBS with $0.1 \%$ Tween (PBS-T), after which membranes were incubated for 1 hour at room temperature with secondary antibodies (1:15000) in blocking buffer. After incubation, membranes were washed with PBS-T and with PBS and were analyzed on an Odyssee IR imaging system (LI-COR Biosciences). Protein expression was determined relative to the housekeeping protein GAPDH.

\section{Statistical analysis}

Relaxations are expressed as percent change of the steady-state contraction. Sensitivity $\left(p E C_{50}\right)$ and efficacy $\left(E_{\max }\right)$ of agonists were calculated by nonlinear regression curve fitting of agonist concentration-response curves using GraphPad Prism 5.0 for Windows. Data are shown as mean \pm standard error of the mean (SEM). Statistical analysis was performed with SPSS 15.0 for Windows. To characterize endothelium-dependent relaxation, the different agonist and inhibitor combinations within either DM or control group were analysed with one-way ANOVA followed by a Bonferroni post-hoc test. To determine the effects of DM, independent samples t-test was used to compare DM with control arteries. Values of $\mathrm{P}<0.05$ were considered statistically significant.

\section{Results}

\section{Animals}

Blood glucose levels of the included alloxan-treated animals reached a steady state within one week, and remained elevated until sacrifice. Glucose levels were significantly higher $(P<0.001)$ in the DM animals $(21.4 \pm 6.9 \mathrm{mM})$ compared to the controls $(6.8 \pm 0.6 \mathrm{mM})$. Body weight was not different between the $\mathrm{DM}$ and control animals, $3.1 \pm 0.2$ and $3.0 \pm 0.3 \mathrm{~kg}$, respectively $(P=0.34)$.

\section{Contraction}

Phenylephrine (PHE) caused a concentration-dependent contraction in collateral arteries of both DM and control animals. Within both groups, incubation with INDO, L-NAME or ODQ did not modify the $E_{\max }$ of the contractions, either induced by PHE or $\mathrm{K}^{+}$, as presented in figure $4.1 \mathrm{~A}$ and $\mathrm{B}$. Moreover, no significant differences were observed between DM and control arteries. 

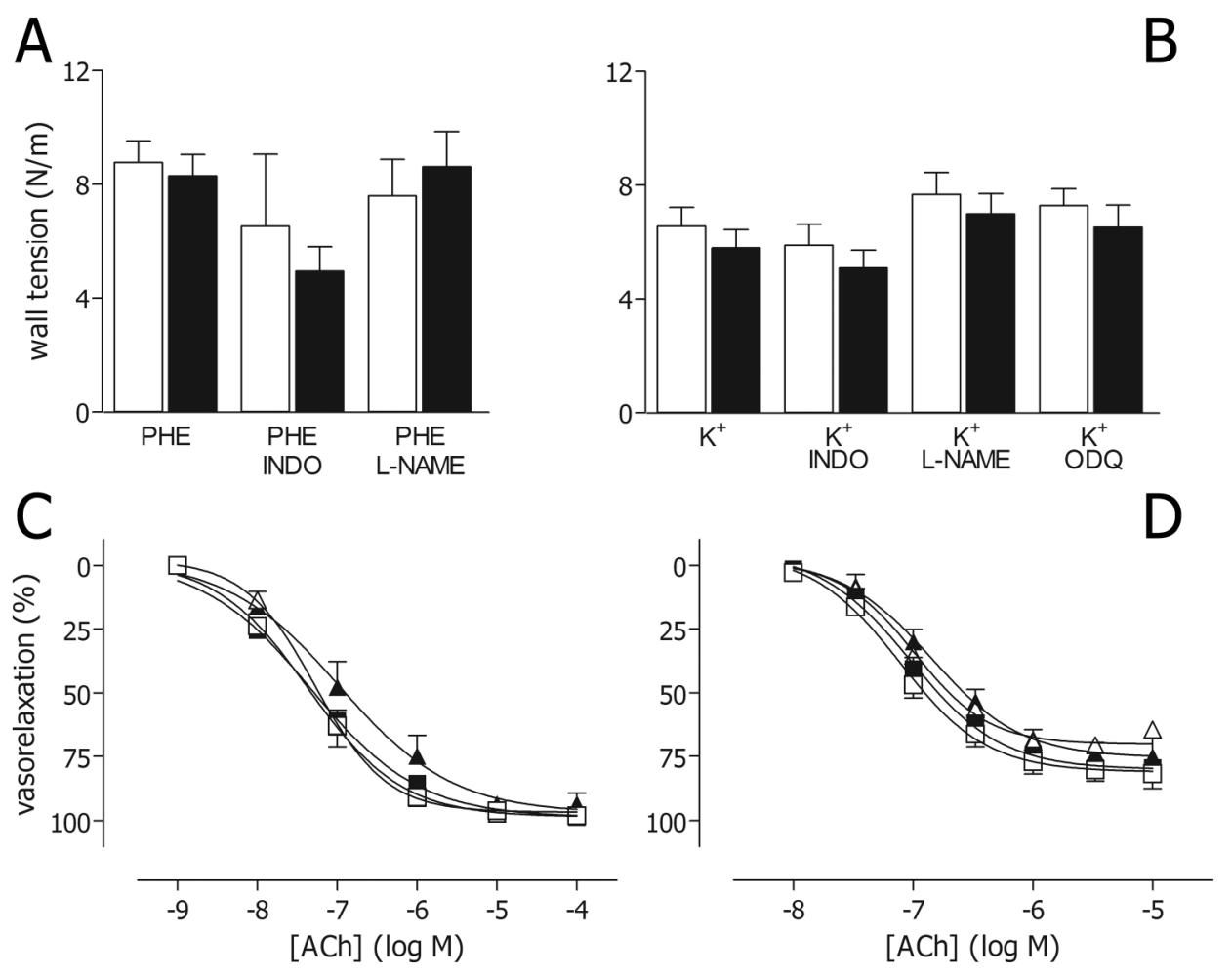

\section{FIGURE 4.1}

Level of contraction and endothelium-dependent relaxation in collateral arteries of DM and control animals. Filled bars and symbols represent DM arteries; open bars and symbols represent controls. Error bars depict SEM. (A) Contraction induced by $10^{-4} \mathrm{M}$ $\mathrm{PHE}$, in absence and presence of INDO and L-NAME. (B) Contraction induced by 32.5 $\mathrm{mM} \mathrm{K}^{+}$in absence and presence of INDO, L-NAME and ODQ. (C) Endotheliumdependent relaxation during PHE-induced contraction, in absence (squares) and presence (triangles) of L-NAME. (D) Endothelium-dependent relaxation during $\mathrm{K}^{+}-$ induced contraction, in absence (squares) and presence (triangles) of INDO.

\section{Endothelium-dependent vasorelaxation}

Administration of ACh during contraction induced with either PHE or $\mathrm{K}^{+}$resulted in concentration-dependent relaxation. Both within the DM and the control group, the sensitivity $\left(\mathrm{pEC}_{50}\right)$ to $A C h$ was not affected by INDO or L-NAME. The potency $\left(\mathrm{E}_{\max }\right)$ of ACh was significantly decreased during depolarization-induced contraction after incubation with INDO $(\mathrm{P}=0.002)$ compared to the other conditions. The results are summarised in table 4.1. Comparison of the DM and control group showed that DM did not affect the endothelium-dependent relaxation in any of the conditions (figure $4.1 \mathrm{C}$ and $\mathrm{D}$ ). 

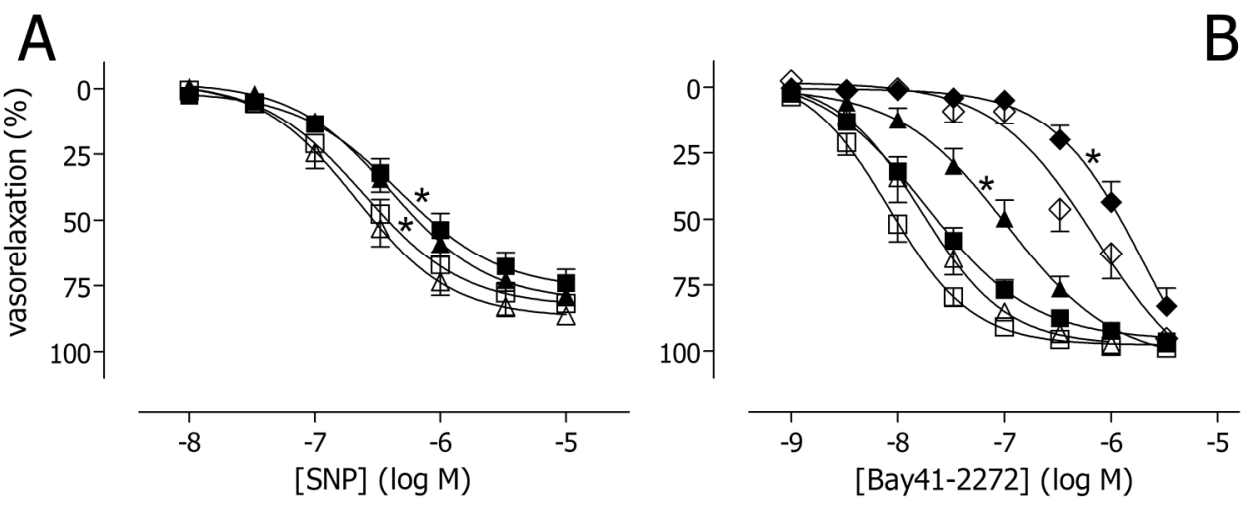

\section{FIGURE 4.2}

Endothelium-independent relaxation in collateral arteries during depolarizationinduced contraction in the presence of INDO. Closed symbols depict DM arteries, open symbols represent control vessels. Error bars depict SEM. Differences in $\mathrm{pEC}_{50}$ with $\mathrm{P}<0.05$ between DM and control group are indicated with *. (A) Relaxation in response to SNP in the presence of

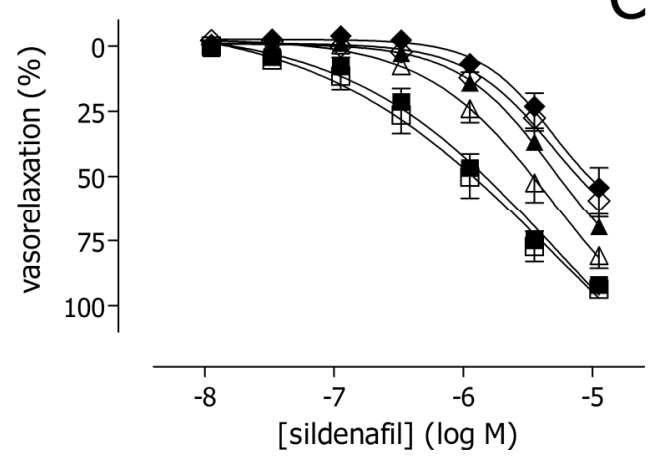
INDO, and in absence (squares) or presence of L-NAME (triangles). (B) Relaxation in response to Bay41-2272 during $\mathrm{K}^{+}$-induced contraction during incubation with INDO (squares). Triangles depict additional incubation with L-NAME, diamonds with ODQ. (C) Relaxation in response to sildenafil during incubation with INDO (squares), and with additional incubation of L-NAME (triangles) or ODQ (diamonds).

\section{Endothelium-independent vasorelaxation}

In both DM and control collateral arteries, administration of the SNP in the presence of INDO during $\mathrm{K}^{+}$-induced contraction resulted in a concentration dependent relaxation. Both in absence and presence of L-NAME, DM significantly attenuated the sensitivity to SNP (both $\mathrm{P}=0.03$ ), without affecting the maximal response (figure 4.2A). A similar pattern was observed with a more direct stimulator of SGC. Sensitivity to Bay41-2272 was significantly decreased in DM arteries compared to controls both in absence $(P=0.01)$ and presence of L-NAME $(P=0.02)$. As expected, presence of the SGC inhibitor ODQ markedly reduced the sensitivity to the relaxing effects of Bay41-2272 (figure 4.2B). In the presence of this inhibitor, the $\mathrm{pEC}_{50}$ of Bay41-2272 did not differ between the DM and control group $(P=0.21)$. The $E_{\max }$ of Bay41-2272 was not affected by $D M$ in any condition. 
At the level of PDE5, no significant differences in vasorelaxation were found between DM and control arteries. The phosphodiesterase type 5 inhibitor sildenafil induced concentration-dependent relaxation in the absence and presence of LNAME or ODQ, and was not affected by DM (figure 4.2C).

\section{TABLE 4.1}

Potency $\left(E_{\max }\right)$ and sensitivity ( $\left.\mathrm{pEC} \mathrm{C}_{50}\right)$ of vasodilators in presence of different inhibitors. Data are shown as mean \pm SEM. $\left({ }^{*}\right) \mathrm{P}<0.05$ compared to control group. $\left({ }^{+}\right) \mathrm{P}<0.05$ compared to the presence of (other) inhibitor. $\left(^{\ddagger}\right)$ No $E_{\max }$ established, relaxation at highest agonist concentration. SIL: Sildenafil.

\begin{tabular}{|c|c|c|c|c|c|c|}
\hline \multirow[b]{2}{*}{ Dilator } & \multirow[b]{2}{*}{ Constrictor } & \multirow[b]{2}{*}{ Inhibitor } & \multicolumn{2}{|c|}{ DM } & \multicolumn{2}{|c|}{ Control } \\
\hline & & & $\mathrm{E}_{\max }$ & $\mathrm{pEC}_{50}$ & $\mathrm{E}_{\max }$ & $\mathrm{pEC}_{50}$ \\
\hline \multicolumn{7}{|c|}{ Endothelium-dependent } \\
\hline ACh & PHE & & $99 \pm 4$ & $7.3 \pm 0.6$ & $99 \pm 3$ & $7.4 \pm 0.2$ \\
\hline $\mathrm{ACh}$ & PHE & L-NAME & $97 \pm 10$ & $7.0 \pm 0.4$ & $97 \pm 5^{\dagger}$ & $7.3 \pm 0.2$ \\
\hline $\mathrm{ACh}$ & $\mathrm{K}^{+}$ & & $81 \pm 3$ & $7.1 \pm 0.1$ & $80 \pm 3$ & $7.0 \pm 0.1$ \\
\hline ACh & $\mathrm{K}^{+}$ & INDO & $70 \pm 6$ & $7.0 \pm 0.2$ & $76 \pm 4$ & $6.8 \pm 0.1$ \\
\hline \multicolumn{7}{|c|}{ Endothelium-independent } \\
\hline SNP & $\mathrm{K}^{+}$ & INDO & $74 \pm 5$ & $6.3 \pm 0.1 *$ & $82 \pm 3$ & $6.6 \pm 0.1$ \\
\hline SNP & $\mathrm{K}^{+}$ & $\begin{array}{l}\text { INDO, } \\
\text { L-NAME }\end{array}$ & $79 \pm 4$ & $6.4 \pm 0.1^{*}$ & $87 \pm 3$ & $6.7 \pm 0.1$ \\
\hline BAY41-2272 & $\mathrm{K}^{+}$ & INDO & $96 \pm 7$ & $7.7 \pm 0.1^{*}$ & $98 \pm 3$ & $8.1 \pm 0.1$ \\
\hline BAY41-2272 & $\mathrm{K}^{+}$ & $\begin{array}{l}\text { INDO, } \\
\text { L-NAME }\end{array}$ & $104 \pm 9$ & $7.0 \pm 0.1 *$ & $98 \pm 6$ & $7.8 \pm 0.1$ \\
\hline SIL & $\mathrm{K}^{+}$ & INDO & $92 \pm 1^{\neq}$ & $5.9 \pm 0.1$ & $94 \pm 2^{\ddagger}$ & $5.9 \pm 0.2$ \\
\hline SIL & $\mathrm{K}^{+}$ & $\begin{array}{l}\text { INDO, } \\
\text { L-NAME }\end{array}$ & $70 \pm 5^{\ddagger}$ & $5.2 \pm 0.3$ & $85 \pm 4^{\ddagger}$ & $5.6 \pm 0.2$ \\
\hline
\end{tabular}

\section{CGMP production}

Arterial segments isolated for biochemical analysis were pooled per condition, as single tissue samples were too small for accurate determination of cyclic guanosine monophosphate (cGMP) content. Therefore results are showed without error bars. DM hindlimb collateral arteries displayed a decreased cGMP content of 308 $\mathrm{pmol} / \mathrm{mg}$ protein compared to $369 \mathrm{pmol} / \mathrm{mg}$ protein in controls, a difference of $16.5 \%$. In mesenteric arteries, DM decreased cGMP production to the same extent, 168 in DM compared to $201 \mathrm{pmol} / \mathrm{mg}$ protein in controls. These differences were not reflected in the plasma, with $751 \pm 16 \mathrm{fmol} / \mathrm{ml}$ in $\mathrm{DM}(\mathrm{n}=8)$ and $747 \pm 31$ $\mathrm{fmol} / \mathrm{ml}$ in controls $(\mathrm{n}=8)$, as depicted in figure $4.3 \mathrm{~A}$. 


\section{Expression of SGC and PKG}

In accordance with reactivity results and cGMP production, the protein levels of both $\mathrm{sGC} \alpha 1$ and PKG1 $\beta$ were significantly decreased in the DM group $(n=8)$ compared to the control group $(n=7)$. Expression of $s G C$ relative to GAPDH was $0.93 \pm 0.19$ in $\mathrm{DM}$, and $1.71 \pm 0.30$ in controls $(P=0.04)$. Relative PKG expression was $0.33 \pm 0.07$ in $D M$, and $0.88 \pm 0.17$ in controls $(P=0.01)$, as depicted in figure 4.3B and $\mathrm{C}$.

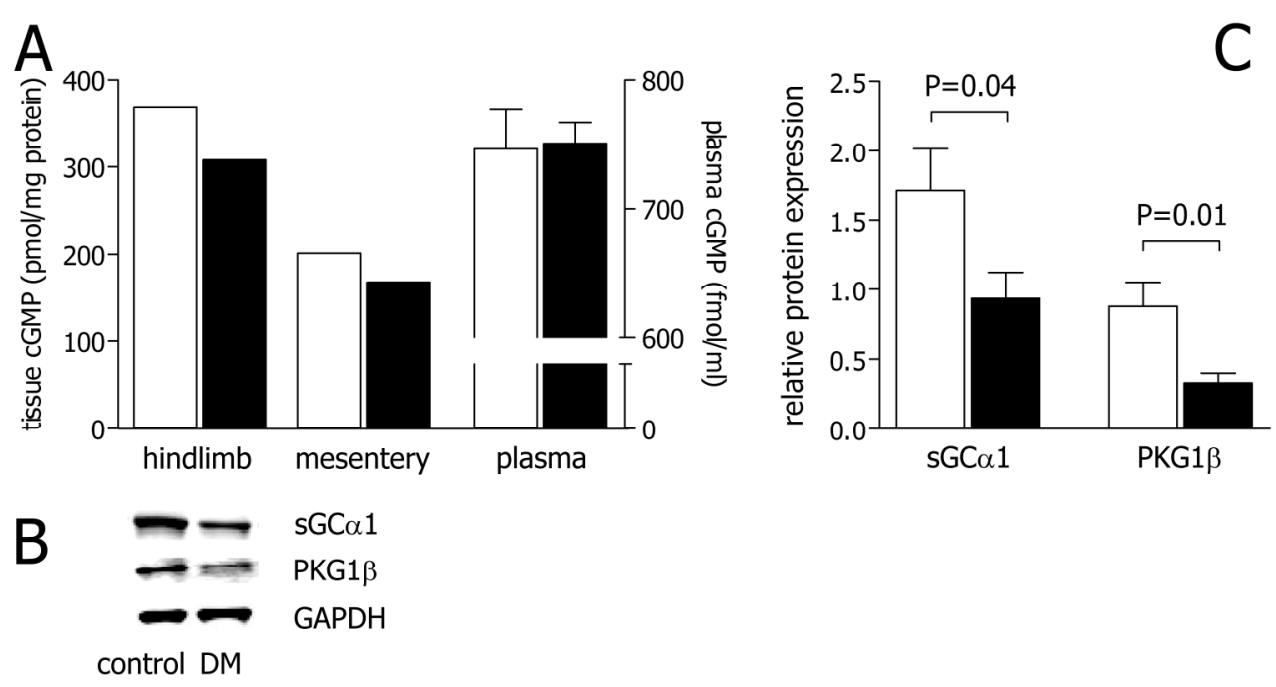

\section{FIGURE 4.3}

cGMP production and expression of sGC $\alpha 1$ and PKG1ß. (A) cGMP production in hindlimb collateral arteries, mesenteric arteries (pooled samples) and in plasma. (B) Representative immunoblots of $\mathrm{SGC} \alpha 1, \mathrm{PKG} 1 \beta$ and GAPDH. (C) Protein expression of sGC $\alpha 1$ and PKG1 $\beta$ relative to GAPDH.

\section{Incubation with high glucose}

Contraction and relaxation of both DM and control arteries was not affected by high glucose incubation (figure 4.4). Contraction induced by either PHE or $\mathrm{K}^{+}$ seemed slightly decreased in DM arteries and increased in control arteries, but these differences were not statistically significant. Relaxation induced by ACh, SNP and Bay41-2272 was not altered by high glucose. 

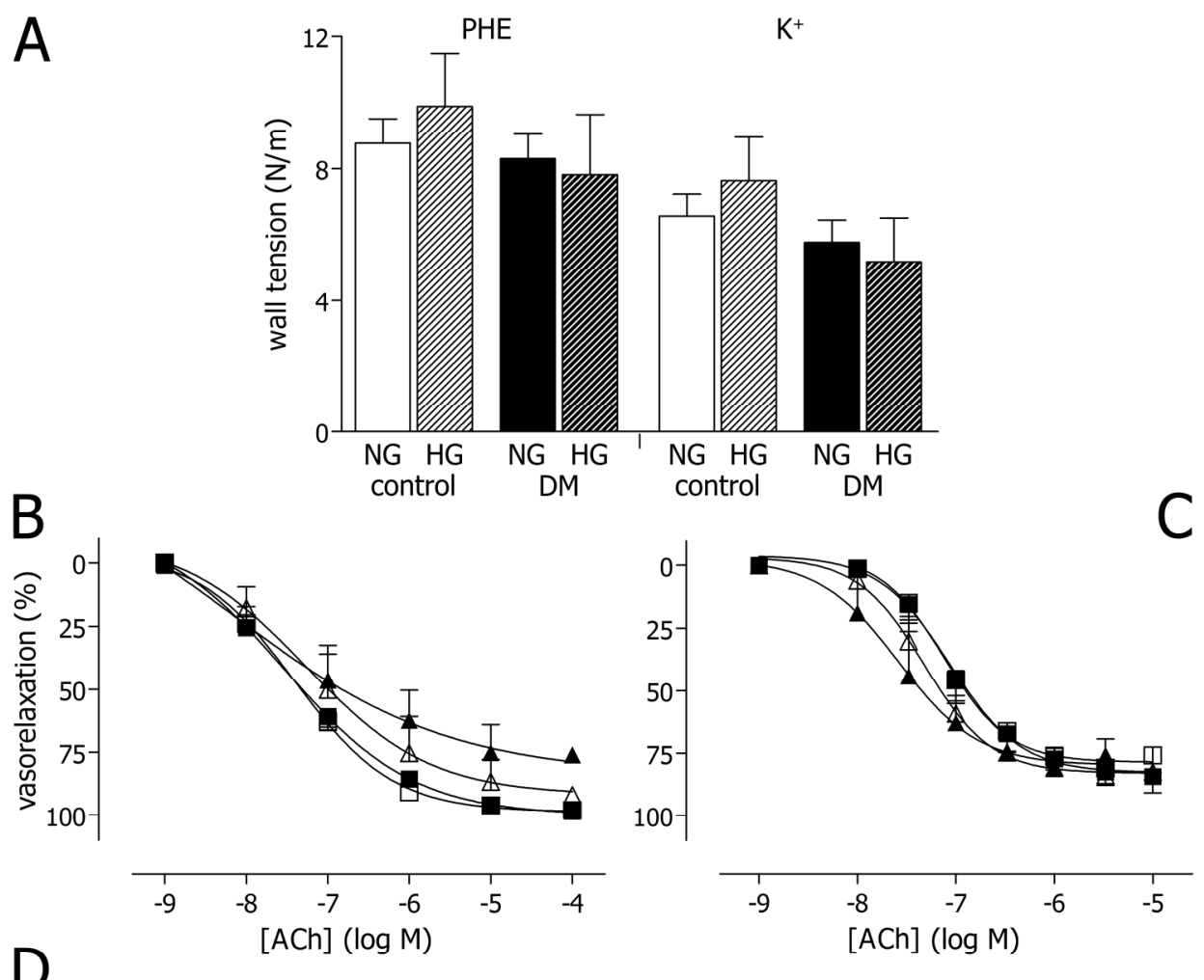

$\mathrm{D}$
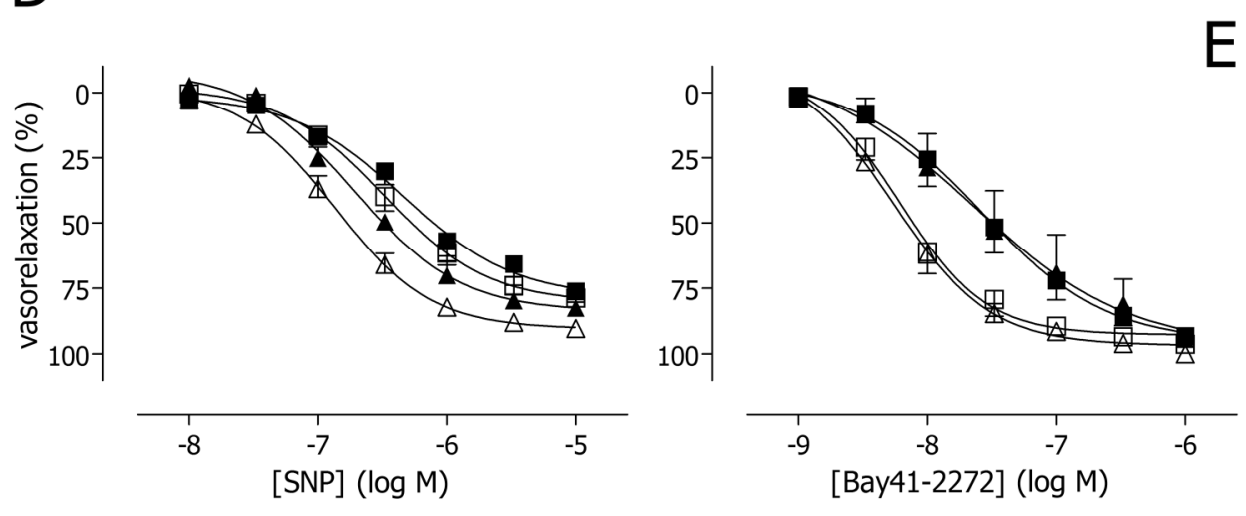

E

FIGURE 4.4

Effects of high glucose incubation on contraction and relaxation. (A) Contraction induced by PHE and $\mathrm{K}^{+}$in $\mathrm{DM}$ and control arteries. NG: normoglycemia $(5.5 \mathrm{mM})$; HG: hyperglycemia (20.0 mM). ACh-induced relaxation during contraction with either PHE (B) or $\mathrm{K}^{+}(\mathrm{C})$. Relaxation induced by SNP (D) and Bay41-2272 (E) during $\mathrm{K}^{+}$-induced contraction in the presence of INDO. Filled symbols depict DM, open symbols depict controls. Normoglycemia is represented by squares, hyperglycemia by triangles. Error bars depict SEM. 


\section{Discussion}

The present study demonstrates that 8 weeks of alloxan-induced DM results in decreased SMC function in hindlimb collateral arteries of the rabbit. Functionally, this was shown by decreased sensitivity to NO and SGC stimulation. Additionally, basal production of cGMP and expression of $\mathrm{SGC} \alpha 1$ and PKG1 $\beta$ were decreased in the DM arterial wall. Stimulation of the endothelium with the endotheliumdependent vasodilator $\mathrm{ACh}$, on the other hand, showed no difference between DM and control vessels.

Vasodilatation of collateral arteries is an important step in the initiation of arteriogenesis, ${ }^{18}$ which is impaired by $\mathrm{DM}^{6,7}$ The endothelium is widely regarded as a major determinant for regulation of vascular tone. Endothelium-dependent vasodilatation involves EDHF, $\mathrm{NO}$, and prostacyclin $\left(\mathrm{PGI}_{2}\right)$, each causing relaxation of the underlying vascular SMC. Several pathological conditions are associated with impaired vascular function, including hypertension, obesity and DM. ${ }^{19-21}$ Both clinically ${ }^{8,19,22}$ and experimentally, ${ }^{10,19,23}$ DM was shown to impair ACh-induced vasodilatation. In isolated mesenteric arteries, abdominal aorta and thoracic aorta from rabbits and rats, the impairment was localised in the endothelium. ${ }^{19,24-27}$ Similarly, in isolated arterioles from the rat hindlimb, DM increased contraction, decreased Ach-induced relaxation, but did not affect SNP-induced relaxation. ${ }^{28}$ The present study is, to our knowledge, the first studying the effect of DM in isolated hindlimb collateral arteries. In this study, DM impaired the SMC without impairing ACh-induced vasorelaxation. First, the sensitivity to NO was reduced. This finding is in accordance with a study in the rat, showing that STZ-induced DM decreased NO sensitivity compared to controls in both iliac and superior mesenteric arteries. ${ }^{29}$ Furthermore, DM significantly reduced the sensitivity to the SGC stimulator Bay412272 in the present study. The function of SGC, the main downstream effector of $\mathrm{NO}$, can be impaired by hyperglycemia ${ }^{30}$ and oxidative stress, ${ }^{31,32}$ resulting in reduced NO sensitivity and CGMP production, leading to altered vascular tone. ${ }^{29}$ In rats, DM enhanced contraction levels of skeletal muscle arterioles. ${ }^{28} \mathrm{sGC}$ converts GTP to the second messenger cGMP, activating PKG, inducing vasorelaxation by lowering the intracellular $\mathrm{Ca}^{2+}$ concentration. ${ }^{28}$ In our study, DM decreased the basal cGMP production in the vessel wall, as well as the expression of both $\mathrm{sGC} \alpha 1$ and PKG1 $\beta$. Interestingly, this is in accordance with a model of NO tolerance. In aortas of transgenic mice overexpressing eNOS, NO sensitivity, SGC activity, and PKG expression were decreased. ${ }^{33}$ Similar desensitization of sGC was observed in rat thoracic aortas and human coronary arteries after prolonged exposure to nitroglycerin. ${ }^{34}$ In addition, ACh-induced relaxation was unchanged in the present 
study, suggesting that DM increased NO production. In contrast, studies in other vascular beds demonstrated decreased ACh-induced relaxation. ${ }^{19,25,27,28}$ Based on the present data, it could not be determined whether the decreased SGC and PKG levels were the cause or the effect of elevated endothelial NO production, but the NO tolerance model provides a possible explanation. We therefore hypothesize that DM increases NO production in the endothelium of hindlimb collateral arteries, which leads to desensitization of the SGC-cGMP pathway. A valuable addition to the results presented is this study would be protein activity measurements the determination of eNOS protein expression. Protein activity could not be determined due to the limited amount of tissue. eNOS expression could not be determined due to cross-reactivity of the antibodies. Further research is needed to investigate the responsible mechanism.

In the present study, the selective PDE5 inhibitor sildenafil relaxed hindlimb collateral arteries concentration-dependently. In accordance, selective inhibition of PDE5 has proven to be effective in establishing vasorelaxation in several vascular beds. ${ }^{35}$ But although the basal cGMP production was lower in arteries of DM animals, sildenafil administration did not result in significant differences between DM and control vessels. This suggests reduced PDE5 activity in the DM collateral arteries. Indeed, in vascular SMC, PDE5 activity is tightly regulated by cGMP and PKG. ${ }^{36}$ Binding of PKG to the GAF domain of PDE5 leads to phosphorylation of the $\mathrm{N}$-terminus, enhancing CGMP catalytic activity. Conversely, reduction of PKG decreases catalytic activity. ${ }^{37}$ Thus, if the decrease of cGMP and PKG in the DM arteries were accompanied by decreased PDE5 activity, this would explain the lack of difference in responsiveness to sildenafil between DM and controls. Notably, incubation of L-NAME and ODQ did not completely abolish sildenafil-induced relaxation. This may indicate a cGMP-independent pathway, as suggested by Salom et al. ${ }^{38}$

In conclusion, the present study demonstrates that experimental DM impairs SMC function in rabbit hindlimb collateral arteries, emphasizing the regional heterogeneity of DM complications in the vasculature. Although this study does not focus on the mechanisms underlying the vascular dysfunctions induced by DM, the results reveal possible targets for therapy aiming at the improvement of recruitment and remodeling of collateral arteries in DM. Collateral vasodilatation may be improved by stimulation of sGC. Stimulators of sGC such as Bay41-2272, or activators, such as Bay58-2667, can relax vascular SMC independently of NO. ${ }^{39}$ Additionally, both substances demonstrated beneficial effects in cardiovascular disease, including a decrease in blood pressure and systemic vascular resistance in 
hypertension, and unloading the heart in congestive heart failure. ${ }^{40,41}$ Additionally, PDE5 inhibition, already used in erectile dysfunction, pulmonary hypertension, and angiogenesis ${ }^{35,42,43}$ may also be an interesting therapeutic target, as DM did not affect the sensitivity and potency of sildenafil.

\section{Acknowledgements}

The authors thank M. van de Waarenburg and G. Janssen for technical assistance. 


\section{References}

1. Dolan NC, Liu K, Criqui MH, Greenland P, Guralnik JM, Chan C, Schneider JR, Mandapat AL, Martin G, McDermott MM: Peripheral artery disease, diabetes, and reduced lower extremity functioning. Diabetes Care 2002;25:113-120.

2. Gregg EW, Sorlie P, Paulose-Ram R, Gu Q, Eberhardt MS, Wolz M, Burt V, Curtin L, Engelgau M, Geiss L: Prevalence of lower-extremity disease in the US adult population $>=40$ years of age with and without diabetes: 1999-2000 national health and nutrition examination survey. Diabetes Care 2004;27:1591-1597.

3. Tapp RJ, Balkau B, Shaw JE, Valensi P, Cailleau M, Eschwege E: Association of glucose metabolism, smoking and cardiovascular risk factors with incident peripheral arterial disease: the DESIR study. Atherosclerosis 2007;190:84-89.

4. Waltenberger J: Impaired collateral vessel development in diabetes: potential cellular mechanisms and therapeutic implications. Cardiovasc Res 2001;49:554-560.

5. Abaci A, Oguzhan A, Kahraman S, Eryol NK, Unal S, Arinc H, Ergin A: Effect of diabetes mellitus on formation of coronary collateral vessels. Circulation 1999;99:2239-2242.

6. Rivard A, Silver M, Chen D, Kearney M, Magner M, Annex B, Peters K, Isner JM: Rescue of diabetes-related impairment of angiogenesis by intramuscular gene therapy with adeno-VEGF. Am J Pathol 1999;154:355-363.

7. van Golde JM, Ruiter MS, Schaper NC, Voo S, Waltenberger J, Backes WH, Post MJ, Huijberts MS: Impaired collateral recruitment and outward remodeling in experimental diabetes. Diabetes 2008;57:2818-2823.

8. Schalkwijk CG, Stehouwer CD: Vascular complications in diabetes mellitus: the role of endothelial dysfunction. Clin Sci (Lond) 2005;109:143-159.

9. Schaper NC, Nabuurs-Franssen MH, Huijberts MS: Peripheral vascular disease and type 2 diabetes mellitus. Diabetes Metab Res Rev 2000;16 Suppl 1:S11-15.

10. Sobrevia L, Mann GE: Dysfunction of the endothelial nitric oxide signalling pathway in diabetes and hyperglycaemia. Exp Physiol 1997;82:423-452.

11. Taubert D, Rosenkranz A, Berkels R, Roesen R, Schomig E: Acute effects of glucose and insulin on vascular endothelium. Diabetologia 2004;47:2059-2071.

12. Pieper GM: Enhanced, unaltered and impaired nitric oxide-mediated endotheliumdependent relaxation in experimental diabetes mellitus: importance of disease duration. Diabetologia 1999;42:204-213.

13. Berman RS, Martin PE, Evans WH, Griffith TM: Relative contributions of NO and gap junctional communication to endothelium-dependent relaxations of rabbit resistance arteries vary with vessel size. Microvasc Res 2002;63:115-128.

14. Sandow SL, Tare M, Coleman HA, Hill CE, Parkington HC: Involvement of myoendothelial gap junctions in the actions of endothelium-derived hyperpolarizing factor. Circ Res 2002;90:1108-1113.

15. Scotland RS, Madhani M, Chauhan S, Moncada S, Andresen J, Nilsson H, Hobbs AJ, Ahluwalia A: Investigation of vascular responses in endothelial nitric oxide synthase/cyclooxygenase-1 double-knockout mice: key role for endothelium-derived hyperpolarizing factor in the regulation of blood pressure in vivo. Circulation 2005;111:796-803. 
16. Halpern W, Mulvany MJ: Tension responses to small length changes of vascular smooth muscle cells [proceedings]. J Physiol 1977;265:21P-23P.

17. Lowry OH, Rosebrough NJ, Farr AL, Randall RJ: Protein measurement with the Folin phenol reagent. J Biol Chem 1951;193:265-275.

18. Schaper W, Scholz D: Factors regulating arteriogenesis. Arterioscler Thromb Vasc Biol 2003;23:1143-1151.

19. De Vriese AS, Verbeuren TJ, Van de Voorde J, Lameire NH, Vanhoutte PM: Endothelial dysfunction in diabetes. Br J Pharmacol 2000;130:963-974.

20. Li J, Zhou Z, Jiang DJ, Li D, Tan B, Liu H, Li YJ: Reduction of NO- and EDHF-mediated vasodilatation in hypertension: role of asymmetric dimethylarginine. Clin Exp Hypertens 2007;29:489-501.

21. Mather KJ, Mirzamohammadi B, Lteif A, Steinberg HO, Baron AD: Endothelin contributes to basal vascular tone and endothelial dysfunction in human obesity and type 2 diabetes. Diabetes 2002;51:3517-3523.

22. Veves A, Akbari CM, Primavera J, Donaghue VM, Zacharoulis D, Chrzan JS, DeGirolami U, LoGerfo FW, Freeman R: Endothelial dysfunction and the expression of endothelial nitric oxide synthetase in diabetic neuropathy, vascular disease, and foot ulceration. Diabetes 1998;47:457-463.

23. Miranda FJ, Alabadi JA, Llorens S, Ruiz de Apodaca RF, Centeno JM, Alborch E: Influence of experimental diabetes on regulatory mechanisms of vascular response of rabbit carotid artery to acetylcholine. Life Sci 2000;66:2071-2080.

24. Makimattila S, Liu ML, Vakkilainen J, Schlenzka A, Lahdenpera S, Syvanne M, Mantysaari M, Summanen P, Bergholm R, Taskinen MR, Yki-Jarvinen H: Impaired endothelium-dependent vasodilation in type 2 diabetes. Relation to $L D L$ size, oxidized LDL, and antioxidants. Diabetes Care 1999;22:973-981.

25. Nascimento NR, Lessa LM, Kerntopf MR, Sousa CM, Alves RS, Queiroz MG, Price J, Heimark DB, Larner J, Du X, Brownlee M, Gow A, Davis C, Fonteles MC: Inositols prevent and reverse endothelial dysfunction in diabetic rat and rabbit vasculature metabolically and by scavenging superoxide. Proc Natl Acad Sci U S A 2006;103:218223.

26. Zanetti M, Sato J, Katusic ZS, O'Brien T: Gene transfer of endothelial nitric oxide synthase alters endothelium-dependent relaxations in aortas from diabetic rabbits. Diabetologia 2000;43:340-347.

27. Brouwers O, Niessen PM, Haenen G, Miyata T, Brownlee M, Stehouwer CD, De Mey JG, Schalkwijk CG: Hyperglycaemia-induced impairment of endothelium-dependent vasorelaxation in rat mesenteric arteries is mediated by intracellular methylglyoxal levels in a pathway dependent on oxidative stress. Diabetologia 2010;53:989-1000.

28. Ungvari Z, Pacher P, Kecskemeti V, Papp G, Szollar L, Koller A: Increased myogenic tone in skeletal muscle arterioles of diabetic rats. Possible role of increased activity of smooth muscle Ca2+ channels and protein kinase C. Cardiovasc Res 1999;43:10181028.

29. Martinez-Nieves B, Dunbar JC: Vascular dilatatory responses to sodium nitroprusside (SNP) and alpha-adrenergic antagonism in female and male normal and diabetic rats. Proc Soc Exp Biol Med 1999;222:90-98. 
30. Kalsi JS, Ralph DJ, Madge DJ, Kell PD, Cellek S: A comparative study of sildenafil, NCX911 and BAY41-2272 on the anococcygeus muscle of diabetic rats. Int J Impot Res 2004;16:479-485.

31. Gerassimou C, Kotanidou A, Zhou Z, Simoes DC, Roussos C, Papapetropoulos A: Regulation of the expression of soluble guanylyl cyclase by reactive oxygen species. $\mathrm{Br}$ J Pharmacol 2007; 150:1084-1091.

32. Stasch JP, Schmidt PM, Nedvetsky PI, Nedvetskaya TY, H SA, Meurer S, Deile M, Taye A, Knorr A, Lapp H, Muller H, Turgay Y, Rothkegel C, Tersteegen A, Kemp-Harper B, Muller-Esterl W, Schmidt HH: Targeting the heme-oxidized nitric oxide receptor for selective vasodilatation of diseased blood vessels. J Clin Invest 2006;116:2552-2561.

33. Yamashita T, Kawashima S, Ohashi Y, Ozaki M, Rikitake Y, Inoue N, Hirata K, Akita H, Yokoyama M: Mechanisms of reduced nitric oxide/cGMP-mediated vasorelaxation in transgenic mice overexpressing endothelial nitric oxide synthase. Hypertension 2000;36:97-102.

34. Waldman SA, Rapoport RM, Ginsburg R, Murad F: Desensitization to nitroglycerin in vascular smooth muscle from rat and human. Biochem Pharmacol 1986;35:3525-3531.

35. Ghofrani HA, Osterloh IH, Grimminger F: Sildenafil: from angina to erectile dysfunction to pulmonary hypertension and beyond. Nat Rev Drug Discov 2006;5:689-702.

36. Kass DA, Takimoto E, Nagayama T, Champion HC: Phosphodiesterase regulation of nitric oxide signaling. Cardiovasc Res 2007;75:303-314.

37. Corbin JD, Turko IV, Beasley A, Francis SH: Phosphorylation of phosphodiesterase- 5 by cyclic nucleotide-dependent protein kinase alters its catalytic and allosteric cGMPbinding activities. Eur J Biochem 2000;267:2760-2767.

38. Salom JB, Burguete MC, Perez-Asensio FJ, Castello-Ruiz M, Torregrosa G, Alborch E: Relaxant effect of sildenafil in the rabbit basilar artery. Vascul Pharmacol 2006;44:1016.

39. Stasch JP, Schmidt P, Alonso-Alija C, Apeler H, Dembowsky K, Haerter M, Heil M, Minuth T, Perzborn E, Pleiss U, Schramm M, Schroeder W, Schroder H, Stahl E, Steinke W, Wunder F: NO- and haem-independent activation of soluble guanylyl cyclase: molecular basis and cardiovascular implications of a new pharmacological principle. $\mathrm{Br}$ J Pharmacol 2002;136:773-783.

40. Boerrigter G, Costello-Boerrigter LC, Cataliotti A, Tsuruda T, Harty GJ, Lapp H, Stasch JP, Burnett JC, Jr.: Cardiorenal and humoral properties of a novel direct soluble guanylate cyclase stimulator BAY 41-2272 in experimental congestive heart failure. Circulation 2003; 107:686-689.

41. Dumitrascu R, Weissmann N, Ghofrani HA, Dony E, Beuerlein K, Schmidt H, Stasch JP, Gnoth MJ, Seeger W, Grimminger F, Schermuly RT: Activation of soluble guanylate cyclase reverses experimental pulmonary hypertension and vascular remodeling. Circulation 2006;113:286-295.

42. Schafer A, Fraccarollo D, Pfortsch S, Flierl U, Vogt C, Pfrang J, Kobsar A, Renne T, Eigenthaler M, Ertl G, Bauersachs J: Improvement of vascular function by acute and chronic treatment with the PDE-5 inhibitor sildenafil in experimental diabetes mellitus. $\mathrm{Br}$ J Pharmacol 2008; 153:886-893.

43. Senthilkumar A, Smith RD, Khitha J, Arora N, Veerareddy S, Langston W, Chidlow JH, Jr., Barlow SC, Teng X, Patel RP, Lefer DJ, Kevil CG: Sildenafil promotes ischemia- 
induced angiogenesis through a PKG-dependent pathway. Arterioscler Thromb Vasc Biol 2007;27:1947-1954. 


\section{CHAPTER 5}

The role of methylglyoxal in

hyperglycemia-induced

impairments of vasoreactivity in

the rat saphenous artery

Matthijs S. Ruiter

Maya S. Huijberts

Nicolaas C. Schaper

Olaf Brouwers

Casper G. Schalkwijk Jo G. De Mey Jolanda M. van Golde 


\section{Summary}

Objective - Oxidative stress and protein glycation play an important role in lower extremity vascular dysfunction in DM. The aim of the present study is to determine the effect of DM on vasoconstriction and dilatation in the lower extremity and the role of methylglyoxal (MGO) therein. We hypothesize that experimental DM attenuates vasorelaxation, and that this difference is restored by glyoxalase-1 (GLO1) overexpression.

Methods - In a wire myograph, vasoreactivity of saphenous arteries from streptozotocin-induced diabetic rats with and without transgenic overexpression of GLO1 and from age-matched controls was tested.

Results - Vascular contraction induced by PHE or high $\mathrm{K}^{+}$was similar between the groups. In the limited instances where DM arteries showed increased contraction compared to control arteries, the difference was normalized by GLO1 overexpression. Relaxation induced by ACh and Bay41-2272 was similar between the groups. Sodium nitroprusside-induced relaxation was reduced in the DM group at $10^{-7} \mathrm{M}$ and higher concentrations. This was partially corrected by GLO1 overexpression. No differences in morphology were observed.

Conclusions - The present study demonstrates that transgenic GLO1 overexpression can restore the mild DMinduced impairments in contraction and relaxation in the rat saphenous artery. This suggests that DM exerts its deleterious effects in the lower extremity vasculature at least partly via MGO. Further research in this vascular bed, relevant for lower extremity complications of DM, is required. 


\section{Introduction}

Peripheral arterial disease (PAD) is, together with infection, a major predictor for the clinical outcome of diabetic foot ulcers. ${ }^{1}$ Patients suffering from both DM and PAD exhibit poor lower extremity function and are at risk for developing critical limb ischemia, ulceration, and amputation. ${ }^{1,2}$ The pathology of diabetic foot ulceration is closely related to impairments in the microcirculation. Both endothelium-dependent and independent vasodilatation are impaired in diabetic patients predisposed to foot ulceration. ${ }^{3}$

Numerous studies have shown that DM impairs vasodilatation and that oxidative stress and protein glycation play an important role in this impairment. ${ }^{4-7}$ AGEs and their precursors, methylglyoxal (MGO), glyoxal and 3-deoxyglucosone, exert vascular damage by intracellular protein glycation and extracellular matrix component modification. This leads to decreased vasodilatation and to stiffening of the vessel wall. ${ }^{8,9}$ In the lower extremity, AGEs and ROS are associated with diabetic neuropathy and impaired wound healing. ${ }^{10,11}$ In experimental models, DM impaired vascular reactivity of different vessels, including aortic, carotid and mesenteric arteries. ${ }^{12-15}$ In chapter 4 of the present thesis, we showed that experimental DM attenuates vasorelaxation of hindlimb collateral arteries at the level of sGC. In that study, the exact mechanism was not investigated, but sGC expression and activity were shown to be decreased by ROS in another study. ${ }^{16}$ To elucidate the role of MGO in diabetic vascular dysfunction in the lower extremity, we studied the distal saphenous artery of the rat. MGO is detoxified by the glyoxalase system, and glyoxalase-1 (GLO1) overexpression can reduce MGO levels.

The aim of the present study is to determine the effect of DM on vasoconstriction and dilatation in the lower extremity and the role of MGO therein. We hypothesize that experimental DM attenuates vasorelaxation, and that this attenuation is restored by GLO1 overexpression.

\section{Methods}

\section{Animal model}

Animal experiments were conducted after approval of the ethical committee of the Maastricht University Medical Centre. The animals used in the present study are a subset of animals used in a study by Brouwers et al. ${ }^{17}$ Briefly, 12 male wild-type (WT) Wistar-Kyoto rats were included, as well as 7 Wistar Kyoto rats with 
overexpression of glyoxalase-1 (GLO1), the enzyme that detoxifies MGO. The transgenic animals were obtained from T. Miyata. ${ }^{18}$ In 6 WT and all transgenic animals, DM was induced by intravenous injection of streptozotocin (STZ, 45 $\mathrm{mg} / \mathrm{kg})$. Thus, the three conditions are DM $(\mathrm{N}=6)$, transgenic DM (DMT, $\mathrm{N}=7)$, and healthy age-matched controls $(\mathrm{N}=6)$. Experiments were conducted 24 weeks after STZ injection, to establish long-term effects of DM. Blood glucose was determined 1 and 20 weeks after STZ injection. Animals were euthanized at week 24, after which the saphenous artery was rapidly isolated from the hindlimb. GLO1 content of heart and kidney was determined as described elsewhere. ${ }^{18}$

\section{Isometric tension recording}

Vessel segments freed of surrounding tissue were mounted on two stainless steel wires (40 $\mu \mathrm{m}$ diameter, Danish Myo Technology, Aarhus, Denmark) in a myograph organ chamber (Danish Myo Technology) between an isometric force transducer and a micropositioner. Organ chambers were filled with Krebs-Ringer bicarbonate solution (KRB, $118.5 \mathrm{mM} \mathrm{NaCl}, 4.7 \mathrm{mM} \mathrm{KCl}, 2.5 \mathrm{mM} \mathrm{CaCl}, 1.2 \mathrm{mM} \mathrm{MgSO}_{4}, 1.2 \mathrm{mM}$ $\mathrm{KH}_{2} \mathrm{PO}_{4}, 25.0 \mathrm{mM} \mathrm{NaHCO}$, and $5.5 \mathrm{mM}$ glucose), heated to $37^{\circ} \mathrm{C}$ and aerated $\left(95 \% \mathrm{O}_{2}, 5 \% \mathrm{CO}_{2}\right)$. High $\mathrm{K}^{+}$solution $(\mathrm{K}-\mathrm{KRB}, 125 \mathrm{mM})$, was composed of $\mathrm{KRB}$ in which $\mathrm{NaCl}$ was replaced by $\mathrm{KCl}$. After calibration, vessels were stretched to $90 \%$ of the internal circumference corresponding to a transmural pressure of $100 \mathrm{mmHg}$ using the procedure of Halpern and Mulvany. ${ }^{19}$ All chemicals were obtained from Sigma-Aldrich (Schnelldorf, Germany).

\section{Vasoreactivity}

Arterial contractions were stimulated with phenylephrine (PHE, $10^{-8}$ to $\left.10^{-4} \mathrm{M}\right)$ or $\mathrm{K}^{+}(4.7$ to $44.8 \mathrm{mM})$ in absence and presence of the COX-inhibitor INDO $\left(10^{-5} \mathrm{M}\right.$, incubation 20 minutes) and NO synthase inhibitor L-NAME $\left(10^{-4} \mathrm{M}\right.$, incubation 30 minutes). The maximal contraction of each artery was determined with $125 \mathrm{mM} \mathrm{K}^{+}$ in the presence of $10^{-4} \mathrm{M}$ PHE. To determine the role of the endothelium in relaxation of the artery, $\mathrm{ACh}$-induced relaxation $\left(10^{-8}\right.$ to $\left.10^{-4} \mathrm{M}\right)$ was determined during contraction induced by $10^{-4} \mathrm{MPHE}$, in absence and presence of COXinhibitor INDO. Contraction induced with $32.5 \mathrm{mM} \mathrm{K}^{+}$, prepared by mixing appropriate volumes of KRB and K-KRB, was used to inhibit the EDHF pathway. Sensitivity of the vascular smooth muscle to NO was investigated with NO the donor sodium nitroprusside (SNP, $10^{-8}$ to $10^{-5} \mathrm{M}$ ), during $\mathrm{K}^{+}$-induced contraction in the presence of INDO. The function of SGC was determined with the SGC stimulator Bay41-2272 (10-8 to $\left.10^{-4} \mathrm{M}\right)$ during depolarization-induced contraction in the presence of both INDO and L-NAME. 


\section{Morphology}

For morphological examination, saphenous artery segments from a subset of animals were excised and immediately fixed for one hour in $4 \%$ formaldehyde at $37^{\circ} \mathrm{C}$, stored in ethanol and embedded in paraffin. Cross-sections were cut $(10 \mu \mathrm{m})$ and stained with hematoxylin and eosin (HE). Sections were imaged (magnification 200x) using a Zeiss axioscope (Zeiss, Germany) and a standard CCD camera (Sony, Japan). With Leica imaging software (Qwin 3.1), surface area of the lumen and vessel wall were quantified to determine lumen diameter, media thickness and media to lumen ratio.

\section{Statistical analysis}

Statistical analysis was performed with GraphPad Prism 5.0 for Windows. Data are presented as mean \pm standard error of the mean (SEM). Contractions are expressed as a percentage of maximal contraction of the same vessel, relaxations are expressed as percent change of the steady-state contraction. Maximal vascular contraction, body weight, blood glucose and GLO1 activity in both heart and kidney were compared between groups using one-way ANOVA with Bonferroni correction. Differences between DM, DMT and control group were analysed using two-way ANOVA followed by a Bonferroni post-hoc test. Values of $\mathrm{P}<0.05$ were considered statistically significant.

\section{Results}

Weight, blood glucose and GLO1 level in the heart and kidney are shown in table 5.1. No differences in weight at baseline were observed between the groups. Both DM and DMT groups showed decreased body weight 24 weeks after STZ injection compared to controls. As expected, STZ injection resulted in significant elevation of blood glucose in both WT and transgenic animals. Overexpression of GLO1 was demonstrated in the DMT animals, with significant higher GLO1 activity in both heart and kidney tissue, compared with the other two groups.

\section{Contraction}

The maximal contraction seemed to be higher in the DMT group $(8.67 \pm 0.53$ $\mathrm{N} / \mathrm{m})$ compared to the other groups $(6.16 \pm 0.87 \mathrm{~N} / \mathrm{m}$ in DM and $6.99 \pm 0.87 \mathrm{~N} / \mathrm{m}$ in controls), although this difference did not reach statistical significance $(P=0.07)$. Administration of PHE resulted in concentration-dependent contraction in all groups, both in absence (figure $5.1 \mathrm{~A}$ ) and presence of INDO (figure 5.1B) or LNAME (figure $5.1 \mathrm{C}$ ). In the absence and presence of INDO, no differences were 
observed between the three groups at any concentration. In the presence of LNAME, contraction in the DM arteries was significantly higher at $10^{-6.5} \mathrm{M}$ PHE compared to controls. The DM elevation was significantly reduced in the DMT arteries. $\mathrm{K}^{+}$-induced contraction showed a similar pattern. Administration of $\mathrm{K}^{+}$ resulted in concentration-dependent contraction in all groups. Between the groups, no significant differences were observed in absence (figure 5.1D) and presence of INDO (figure 5.1E). In the presence of both INDO and L-NAME (figure 5.1F), DM increased contraction at $24.8 \mathrm{mM} \mathrm{K}^{+}$, a difference normalized by GLO1.

\section{TABLE 5.1}

Animal characteristics

\begin{tabular}{|c|c|c|c|c|c|c|}
\hline & \multicolumn{2}{|c|}{ Control } & \multicolumn{2}{|c|}{ DM } & \multicolumn{2}{|c|}{ DMT } \\
\hline & Week 1 & Week 24 & Week 1 & Week 24 & Week 1 & Week 24 \\
\hline Weight (g) & $240 \pm 5$ & $461 \pm 34$ & $240 \pm 15$ & $302 \pm 35^{*}$ & $233 \pm 21$ & $294 \pm 40 *$ \\
\hline $\begin{array}{l}\text { Blood glucose } \\
(\mathrm{mM})\end{array}$ & $4.5 \pm 0.3$ & $5.3 \pm 0.7$ & $24.4 \pm 3.5^{*}$ & $31.4 \pm 2.7 *$ & $30.5 \pm 2.6^{*^{\dagger}}$ & $30.7 \pm 3.0 *$ \\
\hline $\begin{array}{l}\text { Heart GLO1 } \\
\text { activity (u/mg) }\end{array}$ & & $22.6 \pm 4.3$ & & $20.5 \pm 4.9$ & & $\begin{array}{l}723.5 \pm \\
119.2^{*^{\dagger}}\end{array}$ \\
\hline $\begin{array}{l}\text { Kidney GLO1 } \\
\text { activity (u/mg) }\end{array}$ & & $16.7 \pm 3.7$ & & $16.6 \pm 5.4$ & & $\begin{array}{l}325.7 \pm \\
79.3^{*^{\dagger}}\end{array}$ \\
\hline
\end{tabular}

Adapted from Brouwers et al. 2011. ${ }^{17}$

* $\mathrm{P}<0.05$ compared to control group; ${ }^{\dagger} \mathrm{P}<0.05$ compared to DM group

\section{Relaxation}

ACh induced a concentration-dependent relaxation. During contraction induced with $\mathrm{PHE}$, no differences in relaxation were observed between the groups, both in absence (figure 5.2A) and presence of INDO (figure 5.2B). During $\mathrm{K}^{+}$-induced contraction, DM decreased relaxation induced by ACh at a concentration of $10^{-4.5} \mathrm{M}$ ACh (figure 5.2C). In the presence of INDO, this difference was not observed (figure 5.2D). Administration of SNP resulted in concentration-dependent relaxation. SNP-induced relaxation was reduced in the DM group at $10^{-7} \mathrm{M}$ and higher concentrations, a difference which was significantly reduced by GLO1 at SNP concentrations over $10^{-7} \mathrm{M}$ (figure 5.2E). The SGC stimulator Bay41-2272 also induced relaxation in a concentration-dependent fashion. No differences in relaxation induced by Bay41-2272 were found between the groups (figure 5.2F). 
A
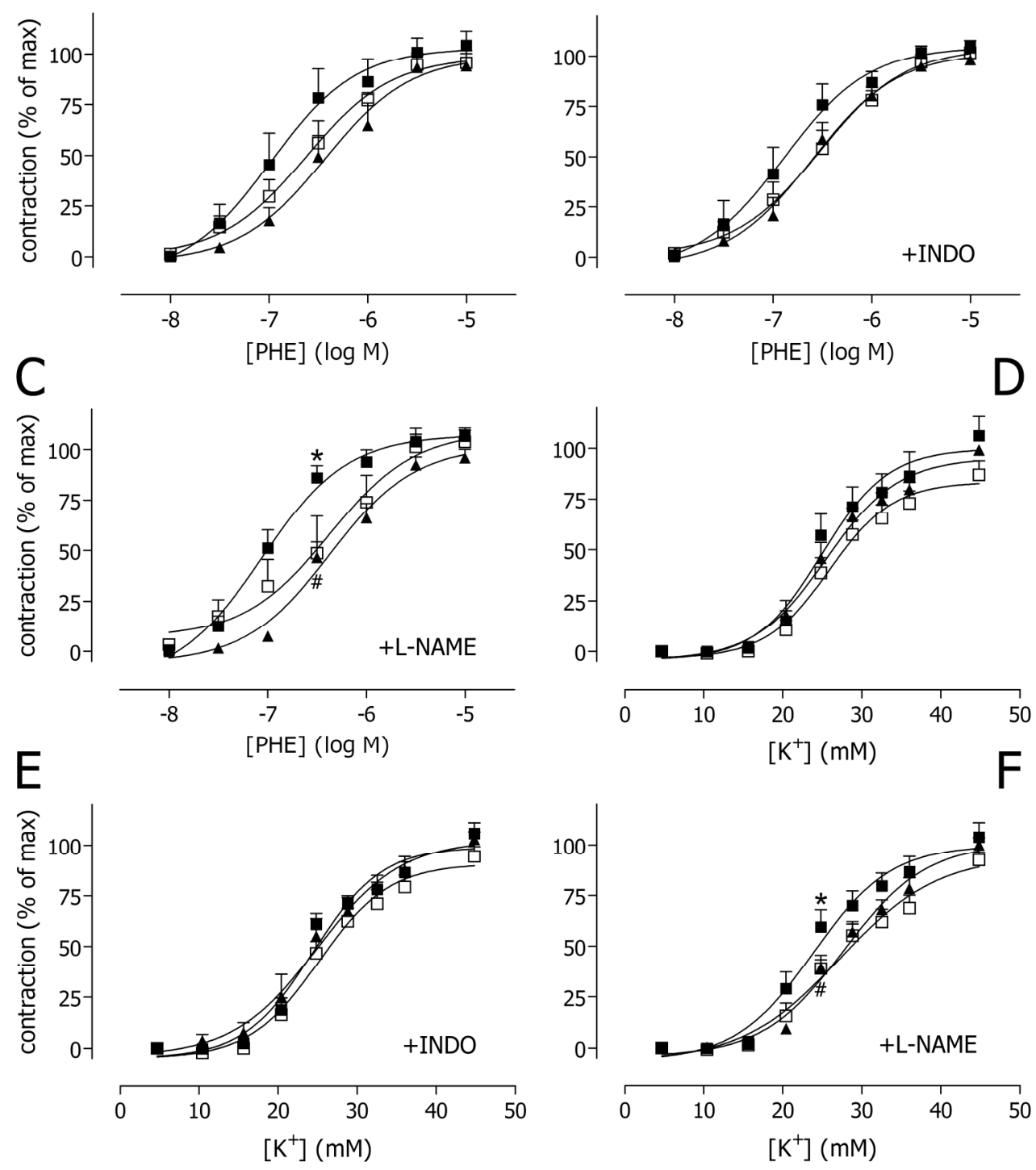

FIGURE 5.1

Contractions induced by PHE $(A, B, C)$ or $K^{+}(D, E, F)$ in saphenous arteries from DM (closed squares), DMT (triangles) and control (open squares) animals. Horizontal axis depicts agonist concentration, vertical axis depicts level of concentration, expressed as the percentage of maximal contraction. Error bars depict SEM. PHE: phenylephrine; INDO: indomethacin. * depicts difference between $\mathrm{DM}$ and control with $\mathrm{P}<0.05$; \# depicts difference between GLO1 and DM with $\mathrm{P}<0.05$. 
A
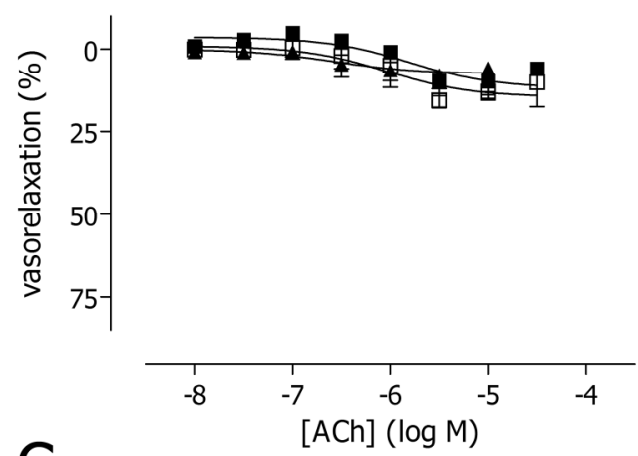

C

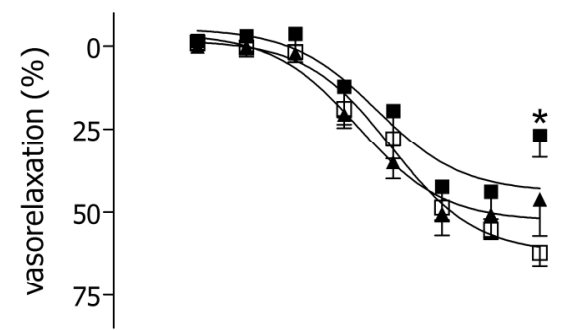

E
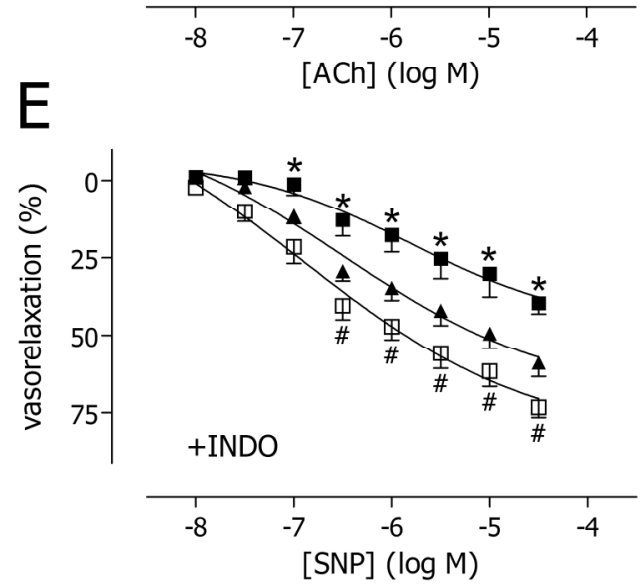

B
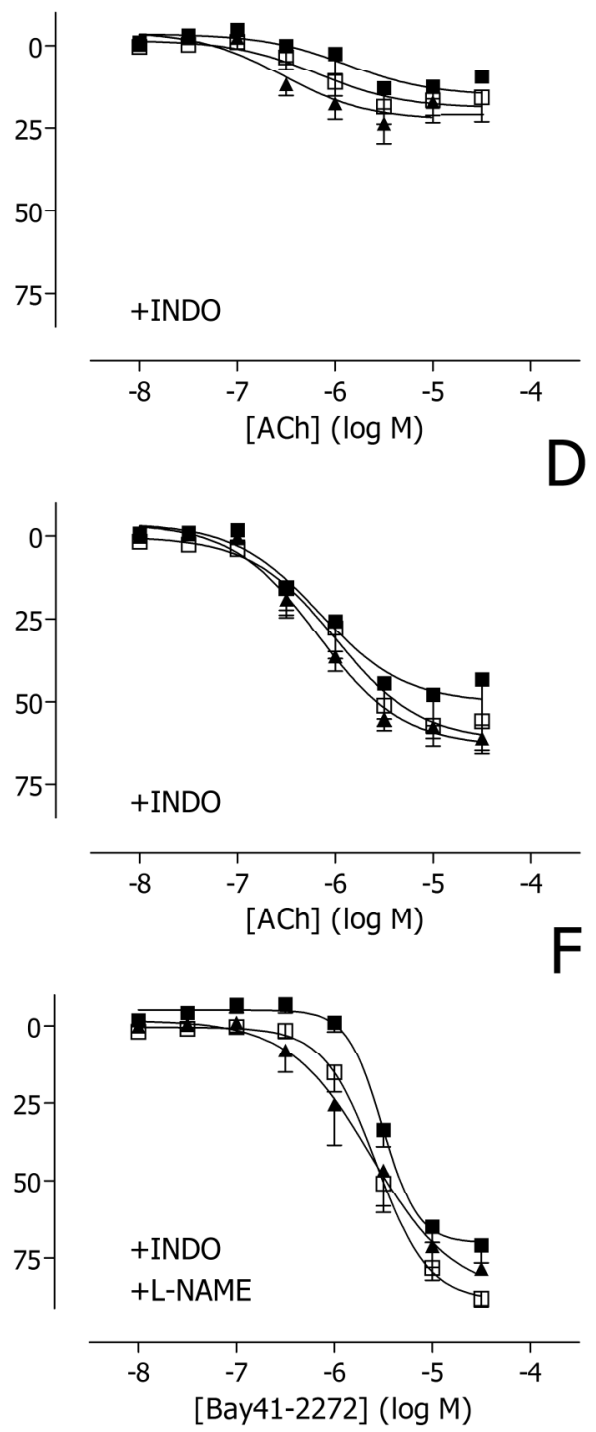

\section{FIGURE 5.2}

Relaxations induced by ACh (A, B, C, D), NO donor SNP (E) and SGC stimulator Bay41-2272 (F) of saphenous arteries from DM (closed squares), DMT (triangles) and control (open squares) animals. Horizontal axis depicts agonist concentration, vertical axis depicts relaxation, expressed as the percentage of steady state contraction. Error bars depict SEM. PHE: phenylephrine; INDO: indomethacin; ACh: acetylcholine; SNP: sodium nitroprusside. * depicts difference between DM and control with $\mathrm{P}<0.05$; \# depicts difference between DMT and DM with $\mathrm{P}<0.05$. 


\section{Morphology}

Representative sections of the three groups are shown in figure 5.3, as well as the morphological quantification. Media thickness (DMT $53.7 \pm 3.2 \mu \mathrm{m}$, DM $55.0 \pm 5.1$ $\mu \mathrm{m}$, control $60.5 \pm 0.5 \mu \mathrm{m}, \mathrm{P}=0.55$ ), lumen diameter (DMT $181 \pm 10 \mu \mathrm{m}$, DM 147 $\pm 10 \mu \mathrm{m}$, control $133 \pm 24 \mu \mathrm{m}, \mathrm{P}=0.11$ ) and media to lumen ratio (DMT $2.58 \pm$ 0.22 , DM $3.16 \pm 0.47$, control $3.80 \pm 0.68, P=0.26$ ) were similar between the groups.
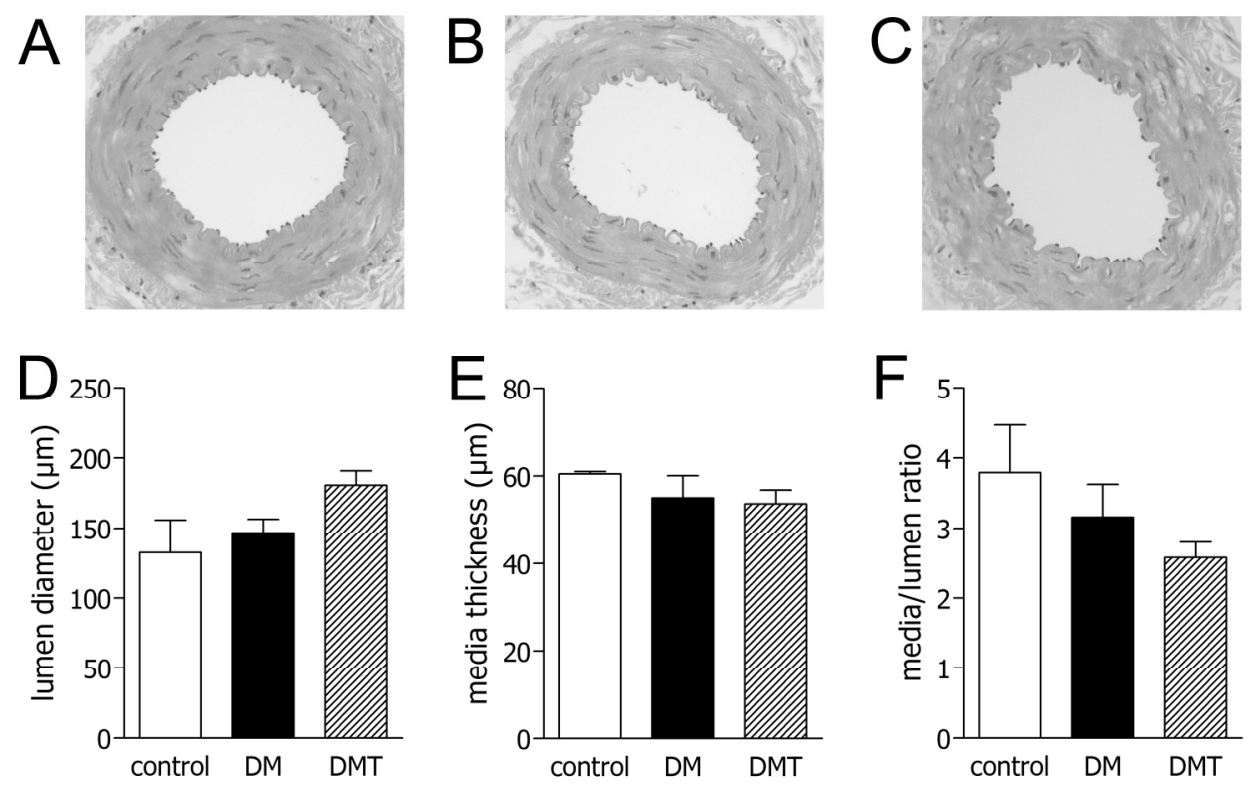

\section{FIGURE 5.3}

Representative HE-stained slices of saphenous artery after in vitro experimentation. HE stained sections of control (A), DM (B) and DMT (C) animals, magnification 200x. Lumen diameter $(D)$, media thickness $(E)$ and media to lumen ratio $(F)$ were calculated from these sections.

\section{Discussion}

The present study demonstrates that transgenic glyoxalase-1 overexpression can restore the mild DM-induced impairments in contraction and relaxation in the rat saphenous artery. This suggests that DM exerts its deleterious effects in the lower extremity vasculature at least partly via MGO. This is in accordance with present literature on vascular dysfunction in DM. DM increases the amount of protein glycation in the circulation. ${ }^{20,21}$ MGO mediates the formation of $A G E$, as a result of hyperglycemia-induced ROS production. ${ }^{22}$ Both in vitro and in vivo, AGEs and their 
precursors, such as MGO, are associated with endothelial dysfunction and vascular disease. ${ }^{5,21,23}$ The role of MGO was investigated in several studies. MGO inhibited endothelial nitric oxide synthase, possibly by an indirect mechanism. ${ }^{24}$ In an animal model of hypertension, aminoguanidine (AG), which breaks down AGEs and oxoaldehydes, prevented the vascular damage and restored the endotheliumdependent relaxation to $\mathrm{ACh}^{25}$ In addition, AG reduced oxidative stress on vascular smooth muscle. ${ }^{26}$ More specific inhibition of MGO can be obtained by enhancing the glyoxalase system. MGO, and to a lesser extent the other oxoaldehydes, are degraded by GLO1 and subsequently glyoxalase- 2 into hydroxyacids. ${ }^{27}$ The glyoxalase system was shown to be involved in diabetic complications. ${ }^{28,29}$ In cultured ECs, overexpression of GLO1 prevented hyperglycemia-induced AGE formation. ${ }^{23}$ In addition, in high glucose conditions, overexpression of GLO1 normalized increased AGE-RAGE binding, ${ }^{22}$ which is known to alter regulation of vascular tone. ${ }^{30}$ In rat mesenteric arteries, Brouwers et al demonstrated that hyperglycemia-induced impairment of endothelium-dependent relaxation is mediated by MGO. ${ }^{31}$ Transgenic overexpression of GLO1 restored the levels of AGEs and ROS, which were elevated in a 12-week DM rat model. ${ }^{18}$

In the present study, DM had mild effects on vascular reactivity. Contraction was only mildly affected by DM. And although endothelium-dependent relaxation was not different between the groups, relaxation induced by SNP was decreased in DM vascular segments. This difference was partially restored by GLO1 overexpression. Stimulation of sGC by Bay41-2272 did not differ between the groups, suggesting that DM decreased NO sensitivity without affecting SGC function. This indicates that either binding of NO to SGC is affected, or that NO is scavenged. In the rabbit hindlimb, experimental DM had similar effects on contraction and endotheliumdependent relaxation, but clearly showed differences at the level of SGC, the target for NO in vascular smooth muscle (chapter 4 of the present thesis). This SGC difference was not present in the rat saphenous arteries. Although different arteries were used, it is remarkable that the SGC impairment was not found in the present study, as the vessels used in these studies are regionally close and functionally similar. In addition, the rat and rabbit models of experimental DM are comparable. Obviously, for a better comparison between the two studies, rat hindleg collateral arteries should have been used. In our experimental set-up however, it was not possible to study vessels of this small caliber. It can not be excluded that differences between the studies reflect interspecies variability, but more likely it illustrates the heterogeneity of vascular complications of DM. This is supported by the observations that in mesenteric arteries from the same animals, 
endothelium-dependent relaxation was clearly attenuated, in contrast to our lower extremity arteries. ${ }^{17}$ The impaired endothelium-dependent relaxation was improved by GLO1 overexpression.

Morphology of the arteries was not visibly different between the groups. Transgenic animals seemed to have a larger lumen compared to the other groups, although the difference was not statistically significant. In rats, mesenteric artery diameter was larger in experimental DM compared to controls, whereas media thickness was similar. ${ }^{32}$ In clinical DM, small artery remodelling is often affected by concomitant hypertension and dyslipidemia, but can benefit from improved metabolic control. ${ }^{33,34}$

Notably, ACh did not induce a strong relaxation during PHE-induced contraction, whereas relaxation during $\mathrm{K}^{+}$-induced contraction was up to $75 \%$. This may indicate that relaxation of the saphenous artery is not largely dependent on the endothelium. However, endothelial function of the saphenous artery was previously confirmed in the rat. ${ }^{35,36}$ Although the presence of ECs in the arterial segments was visually confirmed with light microscopy after the reactivity experiments, it is possible that endothelial function was reduced by the experimentation. The relaxing effect of $\mathrm{ACh}$ during depolarization-induced contraction may merely be a presynaptic effect of $\mathrm{ACh}^{37,38}$

It seems that the present study is statistically underpowered. The differences in vascular reactivity between DM and control arteries were less pronounced than in other vascular beds. ${ }^{4,39,40}$ But although the differences in reactivity between DM and control arteries are small, the increased contractions and decreased relaxations were consistently normalized by GLO1. Extended experiments are needed to confirm these findings.

In conclusion, in the present study we demonstrate that in the lower limb the detrimental effects of DM on vasoreactivity, although mild, were at least in part mediated by MGO. GLO1 transgenic overexpression consistently restored the relaxation of the distal saphenous artery. Further research in this vascular bed, relevant for lower extremity complications of DM, is needed. 


\section{References}

1. Prompers L, Schaper N, Apelqvist J, Edmonds M, Jude E, Mauricio D, Uccioli L, Urbancic V, Bakker K, Holstein P, Jirkovska A, Piaggesi A, Ragnarson-Tennvall G, Reike H, Spraul M, Van Acker K, Van Baal J, Van Merode F, Ferreira I, Huijberts M: Prediction of outcome in individuals with diabetic foot ulcers: focus on the differences between individuals with and without peripheral arterial disease. The EURODIALE Study. Diabetologia 2008;51:747-755.

2. Dolan NC, Liu K, Criqui MH, Greenland P, Guralnik JM, Chan C, Schneider JR, Mandapat AL, Martin G, McDermott MM: Peripheral artery disease, diabetes, and reduced lower extremity functioning. Diabetes Care 2002;25:113-120.

3. Veves A, Akbari CM, Primavera J, Donaghue VM, Zacharoulis D, Chrzan JS, DeGirolami U, LoGerfo FW, Freeman R: Endothelial dysfunction and the expression of endothelial nitric oxide synthetase in diabetic neuropathy, vascular disease, and foot ulceration. Diabetes 1998;47:457-463.

4. De Vriese AS, Verbeuren TJ, Van de Voorde J, Lameire NH, Vanhoutte PM: Endothelial dysfunction in diabetes. Br J Pharmacol 2000;130:963-974.

5. Brownlee M: Biochemistry and molecular cell biology of diabetic complications. Nature 2001;414:813-820.

6. Tan KC, Chow WS, Ai VH, Metz C, Bucala R, Lam KS: Advanced glycation end products and endothelial dysfunction in type 2 diabetes. Diabetes Care 2002;25:1055-1059.

7. Wolffenbuttel BH, Boulanger CM, Crijns FR, Huijberts MS, Poitevin P, Swennen GN, Vasan S, Egan JJ, Ulrich P, Cerami A, Levy BI: Breakers of advanced glycation end products restore large artery properties in experimental diabetes. Proc Natl Acad Sci U S A 1998;95:4630-4634.

8. Schalkwijk CG, Stehouwer CD: Vascular complications in diabetes mellitus: the role of endothelial dysfunction. Clin Sci (Lond) 2005;109:143-159.

9. Sheetz MJ, King GL: Molecular understanding of hyperglycemia's adverse effects for diabetic complications. Jama 2002;288:2579-2588.

10. Huijberts MS, Schaper NC, Schalkwijk CG: Advanced glycation end products and diabetic foot disease. Diabetes Metab Res Rev 2008;24 Suppl 1:S19-24.

11. Schaper NC, Nabuurs-Franssen MH, Huijberts MS: Peripheral vascular disease and type 2 diabetes mellitus. Diabetes Metab Res Rev 2000;16 Suppl 1:S11-15.

12. Shi Y, So KF, Man RY, Vanhoutte PM: Oxygen-derived free radicals mediate endothelium-dependent contractions in femoral arteries of rats with streptozotocininduced diabetes. $\mathrm{Br}$ J Pharmacol 2007;152:1033-1041.

13. Miranda FJ, Alabadi JA, Llorens S, Ruiz de Apodaca RF, Centeno JM, Alborch E: Influence of experimental diabetes on regulatory mechanisms of vascular response of rabbit carotid artery to acetylcholine. Life Sci 2000;66:2071-2080.

14. Sobrevia L, Mann GE: Dysfunction of the endothelial nitric oxide signalling pathway in diabetes and hyperglycaemia. Exp Physiol 1997;82:423-452.

15. Ungvari Z, Pacher P, Rischak K, Szollar L, Koller A: Dysfunction of nitric oxide mediation in isolated rat arterioles with methionine diet-induced hyperhomocysteinemia.

Arterioscler Thromb Vasc Biol 1999;19:1899-1904. 
16. Gerassimou C, Kotanidou A, Zhou Z, Simoes DC, Roussos C, Papapetropoulos A: Regulation of the expression of soluble guanylyl cyclase by reactive oxygen species. $\mathrm{Br}$ J Pharmacol 2007; 150:1084-1091.

17. Brouwers O, Niessen PM, Miyata T, Brownlee M, De Mey JG, Stehouwer CD, Schalkwijk CG: Glyoxalase-I overexpression improves endothelial dysfunction and attenuates renal impairment in diabetic rats. in Brouwers $\mathrm{O}(\mathrm{ed})$ : Intracellular glycation and endothelial dysfunction; role of methylglyoxal. Maastricht: Maastricht University, 2011.

18. Brouwers O, Niessen PM, Ferreira I, Miyata T, Scheffer PG, Teerlink T, Schrauwen P, Brownlee M, Stehouwer CD, Schalkwijk CG: Overexpression of glyoxalase-I reduces hyperglycemia-induced levels of advanced glycation end products and oxidative stress in diabetic rats. J Biol Chem 2011;286:1374-1380.

19. Halpern W, Mulvany MJ: Tension responses to small length changes of vascular smooth muscle cells [proceedings]. J Physiol 1977;265:21P-23P.

20. Ahmed N: Advanced glycation endproducts--role in pathology of diabetic complications. Diabetes Res Clin Pract 2005;67:3-21.

21. Negre-Salvayre A, Salvayre R, Auge N, Pamplona R, Portero-Otin M: Hyperglycemia and glycation in diabetic complications. Antioxid Redox Signal 2009;11:3071-3109.

22. Yao $D$, Brownlee $M$ : Hyperglycemia-induced reactive oxygen species increase expression of the receptor for advanced glycation end products (RAGE) and RAGE ligands. Diabetes 2010;59:249-255.

23. Shinohara M, Thornalley PJ, Giardino I, Beisswenger P, Thorpe SR, Onorato J, Brownlee M: Overexpression of glyoxalase-I in bovine endothelial cells inhibits intracellular advanced glycation endproduct formation and prevents hyperglycemiainduced increases in macromolecular endocytosis. J Clin Invest 1998;101:1142-1147.

24. Brouwers O, Teerlink T, van Bezu J, Barto R, Stehouwer CD, Schalkwijk CG: Methylglyoxal and methylglyoxal-arginine adducts do not directly inhibit endothelial nitric oxide synthase. Ann N Y Acad Sci 2008;1126:231-234.

25. Wang X, Chang T, Jiang B, Desai K, Wu L: Attenuation of hypertension development by aminoguanidine in spontaneously hypertensive rats: role of methylglyoxal. Am J Hypertens 2007;20:629-636.

26. Oak JH, Youn JY, Cai H: Aminoguanidine inhibits aortic hydrogen peroxide production, VSMC NOX activity and hypercontractility in diabetic mice. Cardiovasc Diabetol 2009;8:65.

27. Thornalley PJ: Glyoxalase I--structure, function and a critical role in the enzymatic defence against glycation. Biochem Soc Trans 2003;31:1343-1348.

28. McLellan AC, Thornalley PJ, Benn J, Sonksen PH: Glyoxalase system in clinical diabetes mellitus and correlation with diabetic complications. Clin Sci (Lond) 1994;87:21-29.

29. Bourajjaj M, Stehouwer CD, van Hinsbergh VW, Schalkwijk CG: Role of methylglyoxal adducts in the development of vascular complications in diabetes mellitus. Biochem Soc Trans 2003;31:1400-1402.

30. Rojas A, Morales MA: Advanced glycation and endothelial functions: a link towards vascular complications in diabetes. Life Sci 2004;76:715-730.

31. Brouwers O, Niessen PM, Haenen G, Miyata T, Brownlee M, Stehouwer CD, De Mey JG, Schalkwijk CG: Hyperglycaemia-induced impairment of endothelium-dependent 
vasorelaxation in rat mesenteric arteries is mediated by intracellular methylglyoxal levels in a pathway dependent on oxidative stress. Diabetologia 2010;53:989-1000.

32. Crijns FR, Wolffenbuttel BH, De Mey JG, Struijker Boudier HA: Mechanical properties of mesenteric arteries in diabetic rats: consequences of outward remodeling. Am J Physiol 1999;276:H1672-1677.

33. Greenstein AS, Price A, Sonoyama K, Paisley A, Khavandi K, Withers S, Shaw L, Paniagua O, Malik RA, Heagerty AM: Eutrophic remodeling of small arteries in type 1 diabetes mellitus is enabled by metabolic control: a 10-year follow-up study. Hypertension 2009;54:134-141.

34. Schofield I, Malik R, Izzard A, Austin C, Heagerty A: Vascular structural and functional changes in type 2 diabetes mellitus: evidence for the roles of abnormal myogenic responsiveness and dyslipidemia. Circulation 2002;106:3037-3043.

35. Sandow SL, Goto K, Rummery NM, Hill CE: Developmental changes in myoendothelial gap junction mediated vasodilator activity in the rat saphenous artery. J Physiol 2004;556:875-886.

36. Stoen R, Lossius K, Karlsson JO: Acetylcholine-induced vasodilation may depend entirely upon NO in the femoral artery of young piglets. Br J Pharmacol 2003;138:3946.

37. Vanhoutte PM, Levy MN: Prejunctional cholinergic modulation of adrenergic neurotransmission in the cardiovascular system. Am J Physiol 1980;238:H275-281.

38. Burnstock $G$, Warland JJ: A pharmacological study of the rabbit saphenous artery in vitro: a vessel with a large purinergic contractile response to sympathetic nerve stimulation. Br J Pharmacol 1987;90:111-120.

39. Crijns FR, Struijker Boudier HA, Wolffenbuttel BH: Arteriolar reactivity in conscious diabetic rats: influence of aminoguanidine treatment. Diabetes 1998;47:918-923.

40. Pieper GM, Dondlinger LA: Plasma and vascular tissue arginine are decreased in diabetes: acute arginine supplementation restores endothelium-dependent relaxation by augmenting cGMP production. J Pharmacol Exp Ther 1997;283:684-691. 


\section{ChAPTER 5}




\section{ChAPTER 6}

\section{The effect of local vasodilator}

therapy on arteriogenesis in

the rabbit ischemic hindlimb

Matthijs S. Ruiter

Jolanda M. van Golde

Nicolaas C. Schaper

Walter H. Backes

Aylvin A. Dias

Mark J. Post

Maya S. Huijberts 


\section{Summary}

Objective - Improvement of arteriogenesis has become a focus for treatment of PAD. We investigated whether prolonged local administration of terazosin improved arteriogenesis in the rabbit ischemic hindlimb.

Methods - In vitro, terazosin potency was established in isolated collaterals. In vivo, eleven New Zealand White rabbits underwent unilateral femoral artery ligation and minipump insertion, delivering either terazosin or saline. $\mathrm{X}$-ray angiography was performed immediately, 7 and 21 days after ligation. From this, relative blood volume (RBV), relative filling speed, collateral volume index (CVI), and number of collaterals were determined. The capillary density was assessed in muscle biopsies postmortem.

Results - Terazosin inhibited phenylephrine-induced contraction at all concentrations in vitro $(P=0.018)$. In vivo, terazosin acutely enhanced the number of recruited collaterals (treated: $4.7 \pm 0.5$, control: $3.7 \pm 0.2$, $\mathrm{P}=0.041$ ) and relative filling speed (treated: $0.53 \pm 0.11$, control: $0.23 \pm 0.06, P=0.042$ ). After 1 week of treatment, the experimental group showed a threefold higher CVI (92 \pm 41$)$ compared to controls (30 \pm 6 , $\mathrm{P}=0.045)$. Two weeks post treatment, RBV was higher in the treated group $(1.00 \pm 0.03)$ compared to controls $(0.89 \pm 0.04, P=0.035)$. Terazosin did not affect blood pressure and capillary density.

Conclusions - Administration of terazosin improves blood volume in the occluded rabbit hindlimb by promoting collateral recruitment and outward remodeling, without affecting capillary density and blood pressure. 


\section{Introduction}

PAD is a common problem in the elderly population. Untreated PAD can progress to critical limb ischemia, and is associated with decreased mobility, foot ulcers and lower extremity amputation. ${ }^{1,2}$ The debilitating consequences are associated with substantial medical costs. ${ }^{3,4}$ Both surgical and endovascular procedures can be used for the treatment of PAD. Unfortunately, these therapies have limited value in case of extensive or distal manifestations and co-morbidities. ${ }^{5}$

An alternative strategy is to stimulate the natural processes of vessel growth, angiogenesis and arteriogenesis. Angiogenesis is the sprouting of new capillaries. However, newly formed capillary networks are prone to rupture and their conductive capacity is limited. ${ }^{6}$ Arteriogenesis is the functional outward remodeling of pre-existing anastomoses to conduit arteries. The dramatic increase in lumen of pre-existing arterioles can increase conduction vastly. ${ }^{7}$ In animal models of PAD, GF treatment has resulted in improvement of arteriogenesis. ${ }^{8,9}$ However, GF therapy has had limited success in clinical practice. ${ }^{10,11}$ Moreover, GF treatment can lead to detrimental side effects, including proliferative retinopathy, edema at the site of infusion and progression of plaque formation. ${ }^{12-14}$

Conductance obtained by GFs at high pharmacological doses is only a fraction of the conductance obtained by high shear stress ${ }_{1}^{15}$ which was shown to be the key factor in collateral remodeling. ${ }^{16}$ In peripheral ischemia, vasodilation may promote arteriogenesis by increasing flow in collateral arteries, which is known to induce shear stress on the vessel wall. ${ }^{17}$ Conversely, increased vascular tone may prevent recruitment of collaterals. In chronic limb ischemia, the $\alpha_{1}$-adrenoceptor-mediated contractile response in resistance arteries is elevated. ${ }^{18,19}$ In addition, vasomotor tone is elevated in several conditions associated with arterial occlusion, including obesity, insulin resistance, and $\mathrm{DM}^{20-22}$ Therefore, administration of an adrenoceptor antagonist may stimulate therapeutic neovascularization by enhancing collateral recruitment. In the rat ischemic hindlimb, $\alpha_{1}$-adrenoceptor antagonist prazosin elevated flow and collateral conductance acutely. ${ }^{23}$ In experimental vascular injury models, adrenoceptor stimulation with phenylephrine is associated with inward arterial remodeling, ${ }^{24}$ a process which can be attenuated by delivering an $\alpha_{1}$-adrenoceptor antagonist. ${ }^{25}$ Oral administration of an adrenoceptor antagonist already showed encouraging results in capillary sprouting and muscle perfusion in the hindlimb. ${ }^{26,27}$ Local administration of a vasodilator ensures a high concentration in the target area, without a systemic drop in blood pressure and steal to the non-occluded side. 
Therefore, the aim of the present study was to determine whether arteriogenesis in the rabbit ischemic hindlimb could be improved by prolonged local administration of terazosin. Terazosin is a potent $\alpha_{1}$-adrenoceptor antagonist historically used in hypertension and currently used against prostate hyperplasia. ${ }^{28,29}$ In a proof-of-principle experiment, we first established the presence of $\alpha_{1}$-adrenoceptors in hindlimb collaterals and the response to terazosin in a wire myograph setup. Then, we studied the effect of one week of local terazosin administration on therapeutic neovascularization in a rabbit ischemic hindlimb model. Measurements were conducted immediately after ligation, after one week of terazosin delivery and two weeks post-treatment to determine acute, prolonged and structural effects of the therapy, respectively. It was hypothesized that terazosin administration promotes outward remodeling of collateral arteries.

\section{Methods}

\section{Animal model}

Experiments were conducted under approval of the committee for animal care and ethics of the Maastricht University Medical Centre. Experiments were conducted in male New Zealand White rabbits weighing 3.0 to $3.5 \mathrm{~kg}$. For ex vivo testing of collateral arteries, vessels from 4 animals were used. Eleven rabbits were included for in vivo experiments on structural remodeling.

\section{Organ chamber experiments}

As vasoreactivity in hindlimb collaterals is poorly characterized, hindlimb collateral arteries were tested ex vivo in organ chamber experiments. Hindlimb collateral arteries of 4 healthy, untreated animals were rapidly isolated from the adductor magnus muscle directly after sacrifice. Collaterals were dissected from a predefined location, based on anatomic landmarks, as depicted in figure 6.1A. Vessel segments, typically with an external diameter between 180 and $240 \mu \mathrm{m}$, were mounted on two stainless steel wires (40 $\mu \mathrm{m}$ diameter, Danish Myo Technology, Denmark) in a wire myograph (Danish Myo Technology) between an isometric force transducer and a micropositioner. Chambers were filled with Krebs-Ringer bicarbonate solution $\left(118.5 \mathrm{mmol} / \mathrm{L} \mathrm{NaCl}, 4.7 \mathrm{mmol} / \mathrm{L} \mathrm{KCl}, 2.5 \mathrm{mmol} / \mathrm{L} \mathrm{CaCl}_{2}, 1.2\right.$ $\mathrm{mmol} / \mathrm{L} \mathrm{MgSO}{ }_{4}, 1.2 \mathrm{mmol} / \mathrm{L} \mathrm{KH}_{2} \mathrm{PO}_{4}, 25.0 \mathrm{mmol} / \mathrm{L} \mathrm{NaHCO}_{3}$, and $5.5 \mathrm{mmol} / \mathrm{L}$ glucose), heated to $37^{\circ} \mathrm{C}$ and aerated with $95 \% \mathrm{O}_{2}$ and $5 \% \mathrm{CO}_{2}$. After calibration, vessels were stretched to $90 \%$ of the internal circumference corresponding to a transmural pressure equivalent of $100 \mathrm{mmHg}$ using the procedure of Halpern and Mulvany. ${ }^{30}$ Viability of the endothelium was verified with ACh administration during 
precontraction with phenylephrine. Subsequently, the dose-response relationship for phenylephrine $\left(10^{-7}\right.$ to $\left.10^{-3.5} \mathrm{~mol} / \mathrm{L}\right)$ was detemined either in absence of terazosin, or after 10 minutes of incubation with one of three concentrations $\left(10^{-6}\right.$, $\left.10^{-5.5}, 10^{-5} \mathrm{~mol} / \mathrm{L}\right)$. All chemicals were obtained from Sigma-Aldrich.

\section{In vivo experiments}

Eleven animals underwent unilateral femoral artery ligation. The contralateral femoral artery was sham treated. Animals were randomly assigned to either the experimental group $(n=5)$ receiving terazosin (Sigma-Aldrich) dissolved in saline $(20 \mu \mathrm{g} / \mu \mathrm{L})$, or the control group $(n=6)$ receiving saline only. Surgery was performed under anesthesia and sterile conditions, as described before. ${ }^{31}$ Briefly, the femoral artery was exposed and canulated with a (3 French) sterile polyethylene catheter (inner diameter $1 \mathrm{~mm}$; outer diameter $1.5 \mathrm{~mm}$ ). The catheter was placed with the tip positioned $1 \mathrm{~cm}$ distal to the branches of the lateral femoral circumflex artery and the profunda femoral artery, pointing upstream in order to continuously deliver the substance first-pass into the collateral circulation. The location of the catheter tip is depicted in figure 6.1A. The catheter was attached to an osmotic pump (Alzet 2ML1, Alza Corp., USA), which was implanted subcutaneously in the abdomen, releasing its contents over 7 days into the hindlimb circulation (pumping rate $10 \mu \mathrm{L} / \mathrm{h}$ ). During surgical procedures mean arterial blood pressure (MABP) was monitored in the carotid artery to determine systemic effects of terazosin. After the measurements performed at day 21 , the animals were euthanized by an overdose of pentobarbital. Subsequently, muscle biopsies were collected and the content of the minipump was determined to ensure the drug was released.

\section{$\mathrm{X}$-ray angiography}

Hindlimb vasculature was characterized by serial XRA performed immediately (day $0), 7$ days and 21 days after ligation, as described previously. ${ }^{32}$ In short, through the carotid artery an angiographic catheter was positioned proximal from the bifurcation of the iliac artery. Angiographic recording of hindlimb vasculature (inplane resolution $0.3 \times 0.3 \mathrm{~mm}$; field of view $220 \times 220 \mathrm{~mm}$; frame refresh rate 8 $\mathrm{msec}$; tube voltage $72 \mathrm{kV}$ ) was performed during infusion of Iohexol (240 mg $\mathrm{I} / \mathrm{mL}$, Omnipaque, Amersham Health, the Netherlands) with a portable X-ray system (BV Pulsera, Philips Medical Systems, The Netherlands). Angiographic recordings were stored in a digital format for off-line image analysis. 


\section{Collateral volume, relative blood volume and relative filling speed}

From the XRA recordings, a volume index was calculated as described previously, ${ }^{32}$ providing a measure for luminal volume of the collateral circulation. In the present study we use the term collateral volume index. In brief, precontrast image frames (frame number 5-15) of the angiographic timeseries were averaged to provide a noise-suppressed precontrast mask image (intensity, $I_{\text {pre }}$ ). Image frames during maximal enhancement of the collateral arteries (typically 10 frames) in the manually predefined region of interest (ROI) in the adductor magnus muscle of the ligated limb in the direct surrounding of the occlusion were averaged to provide a noise suppressed maximal contrast image $\left(I_{\max }\right)$. For signal analysis the quantitative description by Bushberg is used. ${ }^{33}$ Subtraction of $I_{\max }$ and $I_{\text {pre }}$ reveals the number of pixels $(0.3 \times 0.3 \mathrm{~mm})$ opacified by the contrast agent, representing collateral filling. The signal intensity of each pixel was normalized to the maximal absolute signal intensity in the aorta. Pixels with an intensity below $1 \%$ of the aortic intensity were discarded as noise. Collateral volume index (CVI) is defined as the sum of all enhanced pixels in the region of collateral circulation times their relative intensities.

In addition, volume and speed of distal filling were assessed, as measures for the conductive capacity of the collateral arteries. The absolute signal change within the predefined ROIs was calculated for all the frames during contrast inflow. A representative time series graph of the signal change is shown in figure 6.1B. Time series typically consisted of a steep increase in absolute signal change, a horizontal part, and a decrease during washout. Filling speed was defined as the slope of the steep increase of the graph. To correct for differences in injection speed and physiological differences across animals, the filling speed is expressed as a ratio of the ligated limb divided by the sham treated limb. Similarly, relative blood volume is the area under the curve from the ligated limb divided by the AUC from the sham side.

\section{Number of collaterals and lumen of feeding arteries}

On the angiographic recordings the number of visible collaterals was determined in a blinded fashion by two independent observers for day 0,7 and 21 according to the Longland method. ${ }^{34}$ In addition, internal diameters of the lateral femoral circumflex artery and profunda femoral artery were determined in the ligated limb, to reveal luminal changes in the feeding arteries directly proximal to the collateral arteries. 


\section{Capillary to muscle fiber ratio}

Postmortem muscle biopsies were taken from the adductor longus, anterior tibial and soleus muscle of the ligated limb and stored at $-80^{\circ} \mathrm{C}$ until processing. Crosssectional $10 \mu \mathrm{m}$ thick slices were cut perpendicular to the muscle fiber direction and stained using nitroblue tetrazolium / 5 bromo-4-chloro-3-indolylphosphate-ptoluidine salt (NBT/BCZP; Gibco, Grand Island, NY) of alkaline phosphatase in ECs, as described previously. ${ }^{35}$ The capillary to muscle fiber ratio was determined independently by two observers in a blinded fashion, using optical microscopy (magnification 200x) in three randomly selected optic fields in each muscle section.
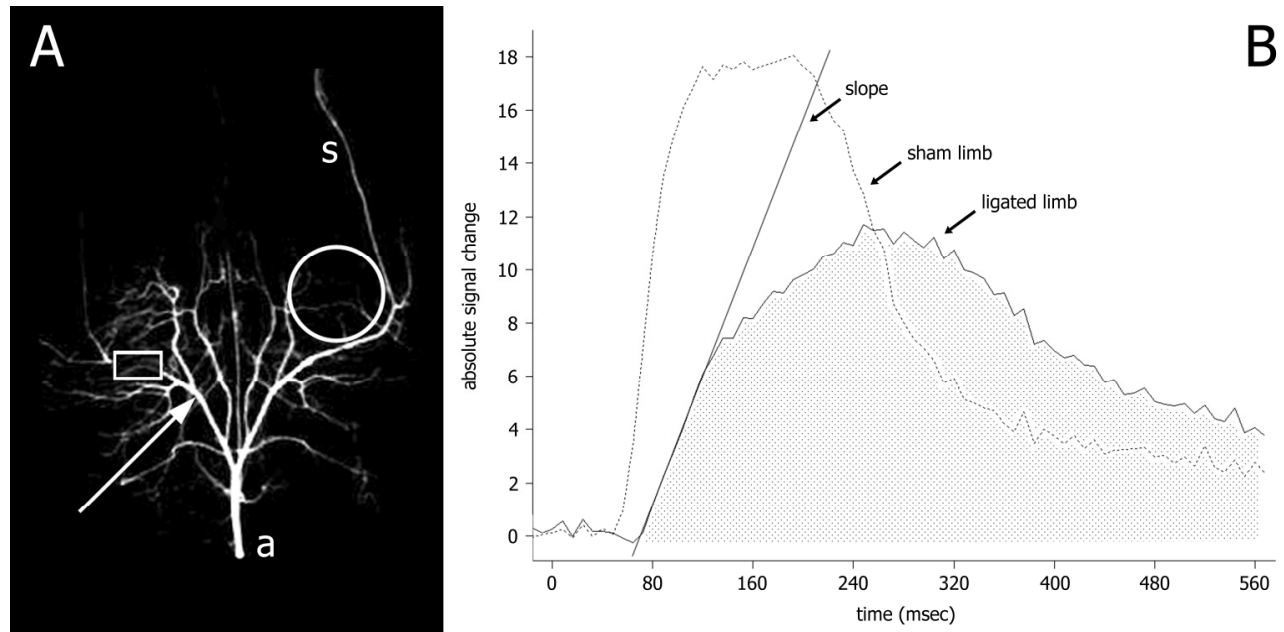

FIGURE 6.1

A: Digital subtraction angiogram of rabbit hindquarters, showing both the left ligated and right sham-treated limb. (a) indicates aorta and (s) indicates rightside saphenous artery. The white rectangle depicts location of femoral artery ligation; the white circle indicates the collaterals isolated for organ bath experiments. The arrow indicates the position of the catheter tip for drug delivery in the femoral artery. B: Representative graph of a distal filling timeseries, showing filling in ligated limb and sham limb, from which filling speed (slope) and blood volume (area under the curve, dotted area) were determined.

\section{Statistical analysis}

Data are presented as mean \pm standard error of the mean (SEM). Analysis of the organ chamber experiments was performed with GraphPad Prism 4.0 for Windows. Contractions are expressed in terms of active wall tension $(\mathrm{N} / \mathrm{m})$, calculated as the force divided by twice the length of the segment. Groups were compared with oneway ANOVA followed by Student-Newman-Keuls post hoc test. Analysis of the results from in vivo experiments was performed using SPSS 15 for Windows. Differences between measurements on day 0,7 and 21 within the groups were 
tested with Friedman's ANOVA, followed by the Wilcoxon signed-rank test with Bonferroni correction for repeated measurements. Differences between control and experimental group were tested using the Mann-Whitney $U$ test for independent samples. Differences were considered significant when $\mathrm{P}<0.05$.

\section{Results}

\section{Effect of terazosin on contraction}

Maximal phenylephrine (PHE) induced contraction was $8.0 \pm 1.1 \mathrm{~N} / \mathrm{m}$ in untreated vessels. Collateral arteries incubated with terazosin did not reach maximal contraction at the PHE concentrations used. Terazosin significantly inhibited PHEinduced contraction at all 3 concentrations ( $\mathrm{P}=0.018, \mathrm{~N}=4$ for all conditions), as illustrated by the shift of the dose response curve to higher PHE concentration, shown in figure 6.2. Inhibition of the contractile response appeared to be dosedependent, as a higher concentration corresponds with more rightward shift.

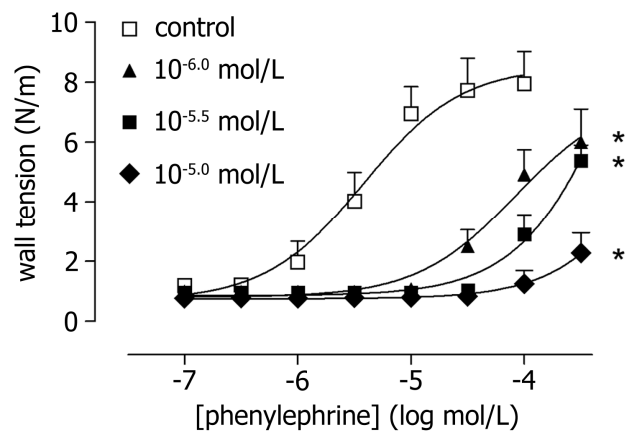

\section{FigURE 6.2}

Active wall tension as a function of phenylephrine concentration (mean + SEM) in absence or presence of terazosin. Open squares depict untreated vessels, closed markers represent vessels incubated with terazosin. $\mathrm{N}=4$ for all conditions. * indicates $\mathrm{P}<0.05$ compared to control vessels.

\section{Mean arterial blood pressure}

The animals endured the operations well. Typically, within 2 days after arterial ligation the animals made use of their ligated limb. No signs of necrosis were observed. Both in control and experimental group, MABP did not change over time (treated, day 0: $59.5 \pm 0.7$; day 7: $52.5 \pm 3.0$; day 21: $74.5 \pm 5.9$. Control, day 0: $64.9 \pm 6.8$; day 7: $56.2 \pm 3.0$; day $21: 61.4 \pm 9.6$ ).

\section{Number of collaterals}

In both groups, the total number of visible collaterals (figure $6.3 \mathrm{~A}$ ) changed significantly over time (treated: $P=0.022$; control: $P=0.005$ ). No significant differences were found between day 7 and 21 in both groups. Acutely, more collateral arteries were visible in the treated group $(4.7 \pm 0.5)$ than in the control 
group ( $3.7 \pm 0.2, P=0.041$ ). The number of visible collaterals after 7 and 21 days was not different between the groups.
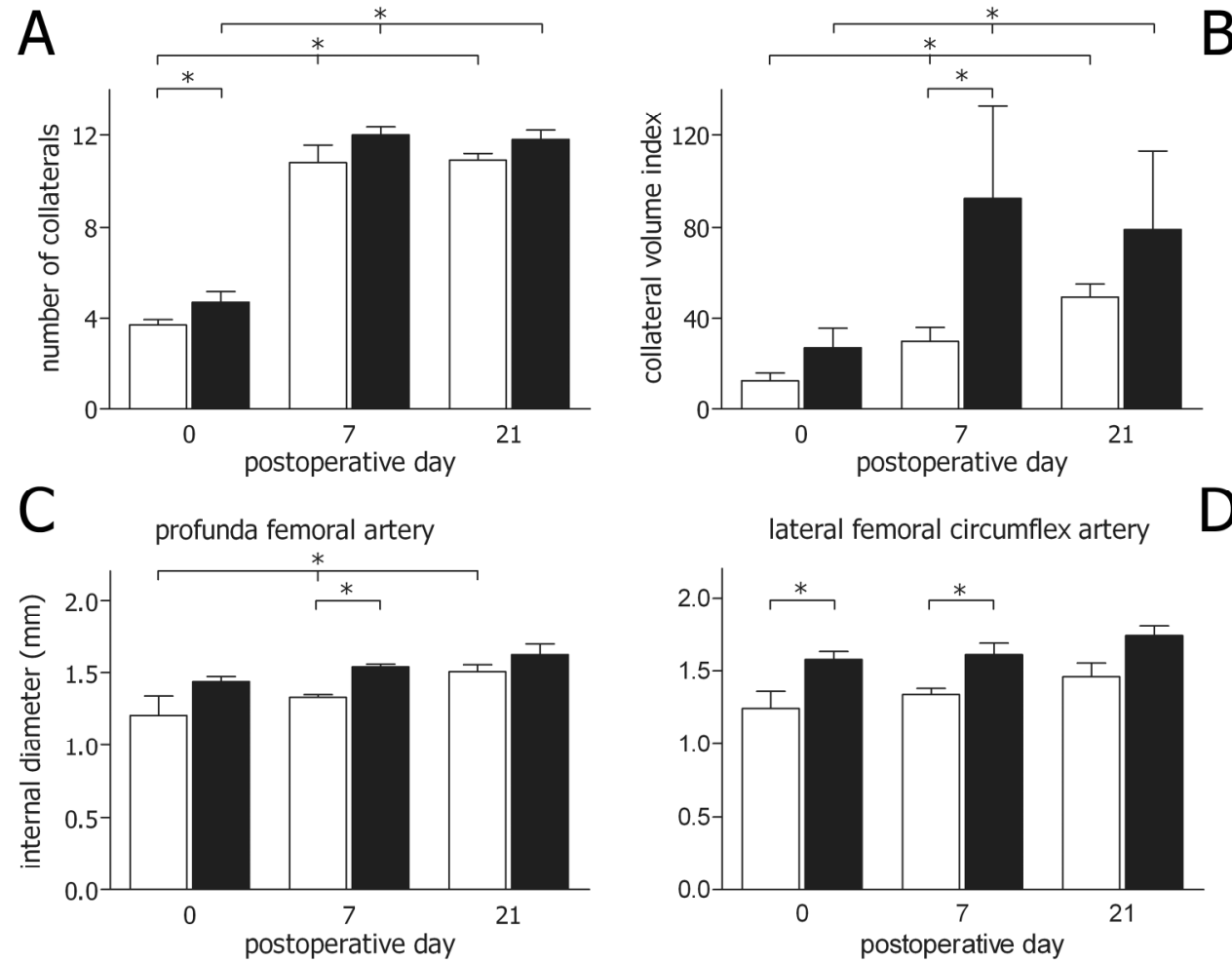

\section{FIGURE 6.3}

Morphological differences 0,7 and 21 days after ligation. A: Number of collaterals. B: Collateral volume index. C: Internal diameter of profunda femoral artery. D: Internal diameter of lateral profunda circumflex artery. Filled bars represent treated animals, open bars represent controls. Error bars depict SEM. * indicates $\mathrm{P}<0.05$.

\section{Collateral volume index}

CVI increased significantly over time in both groups (treated: $P=0.022$; control: $\mathrm{P}=0.006$ ) as depicted in figure $6.3 \mathrm{~B}$. On day 0 , i.e. shortly after ligation and the start of terazosin delivery, CVI was not different between the groups. On day 7 , the treated group showed a threefold higher CVI $(92 \pm 41)$ compared to the control group ( $30 \pm 6, P=0.045)$. At day $21, C V I$ in the treated group was $79 \pm 34$, as opposed to $49 \pm 6$, but this difference did not reach statistical significance.

\section{Internal diameter of feeding arteries}

The internal diameter of the profunda femoral artery increased significantly over time in the treated group $(P=0.034)$, but not in the control group, as shown in 
figure 6.3C. The profunda femoral artery lumen was higher in the experimental group compared to the controls at day $7(P=0.005)$, but not on day 0 and 21 . The lateral femoral circumflex artery diameter did not change significantly over time in the experimental or control group. The experimental group showed a higher internal diameter than the control group, a difference significant at day 0 $(P=0.044)$ and day $7(P=0.022)$, but not on day $21(P=0.067)$.

\section{Relative filling speed}

The filling speed in the ligated limb improved significantly over time in both the treated $(P=0.022)$ and control group $(P=0.009)$, as illustrated in figure 6.4A. In the experimental group, relative filling speed was higher $(0.53 \pm 0.11)$ than in the control group acutely $(0.23 \pm 0.06, \mathrm{P}=0.042)$, but not at day 7 and 21 .
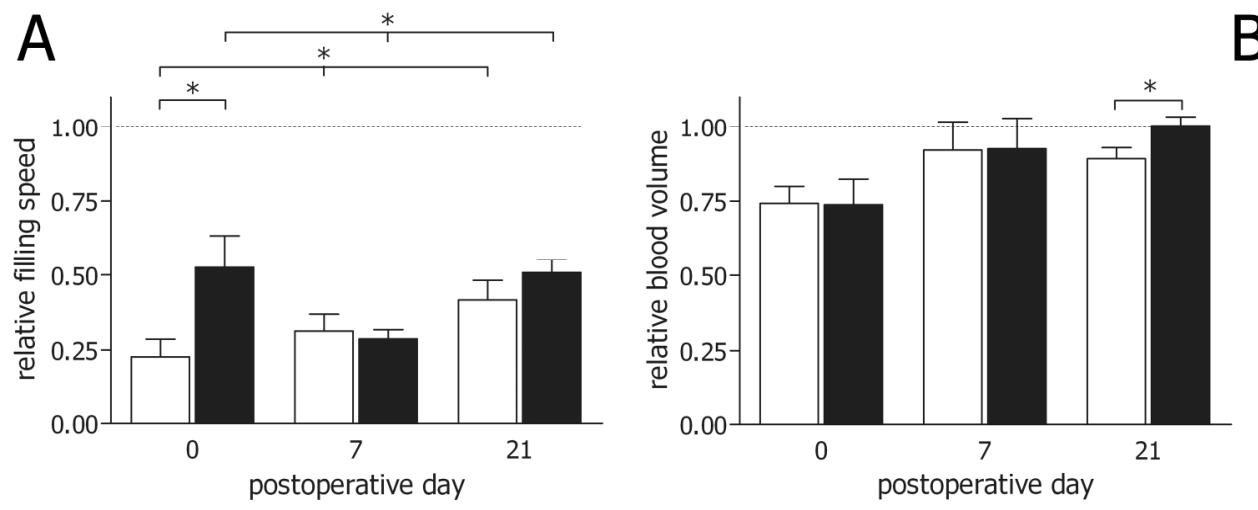

FIGURE 6.4

Functional differences 0,7 and 21 days after ligation. A: relative filling speed (ratio ligated/sham). B: relative blood volume in the hindlimb (ratio ligated/sham). Filled bars represent treated animals, open bars represent controls. Error bars depict SEM. * indicates $\mathrm{P}<0.05$.

\section{Relative blood volume}

The relative blood volume (RBV) of arteries distal to the ligation site, as expressed by the area under the curve of the signal change timeseries (figure 6.4B), was not different between groups at day 0 and 7. At day 21, the treated group showed improved RBV $(1.00 \pm 0.03)$ compared to the control group $(0.89 \pm 0.04$, $P=0.035)$.

\section{Capillary to fiber ratio}

No differences in capillary to fiber ratio were present between the treated and control group in the adductor longus, anterior tibial or soleus muscle 3 weeks after ligation. In one adductor biopsy, capillary to fiber ratio could not be determined 
due to poor quality of the slices. Capillary to fiber ratio in the adductor longus muscle was $1.5 \pm 0.6$ in the treated group and $1.0 \pm 0.1$ in controls. In the anterior tibial muscle, capillary to fiber ratio was $2.3 \pm 0.4$ in the treated group and $2.1 \pm 0.1$ in controls. Capillary to fiber ratio in the soleus muscle was $3.9 \pm 0.3$ in the experimental group versus $3.8 \pm 0.2$ in the control group.

\section{Discussion}

In the present study, prolonged intra-arterial administration of $\alpha_{1}$-adrenoceptor antagonist terazosin stimulated arteriogenesis in the ligated rabbit hindlimb. Two weeks after treatment, relative blood volume in the treated group was higher than in the control group. As proof of principle, presence of $\alpha_{1}$-adrenoceptors was confirmed ex vivo in collateral vessels isolated from the rabbit hindlimb. Terazosin incubation showed a dose-dependent inhibition of contraction, as demonstrated by the rightward shift in the phenylephrine-induced contractile response. In the in vivo experiments, terazosin delivery improved the number of recruited collaterals and the relative filling speed acutely. One week of intra-arterial terazosin administration elevated collateral volume index without affecting the number of visible collaterals. The higher collateral volume level persisted up to week three in the terazosin-treated group. No differences in capillary to fiber ratio were observed after three weeks. Overall, the treatment did not affect systemic blood pressure.

Arteriogenesis is a functional adaptation to impaired blood flow. In case of an arterial obstruction, pre-existing arterioles are transformed into mature conduit arteries within four weeks. ${ }^{36}$ Two phases can be distinguished in the process of collateral remodeling. First, in the acute phase, numerous pre-existing arterioles are recruited, increasing collateral conductance in the first week. ${ }^{17}$ Second, the structural phase of arteriogenesis consists of selective growth of large diameter vessels into conduit arteries, expanding the conductive capacity in the subsequent three weeks. Simultaneously, the recruited smaller caliber vessels are lost by pruning. ${ }^{17}$ Vasodilator delivery may promote arteriogenesis by amplifying the acute phase. Indeed we demonstrated that terazosin increased the recruitment of collaterals in the acute phase directly after ligation, as a higher number of visible vessels at day 0 indicates recruitment of vessels rather than remodeling. The higher recruitment was accompanied by improved filling speed. A rise in filling of collaterals can elevate shear stress on the endothelium, initiating outward remodeling. Delivery of the drug for 7 days led to a threefold increase in CVI. This large increment suggests an increase in structural remodeling, although direct vasodilatory effects of the remaining terazosin at the end of the administration 
period cannot be excluded. Since the higher CVI was sustained up to day 21 in the treated group, we conclude that the treatment indeed results in a structural adaptation. As the higher CVI was not accompanied by a higher number of visible collaterals, we conclude that there is an increase in small caliber collaterals, for which the Longland method lacks sensitivity. The CVI reached a plateau within 1 week in the terazosin-treated group, whereas CVI in the control group increased steadily over time. Possibly, untreated vessels are able to adapt to the same extent as the treated vessels, but require longer convalescence. Comparable remodeling patterns were observed in GF treatment, where the advantage of the treated group was lost after a number of weeks. ${ }^{37}$ So experimental therapies seem to accelerate arteriogenesis, rather than bringing it to a higher level. ${ }^{38}$ Recently, it was shown that oral sildenafil treatment improved blood flow in murine ischemic hindlimb after 7 days, which was maintained after 21 days. ${ }^{39}$ This finding supports the potential of vasodilator treatment for stimulation of arteriogenesis.

In addition to the morphological and functional changes of collateral arteries, we examined the feeding arteries supplying the collateral circulation. In the treated animals, we observed a clear increase in internal diameter of the lateral femoral circumflex artery on day 0 and 7 , and of the profunda femoral artery on day 7 . These arteries may respond to the higher demand downstream, or are affected by terazosin directly at second pass of the drug. Additionally, capillary sprouting was studied, as oral administration of $\alpha_{1}$-adrenoceptor antagonist prazosin, which is closely related to terazosin, has resulted in increased angiogenesis in the ligated rat hindlimb. ${ }^{27}$ However, we did not find differences after three weeks. It is unclear whether in our study terazosin failed to affect the number of capillaries, or that the change induced was lost after three weeks. Due to the serial measurements, we have no data on the capillary density one week after ligation.

The potential of $\alpha_{1}$-adrenoceptor antagonism on sprouting of capillaries was previously investigated in a number of studies. Oral prazosin administration resulted in increased capillary density in the rat ischemic hindlimb after 2 and 5 weeks. This resulted in a mild improvement of performance. ${ }^{27}$ In mice, oral prazosin elevated hindlimb capillary density after 2 weeks even without induction of ischemia. ${ }^{26}$ Capillary networks formed by sprouting and intussusception consist of endothelial tubes, without smooth muslce and adventitial layers. These capillaries are prone to rupture and can only improve perfusion locally, having a limited conductive capacity. ${ }^{6}$ In the present study, the terzosin-induced outward remodeling of collateral arteries in the hindlimb was not associated with sprouting of capillaries. 
In contrast to the aforementioned studies, local drug administration was used in the present study. Local delivery ensures high local concentration of the drug in the target area. Oral administration of a vasodilator in hindlimb ischemia can result in a blood flow steal to the nonligated side, which has a lower resistance than the ligated side. This steal phenomenon reduces flow through the collateral circulation, thus decreasing the stimulus for remodeling. Additionally, local delivery minimizes systemic detrimental side effects and a drop in central blood pressure, enabling application of a high dose of the drug.

A limitation of the present study is that arteriogenesis therapy was investigated in healthy animals. The natural process of outward remodeling can restore hindlimb perfusion to a large extent in healthy animals. ${ }^{7}$ However, recruitment and remodeling of collaterals is attenuated in pathological models. ${ }^{32,40}$ In addition, aging affects the response to hindlimb ischemia. With increasing age, the outward remodeling of pre-existing arterioles decreases, whereas capillary sprouting increases. ${ }^{41}$ These factors should be taken into account in future arteriogenesis research. Notably, the present study uses a model of acute ischemia for PAD. Clinically, chronic ischemia is more relevant. The present strategy however is an accepted model for the study of arteriogenesis. ${ }^{16,32,42-48}$ Other models may be considered for future research, for example hypercholesteremic animals. Based on the results of the present study, it is unclear whether prolonged delivery of a vasodilator is more effective than a single dose. A longer or shorter period of dilator delivery may be considered, exploring the therapeutic time frame. In addition, several bouts of administration may be beneficial, by limiting receptor desensitization and possibly resulting in a stronger stimulus, applying shear stress on the vessel wall repeatedly. The merit of our study is not providing insight into new mechanisms, but narrowing the gap between experimental research and clinical practice, introducing a drug common in clinical practice in a well-known experimental model. In addition to classical morphological measures, this study derived functional variables from angiographic recordings, assessing the amount and speed of blood flow through the collateral circulation.

The present study demonstrates the potential of adrenoceptor inhibition for stimulation of arteriogenesis. Prolonged administration of terazosin improves blood volume in the occluded rabbit hindlimb, by promoting collateral recruitment and outward remodeling, without affecting capillary density and blood pressure. These results encourage further exploration of local delivery of $\alpha_{1}$-adrenoceptor antagonists or other vasodilatory substances for stimulation of arterial remodeling. In the future, arteriogenesis research should extend to relevant pathological models in which arteriogenesis is attenuated. 


\section{References}

1. Dolan NC, Liu K, Criqui MH, Greenland P, Guralnik JM, Chan C, Schneider JR, Mandapat AL, Martin G, McDermott MM: Peripheral artery disease, diabetes, and reduced lower extremity functioning. Diabetes Care 2002;25:113-120.

2. Prompers $L$, Schaper $N$, Apelqvist J, Edmonds $M$, Jude E, Mauricio $D$, Uccioli L, Urbancic V, Bakker K, Holstein P, Jirkovska A, Piaggesi A, Ragnarson-Tennvall G, Reike H, Spraul M, Van Acker K, Van Baal J, Van Merode F, Ferreira I, Huijberts M: Prediction of outcome in individuals with diabetic foot ulcers: focus on the differences between individuals with and without peripheral arterial disease. The EURODIALE Study. Diabetologia 2008;51:747-755.

3. Holler D, Claes C, von der Schulenburg JM: Treatment costs and quality of life of patients with peripheral arterial occlusive disease--the German perspective. Vasa 2004;33:145-153.

4. Margolis J, Barron JJ, Grochulski WD: Health care resources and costs for treating peripheral artery disease in a managed care population: results from analysis of administrative claims data. J Manag Care Pharm 2005;11:727-734.

5. Beckman JA, Creager MA, Libby P: Diabetes and atherosclerosis: epidemiology, pathophysiology, and management. Jama 2002;287:2570-2581.

6. Heil M, Eitenmuller I, Schmitz-Rixen T, Schaper W: Arteriogenesis versus angiogenesis: similarities and differences. J Cell Mol Med 2006;10:45-55.

7. Schaper W, Buschmann I: Arteriogenesis, the good and bad of it. Cardiovasc Res 1999;43:835-837.

8. Buschmann IR, Hoefer IE, van Royen N, Katzer E, Braun-Dulleaus R, Heil M, Kostin S, Bode C, Schaper W: GM-CSF: a strong arteriogenic factor acting by amplification of monocyte function. Atherosclerosis 2001;159:343-356.

9. Nagy JA, Dvorak AM, Dvorak HF: VEGF-A(164/165) and PIGF: roles in angiogenesis and arteriogenesis. Trends Cardiovasc Med 2003;13:169-175.

10. van Royen N, Schirmer SH, Atasever B, Behrens CY, Ubbink D, Buschmann EE, Voskuil M, Bot P, Hoefer I, Schlingemann RO, Biemond BJ, Tijssen JG, Bode C, Schaper W, Oskam J, Legemate DA, Piek JJ, Buschmann I: START Trial: a pilot study on STimulation of ARTeriogenesis using subcutaneous application of granulocytemacrophage colony-stimulating factor as a new treatment for peripheral vascular disease. Circulation 2005;112:1040-1046.

11. Rajagopalan S, Mohler ER, 3rd, Lederman RJ, Mendelsohn FO, Saucedo JF, Goldman CK, Blebea J, Macko J, Kessler PD, Rasmussen HS, Annex BH: Regional angiogenesis with vascular endothelial growth factor in peripheral arterial disease: a phase II randomized, double-blind, controlled study of adenoviral delivery of vascular endothelial growth factor 121 in patients with disabling intermittent claudication. Circulation 2003; 108:1933-1938.

12. Duh E, Aiello LP: Vascular endothelial growth factor and diabetes: the agonist versus antagonist paradox. Diabetes 1999;48:1899-1906. 
13. Shyu KG, Chang $H$, Wang BW, Kuan P: Intramuscular vascular endothelial growth factor gene therapy in patients with chronic critical leg ischemia. Am J Med 2003;114:85-92.

14. Hayden MR, Tyagi SC: Vasa vasorum in plaque angiogenesis, metabolic syndrome, type 2 diabetes mellitus, and atheroscleropathy: a malignant transformation. Cardiovasc Diabetol 2004;3:1.

15. Schierling W, Troidl K, Troidl C, Schmitz-Rixen T, Schaper W, Eitenmuller IK: The Role of Angiogenic Growth Factors in Arteriogenesis. J Vasc Res 2009;46:365-374.

16. Pipp F, Boehm S, Cai WJ, Adili F, Ziegler B, Karanovic G, Ritter R, Balzer J, Scheler C, Schaper W, Schmitz-Rixen T: Elevated fluid shear stress enhances postocclusive collateral artery growth and gene expression in the pig hind limb. Arterioscler Thromb Vasc Biol 2004;24:1664-1668.

17. Eitenmuller I, Volger O, Kluge A, Troidl K, Barancik M, Cai WJ, Heil M, Pipp F, Fischer S, Horrevoets AJ, Schmitz-Rixen T, Schaper W: The range of adaptation by collateral vessels after femoral artery occlusion. Circ Res 2006;99:656-662.

18. Jarajapu YP, Coats P, McGrath JC, MacDonald A, Hillier C: Increased alpha(1)- and alpha(2)-adrenoceptor-mediated contractile responses of human skeletal muscle resistance arteries in chronic limb ischemia. Cardiovasc Res 2001;49:218-225.

19. Williams PB, Saelens DA: Release of norepinephrine by electrical field stimulation of collateral arteries from the hindlimb of the dog. J Cardiovasc Pharmacol 1983;5:786791.

20. Mather KJ, Mirzamohammadi B, Lteif A, Steinberg HO, Baron AD: Endothelin contributes to basal vascular tone and endothelial dysfunction in human obesity and type 2 diabetes. Diabetes 2002;51:3517-3523.

21. Bagi Z, Erdei N, Papp Z, Edes I, Koller A: Up-regulation of vascular cyclooxygenase-2 in diabetes mellitus. Pharmacol Rep 2006;58 Suppl:52-56.

22. White RE, Carrier GO: Enhanced vascular alpha-adrenergic neuroeffector system in diabetes: importance of calcium. Am J Physiol 1988;255:H1036-1042.

23. Taylor JC, Li Z, Yang HT, Laughlin MH, Terjung RL: Alpha-adrenergic inhibition increases collateral circuit conductance in rats following acute occlusion of the femoral artery. J Physiol 2008;586:1649-1667.

24. Erami C, Zhang H, Ho JG, French DM, Faber JE: Alpha(1)-adrenoceptor stimulation directly induces growth of vascular wall in vivo. Am J Physiol Heart Circ Physiol 2002;283:H1577-1587.

25. Teeters JC, Erami C, Zhang H, Faber JE: Systemic alpha 1A-adrenoceptor antagonist inhibits neointimal growth after balloon injury of rat carotid artery. Am J Physiol Heart Circ Physiol 2003;284:H385-392.

26. Baum O, Da Silva-Azevedo L, Willerding G, Wockel A, Planitzer G, Gossrau R, Pries AR, Zakrzewicz A: Endothelial NOS is main mediator for shear stress-dependent angiogenesis in skeletal muscle after prazosin administration. Am J Physiol Heart Circ Physiol 2004;287:H2300-2308.

27. Fulgenzi G, Graciotti L, Collis MG, Hudlicka O: The effect of alpha 1 adrenoceptor antagonist prazosin on capillary supply, blood flow and performance in a rat model of chronic muscle ischaemia. Eur J Vasc Endovasc Surg 1998;16:71-77. 
28. Titmarsh S, Monk JP: Terazosin. A review of its pharmacodynamic and pharmacokinetic properties, and therapeutic efficacy in essential hypertension. Drugs 1987;33:461-477.

29. Santillo VM, Lowe FC: Treatment of benign prostatic hyperplasia in patients with cardiovascular disease. Drugs Aging 2006;23:795-805.

30. Halpern W, Mulvany MJ: Tension responses to small length changes of vascular smooth muscle cells [proceedings]. J Physiol 1977;265:21P-23P.

31. de Lussanet QG, van Golde JC, Beets-Tan RG, Post MJ, Huijberts MS, Schaper NC, Kessels AG, van Engelshoven JM, Backes WH: Dynamic contrast-enhanced MRI of muscle perfusion combined with MR angiography of collateral artery growth in a femoral artery ligation model. NMR Biomed 2007;20:717-725.

32. van Golde JM, Ruiter MS, Schaper NC, Voo S, Waltenberger J, Backes WH, Post MJ, Huijberts MS: Impaired collateral recruitment and outward remodeling in experimental diabetes. Diabetes 2008;57:2818-2823.

33. Bushberg JTSJ, Leidholdt Jr. EM, Boone JM: Book chapter 12. Adjuncts to Radiology. in The essential physics of medical imaging. Second Edition. 2001, 321-323.

34. Longland CJ: Collateral circulation in the limb. Postgrad Med J 1953;29:456-458.

35. Degens ET: Molecular mechanisms on carbonate, phosphate, and silica deposition in the living cell. Top Curr Chem 1976;64:1-112.

36. Schaper W, Scholz D: Factors regulating arteriogenesis. Arterioscler Thromb Vasc Biol 2003;23:1143-1151.

37. van Royen N, Hoefer I, Buschmann I, Kostin S, Voskuil M, Bode C, Schaper W, Piek JJ: Effects of local MCP-1 protein therapy on the development of the collateral circulation and atherosclerosis in Watanabe hyperlipidemic rabbits. Cardiovasc Res 2003;57:178185.

38. Collinson DJ, Donnelly R: Therapeutic angiogenesis in peripheral arterial disease: can biotechnology produce an effective collateral circulation? Eur J Vasc Endovasc Surg 2004;28:9-23.

39. Senthilkumar A, Smith RD, Khitha J, Arora N, Veerareddy S, Langston W, Chidlow JH, Jr., Barlow SC, Teng X, Patel RP, Lefer DJ, Kevil CG: Sildenafil promotes ischemiainduced angiogenesis through a PKG-dependent pathway. Arterioscler Thromb Vasc Biol 2007;27:1947-1954.

40. Tirziu D, Moodie KL, Zhuang ZW, Singer K, Helisch A, Dunn JF, Li W, Singh J, Simons M: Delayed arteriogenesis in hypercholesterolemic mice. Circulation 2005;112:25012509.

41. Westvik TS, Fitzgerald TN, Muto A, Maloney SP, Pimiento JM, Fancher TT, Magri D, Westvik HH, Nishibe T, Velazquez OC, Dardik A: Limb ischemia after iliac ligation in aged mice stimulates angiogenesis without arteriogenesis. J Vasc Surg 2009;49:464473.

42. Pipp F, Heil M, Issbrucker K, Ziegelhoeffer $T$, Martin $S$, van den Heuvel J, Weich $H$, Fernandez B, Golomb G, Carmeliet P, Schaper W, Clauss M: VEGFR-1-selective VEGF homologue PIGF is arteriogenic: evidence for a monocyte-mediated mechanism. Circ Res 2003;92:378-385.

43. Deindl E, Buschmann I, Hoefer IE, Podzuweit T, Boengler K, Vogel S, van Royen N, Fernandez B, Schaper W: Role of ischemia and of hypoxia-inducible genes in arteriogenesis after femoral artery occlusion in the rabbit. Circ Res 2001;89:779-786. 
44. Hoefer IE, van Royen N, Buschmann IR, Piek JJ, Schaper W: Time course of arteriogenesis following femoral artery occlusion in the rabbit. Cardiovasc Res 2001;49:609-617.

45. Schirmer SH, Buschmann IR, Jost MM, Hoefer IE, Grundmann S, Andert JP, Ulusans S, Bode C, Piek JJ, van Royen N: Differential effects of MCP-1 and leptin on collateral flow and arteriogenesis. Cardiovasc Res 2004;64:356-364.

46. Hopkins SP, Bulgrin JP, Sims RL, Bowman B, Donovan DL, Schmidt SP: Controlled delivery of vascular endothelial growth factor promotes neovascularization and maintains limb function in a rabbit model of ischemia. J Vasc Surg 1998;27:886-894; discussion 895.

47. Hoefer IE, Grundmann S, van Royen N, Voskuil M, Schirmer SH, Ulusans S, Bode C, Buschmann IR, Piek J]: Leukocyte subpopulations and arteriogenesis: specific role of monocytes, lymphocytes and granulocytes. Atherosclerosis 2005;181:285-293.

48. Hoefer IE, Grundmann S, Schirmer S, van Royen N, Meder B, Bode C, Piek J], Buschmann IR: Aspirin, but not clopidogrel, reduces collateral conductance in a rabbit model of femoral artery occlusion. J Am Coll Cardiol 2005;46:994-1001. 
Chapter 7

General discussion 


\section{Diabetes complicates peripheral arterial disease}

DM, a well-recognized cardiovascular risk factor, increases the risk of developing PAD. ${ }^{1-4}$ Patients suffering from both $D M$ and PAD exhibit poor lower extremity function and are at risk for developing critical limb ischemia, ulceration, and minor or major amputation of the lower extremities. ${ }^{5-7}$ Moreover, treatment of PAD is compromised by DM. Patients with both DM and PAD have less favorable outcome after leg bypass surgery, a higher incidence of restenosis, more surgical complications, and a lower amputation-free survival. ${ }^{8-10}$ Moreover, the natural adaptation to obstructed blood flow to the lower extremities is hampered by DM. ${ }^{11}$

\section{Diabetes impairs arteriogenesis at various levels}

Arteriogenesis is the functional outward remodeling of preexisting anastomoses, into collateral arteries. Remodeled collateral arteries are able to restore perfusion to the tissue distal to an occlusion. In 4 weeks, collateral arteries can increase their internal diameter to almost a 20 -fold. ${ }^{12,13}$ As described in chapter 2, this complex remodeling process is negatively affected by DM at several levels.

First, DM elevates vasomotor tone and reduces shear stress sensing and vasodilatation. This may lead to impaired recruitment of collateral arteries. In the acute phase of arteriogenesis, attraction of monocytes and their invasion in the vessel wall are pivotal for outward remodeling. Although the attraction of monocytes does not seem to be affected by DM, the downstream signaling was shown to be attenuated in diabetic patients. This may limit outward remodeling. In addition, the function of endothelial progenitor cells and other bone marrowderived cells is impaired by DM. The extent to which this is relevant to arteriogenesis has yet to be determined. After monocyte invasion, the release of GFs is a hallmark in arteriogenesis. Numerous experimental studies demonstrated that DM impairs signaling of several GFs, including FGF-2, VEGF and GM-CSF. Although these defects could be partially restored in animal experiments, clinical results were disappointing. Throughout the remodeling process, nitric oxide signaling plays an important role. The well-established DM-induced impairment of endothelial NO synthase and NO may therefore explain an important part of the impaired outward remodeling seen in DM, and this may provide an interesting therapeutic target. In the structural phase of arteriogenesis, DM impairs matrix turnover, SMC proliferation and fibroblast migration, but the extent to which these changes in the later phases of remodeling affect arteriogenesis is presently unclear. Notably, type 1 and type 2 DM are distinct conditions, with different 
etiology and pathology. It is important to realize that many experimental studies are performed in type 1 DM models, whereas most patients with severe peripheral arterial disease suffer from type $2 \mathrm{DM}$. Interestingly, perfusion recovery after hind limb ischemia is less effective in type 2 than in type $1 \mathrm{DM}$ in mice. ${ }^{14}$

To investigate the extent to which DM attenuates arteriogenesis in vivo, the recovery from hindlimb ischemia was studied in diabetic and non-diabetic animals, as described in the following chapter.

\section{Diabetes impairs recruitment and remodeling of collaterals}

Chapter 3 describes the effect of chronic hyperglycemia on recruitment and remodeling of collateral arteries in an experimental model of hindlimb ischemia. This study demonstrates that chronic hyperglycemia negatively affects the different phases of arteriogenesis. Acutely, experimental DM impaired recruitment of collateral arteries. After 1 and 3 weeks, outward remodeling of collaterals was lower in diabetic animals compared to non-diabetic controls, reflected by the number of visible collateral arteries and blood volume index. Additionally, the experimental DM reduced monocyte chemotaxis. The differences in recruitment and remodeling of collateral arteries were most evident in the acute phase of arteriogenesis, suggesting that impairments in the acute response to an occlusion give the diabetic hindlimb a delayed start. Little is known however, about the functional characteristics of collateral arteries. Therefore, we examined the vasoreactivity of these vessels in vitro.

\section{Diabetes impairs vascular smooth muscle cells of collaterals in vitro}

The effect of experimental DM on reactivity of collateral arteries in vitro is described in chapter 4. In this study, we found that SMC function is impaired by DM in collateral arteries. Functionally, both sensitivity to NO and stimulation of SGC were reduced in diabetic vessels. In addition, production of cGMP and expression of both sGC $\alpha 1$ and PKG1 $\beta$ were reduced. These findings indicate that DM impairs the vascular SMC in collateral arteries. In the SMC, inhibition of PDE5 was not affected by DM.

No differences between diabetic and control vessels were observed upon ACh stimulation. Although this seems to contradict the impaired recruitment demonstrated in chapter 3, this is not the case. One should keep in mind that the model used to study reactivity has two important limitations. First, in isolated 
vessel segments, the influence of the circulation is ruled out. It is well known that DM enhances the amount of circulating ROS, which scavenge NO, decreasing vasodilatation. ${ }^{15}$ Second, only pharmacologically induced relaxation was measured. In vivo however, the main stimulus for vasodilatation and outward remodeling of collateral arteries is shear stress on the vessel wall. In addition to circulating ROS, an alteration in ACh sensitivity or signaling may explain the differences between the in vitro relaxation and the in vivo recruitment. Additional studies of flowmediated vasorelaxation may contribute to a better understanding of these differences in DM. To investigate the mechanism by which DM impairs SMC function in the hindlimb, we studied the role of MGO on vasoreactivity in experimental DM.

\section{Methylglyoxal mediates impaired reactivity in the saphenous artery}

In chapter 5, part of the pathway by which DM affects vasoreactivity in the hindlimb is investigated. This study demonstrates that DM attenuates NO sensitivity in distal saphenous arteries of rats. Furthermore, glyoxalase-1 overexpression ameliorates this DM-induced impairment. This indicates that DM exerts its deleterious effects in the lower extremity vasculature at least partly via methylglyoxal. Notably, the effect of DM on arteries is highly specific. In the collateral arteries investigated in chapter 4, SGC function was impaired by experimental DM, specifically demonstrated by impaired response to SGC stimulation with Bay41-2272. In the distal saphenous arteries examined in chapter 5 however, SGC stimulation was not altered by hyperglycemia. Although an interspecies difference can not be excluded, these differences likely reflect a difference between vessel types. In another study performed with the same DM wildtype and transgenic rats, endothelial function in the mesenteric arteries was clearly reduced by DM, contrary to the hindlimb arteries. This indicates that both the functional characteristics of vessels and the effect of DM can vary between vascular beds.

\section{Diabetes affects vasoreactivity in a vessel-specific fashion}

EC and SMC phenotype is highly specific throughout the vasculature. ${ }^{16,17}$ Gene expression is affected by adjacent cells, leukocytes, erythrocytes, and platelets as well as mechanical forces. ${ }^{17,18}$ The variation in gene expression evidently affects vascular reactivity, as demonstrated in both human and animal studies. Clinically, it has been established that vascular reactivity is affected by age, sex and exercise, 
but also differs between regions in the body. ${ }^{19-21}$ Specifically, aging decreases FMD in leg arteries, but not in the arm, a difference also reflected by the occurrence of vasculopathy in the lower extremities with increasing age. ${ }^{22}$ In addition to regional differences, size and function of the vessels also matter. In elderly subjects, Larginine is positively related to endothelium-dependent vasodilation in resistance arteries, but negatively in a conduit artery. ${ }^{23}$

In isolated animal arteries these differences have been explored in more detail. Contractile responses to electrical stimulation were greater in proximal vessels than in distal vessels in rats. ${ }^{24}$ In hamsters, differences in ACh-induced relaxation were demonstrated between skeletal, coronary and mesenteric small arteries. ${ }^{25}$ In addition, the relative dominance of NO and EDHF in ACh-induced relaxation varied between different arteries within one species. ${ }^{26-28}$ In general, NO-mediated relaxation is more dominant with increasing vessel size. ${ }^{29} \mathrm{ACh}$-induced relaxation in the femoral artery is almost completely NO-mediated, whereas EDHF is the dominant factor in mesenteric arteries. ${ }^{30}$

The relative importance of the different pathways of vascular reactivity can influence the effect of DM on vascular function. In rats, STZ-induced hyperglycemia reduced EDHF-mediated relaxation in mesenteric arteries, but had no effect in the femoral artery and NO availability was not compromised by the hyperglycemia. ${ }^{31}$ In rat mesenteric small arteries, noradrenalin-induced contraction was induced by DM, but endothelial function was normal. ${ }^{32}$ As already discussed in chapter 4, disease duration is also an important determinant of the effect of DM on vascular reactivity. In animal models, chronic hyperglycemia subsequently lead to improved, unaltered and deteriorated vasorelaxation. ${ }^{33}$ Also in human mesenteric and subcutaneous small arteries, increased ACh-induced relaxation was demonstrated after high glucose incubation. ${ }^{34}$ It is important to realize the differences between acute and chronic hyperglycemia, as well as the different models for type 1 and type 2 DM.

\section{Limitations and model considerations}

Limitations of the separate studies were discussed in the chapters. But some considerations rather apply to the whole story. Throughout the present thesis, different models have been discussed. First, it is important to realize that some in vitro studies have used chronic hyperglycemia as a model for diabetes. The effects of acute exposure differ from those of chronic exposure, as argued before. Therefore, such observations should be interpreted with caution. In addition, in 
animal studies both type 1 and 2 models can be used. In the DM studies described in the present thesis (chapters 3, 4 and 5), alloxan and STZ-induced DM were studied. These are models for type $1 \mathrm{DM}$, whereas the lower extremity vascular complications are more common in type 2 DM. Although these models represent the clinical situation less accurately, they enable a study of the effects of high blood glucose, rather than the much more complex interplay of biological imbalances found in clinical type 2 DM.

The studies described in the present thesis focused on the effects of DM on the lower extremities. These studies tried to keep an eye on the clinical perspectives and therapeutic implications of these differences. Therefore, the studied arteries were isolated from the lower extremity, instead of the more commonly used (and more easily dissectible) mesenteric or carotid arteries. The focus was not on studying differences between the commonly used vessels and lower extremity vessels. But since results from the present studies had larger variation than previous observations, size of the experimental groups and experimental set-up may not have been optimal to reveal differences. In hindsight, it may have been informative to start with a comparison of the hindlimb vessels and better explored arteries.

\section{Considerations for future therapy}

The differences between vascular beds and experimental models have important consequences for our understanding of underlying mechanisms. Furthermore, these differences call for careful consideration when experimental findings are translated to therapy. Endothelial dysfunction, consistently reported in mesenteric arteries, may be less relevant for the lower extremities where SMC dysfunction seems to be more prominent. Clearly, this affects the choice of the drug that is to be administered, discussed in the following sections.

\section{Growth factor therapy has limited clinical value}

The majority of experimental studies aiming to promote restoration of perfusion have focused on GFs. ${ }^{35,36}$ Informaiton about GF therapy in the diabetic hindlimb however, is scarce. Most studies have not employed diabetic models, or have focused on the coronary circulation. In the non-diabetic hindlimb, administration of VEGF, ${ }^{37-40}$ PLGF, ${ }^{41}$ GM-CSF, ${ }^{42}$ TGF- $\beta^{43}$ and MCP-1 ${ }^{44,45}$ have improved flow restoration. In addition, in a murine hindlimb ischemia model, combined delivery of VEGF and FGF-2, which work synergistically in vitro, ${ }^{46}$ improved arteriogenesis 
more than both factors alone. ${ }^{47}$ Another study also suggests that combined therapy may be more effective, although this study was not performed in the lower extremity. In mesenteric arteries, gene delivery of eNOS, VEGF, and Angiopoetin-1 induced formation of capillaries and arterioles, and generated vessels that are more mature than after single factor delivery. ${ }^{48}$ However, vessels stimulated by GF often seem fragile and may very well be subject to regression in the long run. ${ }^{49}$

In DM models of the lower extremity, VEGF gene transfer increased capillary density during ischemia. ${ }^{11}$ Accordingly, VEGF-activating transcription factor enhanced therapeutic angiogenesis in hindlimb ischemia. ${ }^{50}$ In addition, intramuscular injection of human HGF plasmid increased flow recovery in a diabetic rat hindlimb ischemia model. ${ }^{51}$ In mice, nerve GF administration normalized the post-ischemic recovery, which was attenuated by type $1 \mathrm{DM} .{ }^{52}$ Comparable to the non-diabetic hindlimb, combination therapy also showed promising results in the presence of DM. Combined administration of FGF-2 and prostaglandin E1 stimulated arteriogenesis in the diabetic murine ischemic hindlimb. ${ }^{53,54}$

GF therapy for the ischemic lower extremity also found its way to the clinic. The results of clinical trials however, are disappointing. In the TRAFFIC trial, studying intra-arterial administration of FGF-2 only gave a small increase in peak walking time, with no dose-dependent effect. ${ }^{55}$ Similarly, neither subcutaneous delivery of GM-CSF (the START trial ${ }^{56}$ ) nor intramuscular injection of angiomatrix protein DEL1 improved walking distance of PAD patients. ${ }^{57}$ Modest success was achieved with VEGF in CLI studies. VEGF gene therapy improved perfusion, ${ }^{58}$ ankle-brachial index (ABI), and neuropathy. ${ }^{59}$ In another CLI study however, VEGF165 gene transfer resulted in a higher number of visible collateral vessels and increased ABI, but not without causing edema in 6 out of 10 patients. ${ }^{60}$

Administration of GFs is not without hazards; angiogenic agents such as VEGF and FGF-2 have several biological functions. These functions can be averted to stimulate revascularization, but also have the potential to induce serious complications. MCP-1 and VEGF are known to be atherogenic, and FGF-2 might stimulate tumor growth. ${ }^{61}$ In animal models, VEGF administration induced cachexia and even death within 2 weeks. ${ }^{62}$ Overexpression of VEGF in non-diabetic mouse hearts can result in vascular tumors near the site of infusion. ${ }^{62}$ In clinical studies, the occurrence of cancer due to GF administration within the study duration is very unlikely. But edema was already observed in several clinical studies using VEGF. ${ }^{58,60,63}$ 
Stem cell treatment has been proposed as an alternative for GF administration. In leptin receptor deficient Lepr(db/db) DM mice, local injection of mesenchymal stem cells prestimulated with epidermal GF restored blood flow and formation of capillaries in the ischemic hindlimb. ${ }^{64}$ In non-diabetic patients with severe PAD who were not amenable for conventional treatment, delivery of autologous bone marrow cells appeared to be safe, and improved ABI, pain-free walking distance and pain. ${ }^{65}$ In DM patients with critical limb ischemia, transplantation of autologous peripheral blood stem cells enhanced therapeutic angiogenesis and resulted in limb salvage in Fontaine stage I to III, but not in phase IV. ${ }^{66}$ The efficacy and long-term safety of this form of therapy has yet to be determined.

In arteriogenesis research, the most potent pharmacological agents can only lead to a fraction of the maximum improvement obtained by high fluid shear stress. ${ }^{67}$ Increasing the shear stress on the vessel wall of a poorly perfused lower extremity, may therefore be an interesting approach. Vasodilatation of collateral arteries that are hardly perfused, may induce shear stress on the vessel wall. This strategy was investigated in a non-diabetic model.

\section{Vasodilatation therapy may improve arteriogenesis in diabetes}

In chapter 6 we show that vasodilator therapy is safe and can improve arteriogenesis in a non-diabetic situation. The study demonstrates the potential of adrenoceptor inhibition for stimulation of arteriogenesis. Prolonged administration of terazosin improves blood volume in the occluded rabbit hindlimb by promoting collateral recruitment and outward remodeling, without affecting systemic blood pressure. Administration of a vasodilator may stimulate recruitment of collateral arteries, thereby enhancing shear stress on the vessel wall, which is the trigger for arteriogenesis. Moreover, vasodilator therapy is not associated with the side effects found in GF therapy. The method of delivery is an important aspect in vasodilator therapy. The desired drug should be administered locally, to prevent systemic hypotension, as well as the "steal phenomenon": an increase in blood flow to the non-occluded extremity, due to the lower resistance. This steal phenomenon reduces rather than enhances flow to the occluded side. Although the results in the study described in chapter 6 are mild, it is promising that terazosin can induce arteriogenesis without side-effects under non-diabetic conditions, when the remodeling process is not even compromised. 
These results encourage further exploration of local delivery of $\alpha_{1}$-adrenoceptor antagonists or other vasodilatory substances for stimulation of arterial remodeling. The effect of vasodilator treatment in arteriogenesis was also demonstrated in other studies. In the non-diabetic hindlimb, the potential of vasodilator therapy in revascularization was also demonstrated with sildenafil. ${ }^{68}$ That study revealed PDE5 inhibition as an effective therapeutic strategy. The potential of vasodilator treatment in DM was demonstrated in two studies in the murine hindlimb, where vasodilators prostaglandin E1 and sarpogrelate both enhanced arteriogenesis. ${ }^{53,54}$ Vasodilatation may be enhanced by targeting eNOS. Several studies have suggested eNOS and eNOS co-factor tetrahydrobiopterin as potential targets for revascularization. ${ }^{69-71}$ However, in chapter 4 we demonstrate that vasorelaxation of hindlimb collateral arteries is not affected by DM at the level of eNOS. For improvement of diabetic arteriogenesis, we therefore advocate to either stimulate SGC specifically, ${ }^{72}$ or to target other molecules in the vascular SMC, rather than in the EC. To test these strategies, arteriogenesis research should be extended to DM models, in which arteriogenesis is attenuated.

For clinical applications, the selection of a therapeutic target is not the final chapter in therapy development. An appropriate delivery method of the substance is also of cardinal importance. For arteriogenesis this is no exception, and in the case of DM, various aspects should be considered.

\section{Diabetic patients may benefit from local administration}

In the early experiments of GF therapy, therapeutic agents were intravenously injected. This was hardly effective, as most GFs have a half-life of minutes. To ensure effective concentrations at the target region, the systemic dose may lead to side-effects. ${ }^{49}$ Another strategy already tried in clinical research is gene therapy. This form of therapy has improved sensory deficits, exercise tolerance, and limb salvage in patients at risk for lower extremity amputation, ${ }^{73}$ but the safety of this therapy is disputed. ${ }^{61}$ In order to achieve high local concentrations with minimal effect to the systemic circulation, several methods of local delivery have been tested. Therapeutics can be released by artificial extravascular matrices, drugeluting intravascular scaffolds or endovascular reservoirs. ${ }^{49,74-76}$ Drug-eluting devices should be carefully constructed, to ensure the right release duration and concentration of the therapeutic agent, and to reach the affected region. In addition, structure and construction of the device should not interfere with the function of the drug. ${ }^{49}$ As discussed before, dual administration may be more 
effective than a single drug. This can also be achieved with polymer scaffolds, as demonstrated by a number of studies in vascular remodeling. ${ }^{77,78}$

Therapeutic substances may also be administered in another form, such as injectable gels, micro- or nanoparticles. ${ }^{49}$ If these injectables can be targeted to the area of interest, this may provide a therapy with limited invasiveness. This is attractive for diabetic patients, with impaired wound healing and increased risk of surgical complications. A more detailed study of these strategies falls beyond the scope of the present thesis.

\section{Conclusion}

In the present thesis it is shown that DM affects vascular function and impairs arteriogenesis in the peripheral circulation at numerous levels. In an experimental model of hindlimb ischemia, DM attenuated recruitment and remodeling of hindlimb collateral arteries. In an organ bath study, we showed that DM impairs the sensitivity to NO and SGC stimulation in SMCs. MGO may in part explain the impairment in NO sensitivity. Finally, we demonstrated that vasodilatation can improve arteriogenesis in vivo, even in a non-DM setting, without systemic sideeffects. Vasodilatation may provide a safe and effective alternative to stimulate arteriogenesis for GF administration, which was clinically disappointing and may not be safe. For selection of an effective vasodilator, studies should be performed in the appropriate vascular bed, and in the presence of DM. 


\section{References}

1. Donahue RP, Orchard TJ: Diabetes mellitus and macrovascular complications. An epidemiological perspective. Diabetes Care 1992;15:1141-1155.

2. Lange S, Diehm C, Darius H, Haberl R, Allenberg JR, Pittrow D, Schuster A, von Stritzky $B$, Tepohl G, Trampisch HJ: High prevalence of peripheral arterial disease and low treatment rates in elderly primary care patients with diabetes. Exp Clin Endocrinol Diabetes 2004;112:566-573.

3. Marso SP, Hiatt WR: Peripheral arterial disease in patients with diabetes. J Am Coll Cardiol 2006;47:921-929.

4. Pyorala K, Laakso M, Uusitupa M: Diabetes and atherosclerosis: an epidemiologic view. Diabetes Metab Rev 1987;3:463-524.

5. Kamalesh M, Shen J: Diabetes and peripheral arterial disease in men: trends in prevalence, mortality, and effect of concomitant coronary disease. Clin Cardiol 2009;32:442-446.

6. Larsson J, Agardh CD, Apelqvist J, Stenstrom A: Long-term prognosis after healed amputation in patients with diabetes. Clin Orthop Relat Res 1998:149-158.

7. Sheahan MG, Hamdan AD, Veraldi JR, McArthur CS, Skillman JJ, Campbell DR, Scovell SD, Logerfo FW, Pomposelli FB, Jr.: Lower extremity minor amputations: the roles of diabetes mellitus and timing of revascularization. J Vasc Surg 2005;42:476-480.

8. Currie CJ, Morgan CL, Peters JR: The epidemiology and cost of inpatient care for peripheral vascular disease, infection, neuropathy, and ulceration in diabetes. Diabetes Care 1998;21:42-48.

9. Faglia E, Clerici G, Clerissi J, Gabrielli L, Losa S, Mantero M, Caminiti M, Curci V, Quarantiello A, Lupattelli T, Morabito A: Long-term prognosis of diabetic patients with critical limb ischemia: a population-based cohort study. Diabetes Care 2009;32:822827.

10. Malmstedt J, Leander K, Wahlberg E, Karlstrom L, Alfredsson L, Swedenborg J: Outcome after leg bypass surgery for critical limb ischemia is poor in patients with diabetes: a population-based cohort study. Diabetes Care 2008;31:887-892.

11. Rivard A, Silver M, Chen D, Kearney M, Magner M, Annex B, Peters K, Isner JM: Rescue of diabetes-related impairment of angiogenesis by intramuscular gene therapy with adeno-VEGF. Am J Pathol 1999;154:355-363.

12. Wahlberg E: Angiogenesis and arteriogenesis in limb ischemia. J Vasc Surg 2003;38:198-203.

13. Wolf C, Cai WJ, Vosschulte R, Koltai S, Mousavipour D, Scholz D, Afsah-Hedjri A, Schaper W, Schaper J: Vascular remodeling and altered protein expression during growth of coronary collateral arteries. J Mol Cell Cardiol 1998;30:2291-2305.

14. Yan J, Tie G, Park B, Yan Y, Nowicki PT, Messina LM: Recovery from hind limb ischemia is less effective in type 2 than in type 1 diabetic mice: roles of endothelial nitric oxide synthase and endothelial progenitor cells. J Vasc Surg 2009;50:1412-1422.

15. Kashiwagi A, Asahina T, Nishio Y, Ikebuchi M, Tanaka Y, Kikkawa R, Shigeta Y: Glycation, oxidative stress, and scavenger activity: glucose metabolism and radical scavenger dysfunction in endothelial cells. Diabetes 1996;45 Suppl 3:S84-86. 
16. Gumkowski F, Kaminska G, Kaminski M, Morrissey LW, Auerbach R: Heterogeneity of mouse vascular endothelium. In vitro studies of lymphatic, large blood vessel and microvascular endothelial cells. Blood Vessels 1987;24:11-23.

17. Langenkamp E, Molema G: Microvascular endothelial cell heterogeneity: general concepts and pharmacological consequences for anti-angiogenic therapy of cancer. Cell Tissue Res 2009;335:205-222.

18. Aird WC: Spatial and temporal dynamics of the endothelium. J Thromb Haemost 2005;3:1392-1406.

19. Nishiyama SK, Walter Wray D, Berkstresser K, Ramaswamy M, Richardson RS: Limbspecific differences in flow-mediated dilation: the role of shear rate. J Appl Physiol 2007; 103:843-851.

20. Nishiyama SK, Wray DW, Richardson RS: Aging affects vascular structure and function in a limb-specific manner. J Appl Physiol 2008;105:1661-1670.

21. Nishiyama SK, Wray DW, Richardson RS: Sex and limb-specific ischemic reperfusion and vascular reactivity. Am J Physiol Heart Circ Physiol 2008;295:H1100-H1108.

22. Wray DW, Richardson RS: Aging, exercise, and limb vascular heterogeneity in humans. Med Sci Sports Exerc 2006;38:1804-1810.

23. Lind $L$, Larsson A, Teerlink $T$ : L-Arginine is related to endothelium-dependent vasodilation in resistance and conduit arteries in divergent ways-The Prospective Investigation of the Vasculature in Uppsala Seniors (PIVUS) study. Atherosclerosis 2009;203:544-549.

24. Tarasova O, Sjoblom-Widfeldt N, Nilsson H: Transmitter characteristics of cutaneous, renal and skeletal muscle small arteries in the rat. Acta Physiol Scand 2003;177:157166.

25. Clark SG, Fuchs LC: Role of nitric oxide and Ca++-dependent $\mathrm{K}+$ channels in mediating heterogeneous microvascular responses to acetylcholine in different vascular beds. J Pharmacol Exp Ther 1997;282:1473-1479.

26. Nagao T, Illiano S, Vanhoutte PM: Heterogeneous distribution of endotheliumdependent relaxations resistant to NG-nitro-L-arginine in rats. Am J Physiol 1992;263:H1090-1094.

27. Ferrer M, Encabo A, Conde MV, Marin J, Balfagon G: Heterogeneity of endotheliumdependent mechanisms in different rabbit arteries. J Vasc Res 1995;32:339-346.

28. Cowan CL, Palacino JJ, Najibi S, Cohen RA: Potassium channel-mediated relaxation to acetylcholine in rabbit arteries. J Pharmacol Exp Ther 1993;266:1482-1489.

29. Hwa JJ, Ghibaudi L, Williams P, Chatterjee M: Comparison of acetylcholine-dependent relaxation in large and small arteries of rat mesenteric vascular bed. Am J Physiol 1994;266:H952-958.

30. Zygmunt PM, Ryman T, Hogestatt ED: Regional differences in endothelium-dependent relaxation in the rat: contribution of nitric oxide and nitric oxide-independent mechanisms. Acta Physiol Scand 1995;155:257-266.

31. Wigg SJ, Tare M, Tonta MA, O'Brien RC, Meredith IT, Parkington HC: Comparison of effects of diabetes mellitus on an EDHF-dependent and an EDHF-independent artery. Am J Physiol Heart Circ Physiol 2001;281:H232-240. 
32. Brondum $\mathrm{E}$, Kold-Petersen $\mathrm{H}$, Nilsson $\mathrm{H}$, Flyvbjerg A, Aalkjaer C: Increased contractility to noradrenaline and normal endothelial function in mesenteric small arteries from the goto-kakizaki rat model of type 2 diabetes. J Physiol Sci 2008;58:333-339.

33. Pieper GM: Enhanced, unaltered and impaired nitric oxide-mediated endotheliumdependent relaxation in experimental diabetes mellitus: importance of disease duration. Diabetologia 1999;42:204-213.

34. MacKenzie A, Cooper EJ, Dowell FJ: Differential effects of glucose on agonist-induced relaxations in human mesenteric and subcutaneous arteries. $\mathrm{Br} \mathrm{J}$ Pharmacol 2008;153:480-487.

35. Zhou B, Poon MC, Pu WT, Han ZC: Therapeutic neovascularization for peripheral arterial diseases: advances and perspectives. Histol Histopathol 2007;22:677-686.

36. Schaper W: Collateral circulation: past and present. Basic Res Cardiol 2009;104:5-21.

37. Hopkins SP, Bulgrin JP, Sims RL, Bowman B, Donovan DL, Schmidt SP: Controlled delivery of vascular endothelial growth factor promotes neovascularization and maintains limb function in a rabbit model of ischemia. J Vasc Surg 1998;27:886-894; discussion 895.

38. Takeshita S, Isshiki T, Ochiai M, Eto K, Mori H, Tanaka E, Umetani K, Sato T: Endothelium-dependent relaxation of collateral microvessels after intramuscular gene transfer of vascular endothelial growth factor in a rat model of hindlimb ischemia. Circulation 1998;98:1261-1263.

39. Chang DS, Su H, Tang GL, Brevetti LS, Sarkar R, Wang R, Kan YW, Messina LM: Adeno-associated viral vector-mediated gene transfer of VEGF normalizes skeletal muscle oxygen tension and induces arteriogenesis in ischemic rat hindlimb. Mol Ther 2003;7:44-51.

40. Bauters C, Asahara T, Zheng LP, Takeshita S, Bunting S, Ferrara N, Symes JF, Isner JM: Physiological assessment of augmented vascularity induced by VEGF in ischemic rabbit hindlimb. Am J Physiol 1994;267:H1263-1271.

41. Pipp F, Heil M, Issbrucker K, Ziegelhoeffer $T$, Martin S, van den Heuvel J, Weich $H$, Fernandez B, Golomb G, Carmeliet P, Schaper W, Clauss M: VEGFR-1-selective VEGF homologue PIGF is arteriogenic: evidence for a monocyte-mediated mechanism. Circ Res 2003;92:378-385.

42. Buschmann IR, Hoefer IE, van Royen N, Katzer E, Braun-Dulleaus R, Heil M, Kostin S, Bode C, Schaper W: GM-CSF: a strong arteriogenic factor acting by amplification of monocyte function. Atherosclerosis 2001;159:343-356.

43. van Royen N, Hoefer I, Buschmann I, Heil M, Kostin S, Deindl E, Vogel S, Korff T, Augustin $\mathrm{H}$, Bode $\mathrm{C}$, Piek JJ, Schaper W: Exogenous application of transforming growth factor beta 1 stimulates arteriogenesis in the peripheral circulation. Faseb J 2002;16:432-434.

44. van Royen N, Hoefer I, Buschmann I, Kostin S, Voskuil M, Bode C, Schaper W, Piek JJ: Effects of local MCP-1 protein therapy on the development of the collateral circulation and atherosclerosis in Watanabe hyperlipidemic rabbits. Cardiovasc Res 2003;57:178185.

45. Hoefer IE, van Royen N, Buschmann IR, Piek JJ, Schaper W: Time course of arteriogenesis following femoral artery occlusion in the rabbit. Cardiovasc Res 2001;49:609-617. 
46. Pepper MS, Ferrara N, Orci L, Montesano R: Potent synergism between vascular endothelial growth factor and basic fibroblast growth factor in the induction of angiogenesis in vitro. Biochem Biophys Res Commun 1992;189:824-831.

47. Lee JS, Kim JM, Kim KL, Jang HS, Shin IS, Jeon ES, Suh W, Byun J, Kim DK: Combined administration of naked DNA vectors encoding VEGF and bFGF enhances tissue perfusion and arteriogenesis in ischemic hindlimb. Biochem Biophys Res Commun 2007; 360:752-758.

48. Benest AV, Stone OA, Miller WH, Glover CP, Uney JB, Baker AH, Harper SJ, Bates DO: Arteriolar genesis and angiogenesis induced by endothelial nitric oxide synthase overexpression results in a mature vasculature. Arterioscler Thromb Vasc Biol 2008;28:1462-1468.

49. Chen RR, Mooney DJ: Polymeric growth factor delivery strategies for tissue engineering. Pharm Res 2003;20:1103-1112.

50. Li Y, Hazarika S, Xie D, Pippen AM, Kontos CD, Annex BH: In mice with type 2 diabetes, a vascular endothelial growth factor (VEGF)-activating transcription factor modulates VEGF signaling and induces therapeutic angiogenesis after hindlimb ischemia. Diabetes 2007; 56:656-665.

51. Taniyama Y, Morishita R, Hiraoka K, Aoki M, Nakagami H, Yamasaki K, Matsumoto K, Nakamura T, Kaneda Y, Ogihara T: Therapeutic angiogenesis induced by human hepatocyte growth factor gene in rat diabetic hind limb ischemia model: molecular mechanisms of delayed angiogenesis in diabetes. Circulation 2001;104:2344-2350.

52. Salis MB, Graiani G, Desortes E, Caldwell RB, Madeddu P, Emanueli C: Nerve growth factor supplementation reverses the impairment, induced by Type 1 diabetes, of hindlimb post-ischaemic recovery in mice. Diabetologia 2004;47:1055-1063.

53. Huang Y, Marui A, Sakaguchi H, Esaki J, Arai Y, Hirose K, Bir SC, Horiuchi H, Maruyama T, Ikeda T, Tabata $Y$, Komeda M: Sustained release of prostaglandin E1 potentiates the impaired therapeutic angiogenesis by basic fibroblast growth factor in diabetic murine hindlimb ischemia. Circ J 2008;72:1693-1699.

54. Bir SC, Fujita M, Marui A, Hirose K, Arai Y, Sakaguchi H, Huang Y, Esaki J, Ikeda T, Tabata $Y$, Komeda M: New therapeutic approach for impaired arteriogenesis in diabetic mouse hindlimb ischemia. Circ J 2008;72:633-640.

55. Lederman RJ, Mendelsohn FO, Anderson RD, Saucedo JF, Tenaglia AN, Hermiller JB, Hillegass WB, Rocha-Singh K, Moon TE, Whitehouse MJ, Annex BH: Therapeutic angiogenesis with recombinant fibroblast growth factor-2 for intermittent claudication (the TRAFFIC study): a randomised trial. Lancet 2002;359:2053-2058.

56. van Royen $\mathrm{N}$, Schirmer SH, Atasever B, Behrens CY, Ubbink D, Buschmann EE, Voskuil M, Bot P, Hoefer I, Schlingemann RO, Biemond BJ, Tijssen JG, Bode C, Schaper W, Oskam J, Legemate DA, Piek JJ, Buschmann I: START Trial: a pilot study on STimulation of ARTeriogenesis using subcutaneous application of granulocytemacrophage colony-stimulating factor as a new treatment for peripheral vascular disease. Circulation 2005;112:1040-1046.

57. Grossman PM, Mendelsohn F, Henry TD, Hermiller JB, Litt M, Saucedo JF, Weiss RJ, Kandzari DE, Kleiman N, Anderson RD, Gottlieb D, Karlsberg R, Snell J, Rocha-Singh K: Results from a phase II multicenter, double-blind placebo-controlled study of Del-1 
(VLTS-589) for intermittent claudication in subjects with peripheral arterial disease. Am Heart J 2007;153:874-880.

58. Shyu KG, Chang H, Wang BW, Kuan P: Intramuscular vascular endothelial growth factor gene therapy in patients with chronic critical leg ischemia. Am J Med 2003;114:85-92.

59. Simovic $D$, Isner JM, Ropper $A H$, Pieczek $A$, Weinberg $D H$ : Improvement in chronic ischemic neuropathy after intramuscular phVEGF165 gene transfer in patients with critical limb ischemia. Arch Neurol 2001;58:761-768.

60. Baumgartner I, Pieczek A, Manor O, Blair R, Kearney M, Walsh K, Isner JM: Constitutive expression of phVEGF165 after intramuscular gene transfer promotes collateral vessel development in patients with critical limb ischemia. Circulation 1998;97:1114-1123.

61. Epstein SE, Kornowski R, Fuchs S, Dvorak HF: Angiogenesis therapy: amidst the hype, the neglected potential for serious side effects. Circulation 2001;104:115-119.

62. Lee RJ, Springer ML, Blanco-Bose WE, Shaw R, Ursell PC, Blau HM: VEGF gene delivery to myocardium: deleterious effects of unregulated expression. Circulation 2000;102:898-901.

63. Baumgartner I, Rauh G, Pieczek A, Wuensch D, Magner M, Kearney M, Schainfeld R, Isner JM: Lower-extremity edema associated with gene transfer of naked DNA encoding vascular endothelial growth factor. Ann Intern Med 2000;132:880-884.

64. Amin AH, Abd Elmageed ZY, Nair D, Partyka MI, Kadowitz PJ, Belmadani S, Matrougui $\mathrm{K}$ : Modified multipotent stromal cells with epidermal growth factor restore vasculogenesis and blood flow in ischemic hind-limb of type II diabetic mice. Lab Invest 2010;90:985-996.

65. Van Tongeren RB, Hamming JF, Fibbe WE, Van Weel V, Frerichs SJ, Stiggelbout AM, Van Bockel JH, Lindeman JH: Intramuscular or combined intramuscular/intra-arterial administration of bone marrow mononuclear cells: a clinical trial in patients with advanced limb ischemia. J Cardiovasc Surg (Torino) 2008;49:51-58.

66. Kawamura A, Horie T, Tsuda I, Abe Y, Yamada M, Egawa H, Iida J, Sakata H, Onodera K, Tamaki T, Furui H, Kukita K, Meguro J, Yonekawa M, Tanaka S: Clinical study of therapeutic angiogenesis by autologous peripheral blood stem cell (PBSC) transplantation in 92 patients with critically ischemic limbs. J Artif Organs 2006;9:226233.

67. Schierling W, Troidl K, Troidl C, Schmitz-Rixen T, Schaper W, Eitenmuller IK: The Role of Angiogenic Growth Factors in Arteriogenesis. J Vasc Res 2009;46:365-374.

68. Senthilkumar A, Smith RD, Khitha J, Arora N, Veerareddy S, Langston W, Chidlow JH, Jr., Barlow SC, Teng X, Patel RP, Lefer DJ, Kevil CG: Sildenafil promotes ischemiainduced angiogenesis through a PKG-dependent pathway. Arterioscler Thromb Vasc Biol 2007;27:1947-1954.

69. Yu J, deMuinck ED, Zhuang Z, Drinane M, Kauser K, Rubanyi GM, Qian HS, Murata T, Escalante B, Sessa WC: Endothelial nitric oxide synthase is critical for ischemic remodeling, mural cell recruitment, and blood flow reserve. Proc Natl Acad Sci U S A 2005;102:10999-11004.

70. Moens AL, Kass DA: Therapeutic potential of tetrahydrobiopterin for treating vascular and cardiac disease. J Cardiovasc Pharmacol 2007;50:238-246. 
71. Namba T, Koike H, Murakami K, Aoki M, Makino H, Hashiya N, Ogihara T, Kaneda Y, Kohno M, Morishita R: Angiogenesis induced by endothelial nitric oxide synthase gene through vascular endothelial growth factor expression in a rat hindlimb ischemia model. Circulation 2003;108:2250-2257.

72. Evgenov OV, Pacher P, Schmidt PM, Hasko G, Schmidt HH, Stasch JP: NO-independent stimulators and activators of soluble guanylate cyclase: discovery and therapeutic potential. Nat Rev Drug Discov 2006;5:755-768.

73. Isner JM, Vale PR, Symes JF, Losordo DW: Assessment of risks associated with cardiovascular gene therapy in human subjects. Circ Res 2001;89:389-400.

74. Lee KY, Peters MC, Anderson KW, Mooney DJ: Controlled growth factor release from synthetic extracellular matrices. Nature 2000;408:998-1000.

75. Ennett $A B$, Mooney $D J$ : Tissue engineering strategies for in vivo neovascularisation. Expert Opin Biol Ther 2002;2:805-818.

76. Zisch $\mathrm{AH}$, Lutolf MP, Hubbell JA: Biopolymeric delivery matrices for angiogenic growth factors. Cardiovasc Pathol 2003;12:295-310.

77. Richardson TP, Peters MC, Ennett AB, Mooney DJ: Polymeric system for dual growth factor delivery. Nat Biotechnol 2001;19:1029-1034.

78. Layman H, Sacasa M, Murphy AE, Murphy AM, Pham SM, Andreopoulos FM: Co-delivery of FGF-2 and G-CSF from gelatin-based hydrogels as angiogenic therapy in a murine critical limb ischemic model. Acta Biomater 2009;5:230-239. 
Abbreviations 
ACh acetylcholine

AGE advanced glycation endproduct

Bay41-2272 5-cyclopropyl-2-[1-(2-fluoro-benzyl)-1H-pyrazolo[3,4-b]pyridin-3yl]-pyrimidin-ylamine

$\mathrm{BH}_{4} \quad$ tetrahydrobiopterin

BMI body mass index

cGMP cyclic guanosine monophosphate

CVI collateral volume index

DM diabetes mellitus

EC endothelial cell

EDHF endothelium-derived hyperpolarizing factor

EPC endothelial progenitor cell

ERK extracellular signal-regulated kinase

Flt-1 vascular endothelial growth factor receptor-1

FMD flow-mediated dilatation

GF growth factor

GLO1 glyoxalase-1

HGF hepatocyte growth factor

HIF- $1 \alpha \quad$ hypoxia-inducible factor- $1 \alpha$

INDO indomethacin

ICAM intracellular adhesion molecule

KLF-2 Krüppel-like factor-2

KRB Krebs-Ringer bicarbonate buffer

L-NAME N-nitro-L-arginine methylester

MCP-1 monocyte chemotactic protein-1

MGO methylglyoxal

NFkB nuclear factor kappa B

NO nitric oxide

ODQ $\quad 1 \mathrm{H}-[1,2,4]$ oxadiazolo[4,3-a]quinoxalin-1-one

PAD peripheral arterial disease

PDE5 phosphodiesterase type 5

PI3K phosphatidylinositol 3-kinase

PGI2 prostacyclin

PHE phenylephrine

PKC protein kinase $\mathrm{C}$

sGC soluble gyanylate cyclase

PKG protein kinase $\mathrm{G}$

RAGE receptor for advanced glycation endproducts 
RBV

ROS

SMC

SNP

$\mathrm{STZ}$

TGF- $\beta$

TNF- $\alpha$

VCAM

VEGF

XRA relative blood volume reactive oxygen species smooth muscle cell sodium nitroprusside streptozotocin transforming growth factor $\beta$ tumor necrosis factor- $\alpha$ vascular cell adhesion molecule vascular endothelial growth factor $\mathrm{X}$-ray angiography 
